Portland State University

PDXScholar

Dissertations and Theses

Dissertations and Theses

1982

\title{
A qualitative analysis of nine nonverbal communications texts
}

\author{
Edward J. Cavin \\ Portland State University
}

Follow this and additional works at: https://pdxscholar.library.pdx.edu/open_access_etds

Part of the Educational Methods Commons, Other Communication Commons, and the Speech and Hearing Science Commons

Let us know how access to this document benefits you.

\section{Recommended Citation}

Cavin, Edward J., "A qualitative analysis of nine nonverbal communications texts" (1982). Dissertations and Theses. Paper 3246.

https://doi.org/10.15760/etd.3238

This Thesis is brought to you for free and open access. It has been accepted for inclusion in Dissertations and Theses by an authorized administrator of PDXScholar. Please contact us if we can make this document more accessible: pdxscholar@pdx.edu. 
AN ABSTRACT OF THE THESIS OF Edward J. Cavin for the Master of Science in Speech Communication presented October 28, 1982 .

Title: A Qualitative Analysis of Nine Nonverbal Communications Texts.

APPROVED BY MEMBERS OF THE THESIS COMMITTEE:

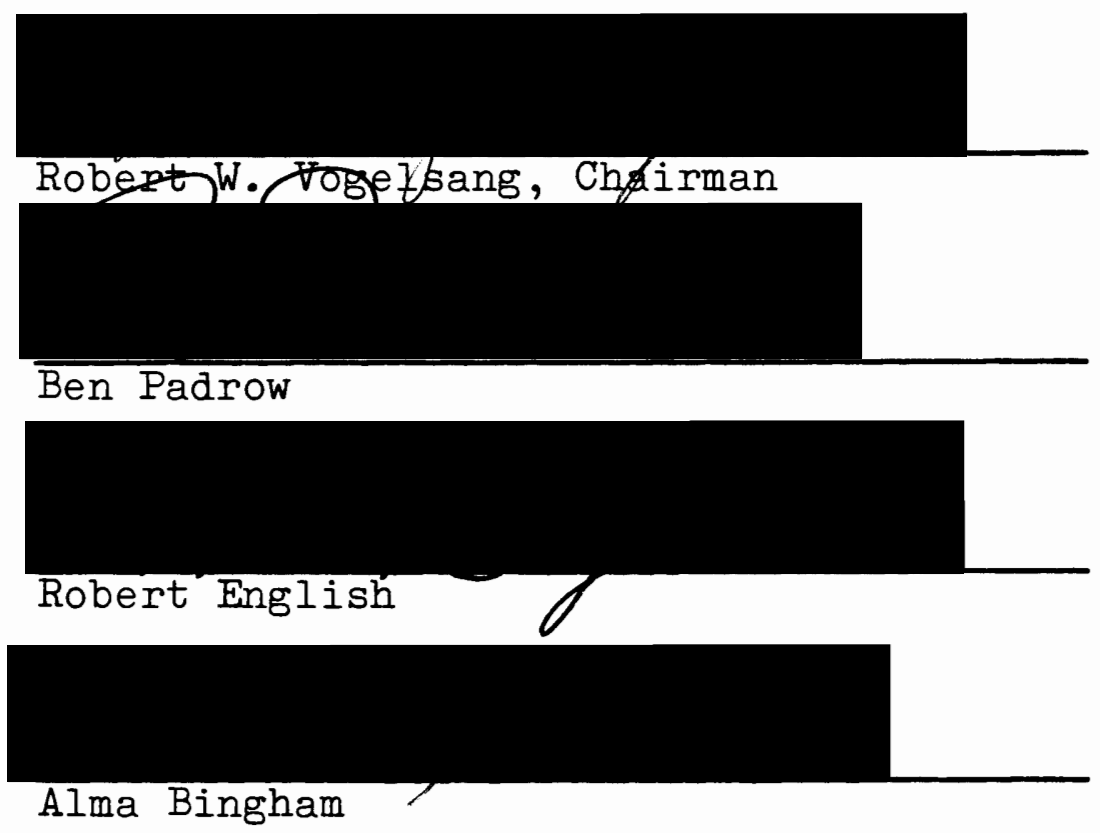

Throughout the past decade, numerous texts have been published which claim to be ideally suited for use in a basic, introductory nonverbal communication course. Many authors state that their text will comprehensively cover all aspects of the field of nonverbal communication. Unfortunately, many of the texts cover only a portion of the concepts which have been deemed as essential for 
inclusion in a beginning nonverbal communication course. With the plethora of material relating to this topic on the market, there is a need for a comprehensive evaluation form by which an evaluator could determine the specific method of layout (manner of organization and construction) as well as the content (nonverbal material) contained in each text under scrutiny. This thesis will examine criteria for evaluating texts in addition to listing the proposed method for constructing a textbook in terms of the order in which the various parts of the work are to be organized.

The purpose of the thesis is to: (I) identify the specific nonverbal communication components which are necessary for inclusion in a basic, introductory text, (2) identify the general elements of an effectively constructed nonverbal communication text in terms of (a) Content, and (b) Layout; (3) identify the specific nonverbal components which must be included in a comprehensive nonverbal communication text; (4) determine which text, if any, comes closest to meeting the ideal requirements as determined by the evaluation form. The evaluation form is divided into two parts. Part 1 includes material relating to general textbook construction, organization, and layout. Part 2 contains material relating to the nine components of nonverbal communication.

The evaluation form is the instrument which has been used to determine the overall quality of each text in the 
study. Accompanying every evaluation form is a listing of the material in each text. This is followed by an individual summary relating to the specific quality of each text being studied.

The last section of the thesis reviews the text which has been rated as the best, most comprehensive, well constructed and organized one evaluated. 
A QUALITATIVE ANALYSIS OF NINE NONVERBAI COMMUNICATIONS TEXTS

\author{
by \\ EDWARD J. CAVIN
}

A thesis submitted in partial fulfillment of the requirements for the degree of

\author{
MASTER OF SCIENCE \\ in \\ SPEECH COMMUNICATION
}

Portland State University

1983 
TO THE OFFICE OF GRADUATE STUDIES AND RESEARCH:

The members of the Committee approve the thesis of Edward J. Cavin presented October 28, 1982.

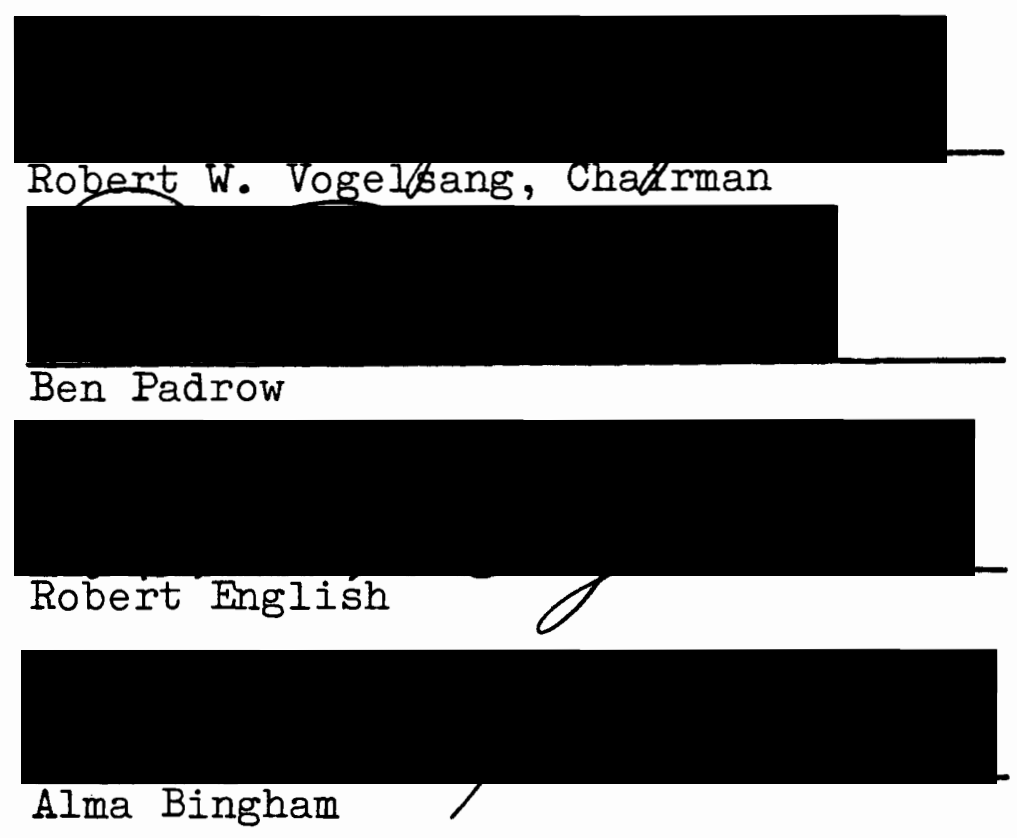

APPROVED :

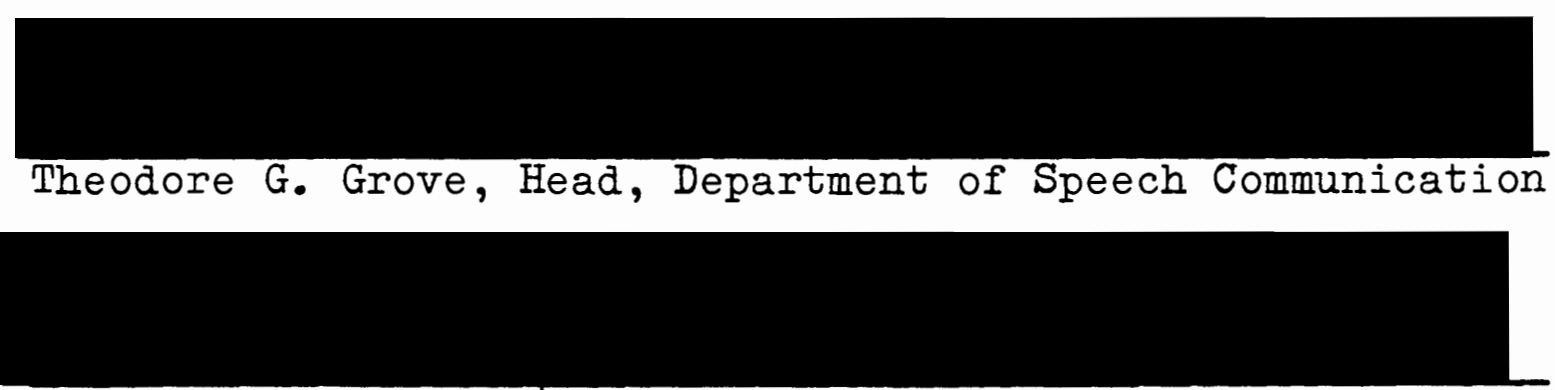

Stanley E. Rauch, Dean of Graduate Studies and Research 
Dedication

This thesis is dedicated to my wife Kristi, the greatest blessing any man could ever hope for. 


\section{ACKNOWLEDGMENTS}

My wife Kristi for her unfailing and unwavering love and support.

Dr. Robert Vogelsang and his charming wife Barbara, two of the finest people I have ever known, for their friendship, guidance, and encouragement.

Ben Padrow, Speech professor extraordinaire, for his Padrowisms, guidance, support, friendship, and trust in me.

Pat Hamilton, department secretary and moving force, and good friend, for her generosity, friendship, and help on far too many matters for me to name. 
TABLE OF CONTENTS

PAGE

ACKNOWLEDGMENTS • • • • • • • • • • • • • • iv

LIST OF TABLES ................. . vii

CHAPTER

I HISTORICAL PERSPECTIVES OF INFORMATION

DISTRIBUTION •. . . . . . . . . . . 1

Purpose of the Study . . . . . . 6

II ESSENTIAL NONVERBAL COMMUNICATION

Study of Nonverbal Communication . . 9

Components of Nonverbal Communication ........ . 13

Functions of Nonverbal

Communication . . . . . . 14

III DEVELOPMENT OF THE EVALUATION FORM FOR NONVERBAL COMMUNICATION TEXTBOOKS . • • • 17

IV ESSENTIAL COMPONENTS OF AN IDEAL NONVERBAL COMMUN ICATION TEXT . . . . . . . . 28

Content . . . . . . . . 29

Layout . . . . . . . . . . 35

$\mathrm{V}$ NONVERBAL COMMUNICATION TEXT EVALUATION FORM

VI DESCRIPTION AND EVALUATION OF NINE NONVERBAL COMMUNICATION TEXTS . . . . . 53

The Rhetoric of Nonverbal Communication: Readings 
Nonverbal Communication in Human Interaction

Beyond Words: An Introduction to Nonverbal Communication

Nonverbal Communication: Readings with Commentary

With Words Unspoken

Nonverbal Communication Systems

The Unspoken Dialogue: An Introduction to Nonverbal Communication

Moving Bodies: Nonverbal Communication in Social Relationships

Essentials of Nonverbal Communication

VII SUMMARIES AND TABLES FOR THE NINE NONVERBAL COMMUN ICATION TEXTBOOKS . . . . . . . 158 Implications for Further Study . . . 184

VIII SUMMARY OF THE TEXT SELECTED AS THE MOST COMPREHENSIVE, THOROUGH ONE EVALUATED • • 188

BIBLIOGRAPHY • • • • • • • • • • • • • • 191 APPENDIX . . . . . . . . . . . . . . 194 


\section{IIST OF TABLES}

TABLE

PAGE

I Percentages of Essentials in Rhetoric of

Nonverbal Communication: Readings

Necessary for Comprehensive,

Introductory Nonverbal

Communication Texts . . . . . . 160

II Percentages of Essentials in Nonverbal

Communication in Human Interaction

Necessary for Comprehensive,

Introductory Nonverbal

Communication Texts . . . . . . 163

II Percentages of Essentials in Beyond Words

Necessary for Comprehensive,

Introductory Nonverbal

Communication Texts . . . . . . 165

IV Percentages of Essentials in Nonverbal

Communication: Readings and

Commentary Necessary for

Comprehensive, Introductory

Nonverbal Communication

Texts . . . . . . . . . . 169 
V Percentages of Essentials in With Words

Unspoken Necessary for Comprehensive,

Introductory Nonverbal Communication

Texts . . . . . . . . . . 171

VI Percentages of Essentials in Nonverbal

Communication Systems Necessary for

Comprehensive, Introductory Nonverbal

Communication Texts . . . . . . 174

VII Percentages of Essentials in The Unspoken

Dialogue Necessary for Comprehensive,

Introductory Nonverbal Communication

Texts • . • . . . . . . . 177

VIII Percentages of Essentials in Moving Bodies:

Nonverbal Communication in Social

Relationships Necessary for

Comprehensive, Introductory

Nonverbal Communication Texts . . . 180

IX Percentages of Essentials in Essentials of

Nonverbal Communication Necessary for

Comprehensive, Introductory Nonverbal

Communication Texts . . . . . . 183

X Percentages of the Essential Components

Contained in All the Nonverbal

Communication Texts .. . . . . 184 
CHAPTER I

\section{HISTORICAI PERSPECTIVES OF}

INFORMATION DISTRIBUTION

The universal form of human communication has been oral language which, in turn, has allowed experiences to become cumulative. Not only facts, but abstractions as well, could be passed on for new generations to build upon. However, the reliance on human speech meant that accurate transference of information depended solely upon the memory of the person conveying the information.

With writing, complex abstractions and involved factual knowledge could be passed on and improved upon. A stylus could punch marks on a wet clay surface, a chisel could incise marks in stone, a brush could smear ink on papyrus or parchment. Some alternatives were easier, some more economical, some more permanent, but all were painstaking and slow. The tedious process of making duplicates by repetitive writing was time and energy consuming, thereby making most books short, few in number, and very error prone because they were copied by people without the knowledge of the authors. Iiteracy was also very low since few people had access to education. During this period in history, the destruction of even a few temples could mean the loss of all the irreplaceable records of a culture. 
The step from writing to printing was not merely a simple invention. It produced a quantum leap in communication and it took no small degree of technology to accomplish the result. In 1440, Johann Gutenburg and others began working with movable type. ${ }^{1}$ The basic concept was simple by today's standards but Gutenburg had to develop a metal alloy for casting type that melted easily when heated, expanded slightly when frozen, and produced sharp outlines when applied to paper. He had to devise proper techniques to align type accurately and to press it against paper evenly and firmly in order to obtain clear prints. ${ }^{2} \mathrm{~A}$ practical printing technology was useless without the proper paper--which presents still another technological evolution that began about 105 A.D. in China. 3

Printing revolutionized human culture faster than any technological advance in history up to that time. It became possible to produce books at a much greater rate than in previous times so that the archives of knowledge were multiplied enormously. The literacy rate increased and a minimum amount of education became possible for everyone, not just for a select few. The wider spread of education formed a larger reservoir of competent scientists and technologists. Their printed thoughts and discoveries quickly supplemented those of their fellow workers throughout Europe.

Printing brought the first community of contemporary thought and, as a result, a rapid scientific and technological 
advance. It was no accident that the scientific revolution of the mid-sixteenth century began only after printing had established itself on the continent. Later centuries brought greater and faster production of the printed word and a wholesale outward spreading of human thought.

The all metal press was invented in Great Britain in 1790. 4 In 1847, Richard Hoe, an American, invented the eight thousand copies per hour rotary press. 5 In the 1880's, a German-American, Otto Merganthaler, invented the Linotype, which could mechanically set an entire line of type at the same time. ${ }^{6}$ By the mid-twentieth century, the whole printing process had become almost entirely automatic with a large percentage of volume printing currently being controlled by the use of computers.?

The flood of printed information has become so large that no one can keep up with the available knowledge in even a very narrow field, e.g., nonverbal communication. The quantity of scientific information generated in the laboratories, observatories, institutes, and universities is said to double each decade. NThe number of scientific papers published since 1965 is equal to, if not more than, the total number published in all the years preceding $1965 .^{8}$ This runaway inflation of information cannot continue for long without breaking down the process it should be serving. If the information explosion continues at its present rate, science and the human progress it benefits will be held 
back, not by a lack of knowledge, but by the information overload that has now become an inherent part of the process. If humanity is to continue to advance using knowledge, technology, and wisdom, then new revolutions for handling the information overload must be developed. The most probable answer to this problem is the computer, which is currently revolutionizing society in the same manner as the printing press--but far more rapidly. The computer can aid people in separating the relevant from the irrelevant, the worthwhile from the worthless. It can also selectively disseminate relevant information to those people to whom it can be of value. Taking this one step further, it is not hard to imagine a vast computerized worldwide library network storing, and offering for easy retrieval, the accumulated knowledge of humanity, the output of a particular writer, or all significant information on a particular subject. In fact, a computer with a sufficiently advanced program might be able to search through its store of information, weigh and combine items from the store, and then deliver conclusions that would be a synthesis of many works. Such a partnership of people and machines could do more toward probing the deeper knowledge of the laws of nature and their consequences than either partner could do separately. It is only through far more sophisticated information processing, storage, and communication that knowledge will be universally available and acceptable. History has 
revealed that when information is available and widespread, progress is made. 9 Most importantly, the benefits of the information could be available, for the first time in history, to everyone.

The current state of affairs indicate that colleges and universities are a major contributor to the problem of information overload by requiring their faculties to "publish or perish." While this rule sees to it that ongoing research is an integral part of a professor's duties, it can also limit, in some cases, the quality of work that is ultimately put into print. Thus, many new textbooks are simply a rehash of material which has been in print for a substantial period of time. Each author states that his/her work is a new, definitive statement about their particular topic when, in actuality, it is his/her interpretation of several other people's work as well as his/her own contributions.

Each year professors are deluged with a plethora of textbooks that have been designed and written to serve the curricular needs of the various classes which are taught at their school. Each text is supposed to be different from every other text but, in this respect, many fall far short. It is often much easier to cite the obvious similarities in texts rather than the hidden differences. Subjects may be esoterically worded to suit the predetermined needs of the author or they may be organized using various formats, 
but the information contained within is often very similar to, and overlaps that found in many of the other texts which have been written about the same topic. In all cases, the overall quality of the work is dependent on the perception, interpretation, organizational skill, writing ability, and ethical standards of the author.

\section{PURPOSE OF THE STUDY}

The purpose of this thesis is to examine nine contemporary nonverbal communication textbooks which are currently being used at Portland State University. In conducting this study, it will be necessary to develop an evaluation scale which lists the topics that have been deemed most important for inclusion in a comprehensive, contemporary nonverbal communication textbook. The scale will then be applied to each text so that the contents can be analyzed in terms of the topics within, as well as the organizational layout of the material in each text. Based on the results obtained from the evaluation scale, a synopsis of what should be included in a contemporary, comprehensive nonverbal communication textbook will be developed along with a recommendation of how an ideal nonverbal textbook should be organized.

The reason for a monographical study of this nature relates directly to the information overload discussed earlier in the chapter. Even in a relatively small component 
of the overall field of speech communication, there is an enormous amount of published material which relates directly to nonverbal communication texts already in print--with a great deal more coming out each year. This thesis will examine and analyze a small percentage of the contemporary texts which have been widely circulated between 1971 and 1980 to assess the quality and comprehensiveness of each work. A compilation of the most comprehensive, substantive works, as determined by the evaluation scale, will then be developed with an emphasis on what has been designated as the "ideal" in relation to nonverbal communication textbooks. 
Chapter 1--Notes

${ }^{1}$ Stephen F. Mason, A History of the Sciences (New York: Collier Books, 1966), pp. 107-108.

2 John M. Fontana, Mankinds Greatest Invention (New York: Stratford Press, 1964), p. 21, 27-30.

3 Mason, p. 74 .

${ }^{4}$ W. Turner Berry and H. Edmund Poole, Annals of Printing (Toronto: University of Toronto Press, 1966), p. 190.

$$
{ }^{5} \text { Toid., p. 235. }{ }^{6} \text { Ibid., pp. 256-257. }
$$

7 Author Unknown, "Science and Technology--Communication," Date Unknown, 5 pp. (p. 2).

$$
8_{\text {Ibid., p. 2. }} 9_{\text {Ibid., p. } 5 .}
$$


CHAPTER II

\author{
ESSENTIAL NONVERBAL COMMUNICATION \\ BACKGROUND INFORMATION
}

STUDY OF NONVERBAL COMMUNICATION

The textbook is a far more versatile medium than its critics would have people believe. It can be read for a few minutes at a time or for many hours at a stretch. It can be studied or skimmed quickly, read once or reread often. All students can be given the same reading assignment or each can be given a different one. The students can move through the material at the same pace or at very different speeds. The reader can move from the beginning of the book to the end or he can jump erratically from one section to another. The text can be used in class, at home, in the library or any other location deemed appropriate for studying.1

University scholars have sought to prepare texts that would represent the subject matter as seen by academicians in their particular disciplines. As a result of these projects, a myriad of printed material has been, and is being prepared, which will expand and supplement the material already in print. With an emphasis on research, many departments/schools encourage (if not demand) that their faculty be involved in studies which will enhance knowledge in a given area, hence, the study of nonverbal communication. As a discipline, systematic and scientific methods of inquiry have only recently begun to be applied to the various aspects of "communicating without words," but these recent contributions are not without important predecessors. 
Since the beginning of civilization, dancers, dramatists, orators, and other storytellers have studied and understood the importance of nonverbal communication. The very word, "drama," is a Greek word meaning an action. 2 In the 19th century, speech students and teachers were actively interested in nonverbal communication. Practitioners of the so-called school of public address (elocution) actually memorized postures, gestures, and facial expressions for communicating shades of meaning to listeners. This practice led to such artificiality that it fell into disrepute. 3

Darwin's The Expression of Emotion in Man and Animals, published in 1872, has been highly influential in the modern study of facial expressions. Kretschmer's Physique and Character, 1940, laid the foundation for work on body types. Efron's 1941 classic, Gesture and Environment, introduced innovative ways of studying body language. In his book, Efron set forth the important role of culture in shaping many of our gestures. He constructed a framework for classifying nonverbal behaviors that still influences researchers today. Anthropologists Ray Birdwhistell (Introduction to Kinesics, 1952) and Edward T. Hall (The Silent Language, 1959) founded research programs in kinesics and proxemics. A psychiatrist, Jurgen Ruesch, and photographer, Weldon Kees, coauthored the first book to use the term "nonverbal communication," in its title in 1956 with Nonverbal Communication: Notes on the Visual Perception of Human Relations. 4 
In 1970, a journalist named Julius Fast published a book called Body Language, which detailed his account of the study of nonverbal communication. This caught the public's imagination and a steady stream of books and magazine articles soon followed that were designed for the popular audience. Some of these, in the interest of simplification and readability, misrepresented findings about the role of nonverbal communication in such areas as: making a sale, detecting deception, finding a sex partner, and the like. To the extent that these books suggest nonverbal language can be interpreted uniformly, automatically, and consistently, they are premature and misleading. Some imply that all one needs to do in order to read a person is to memorize the specific meanings for specific nonverbal cues. This idea is less than realistic because it is just not true; nonverbal cues do not always mean the same thing in every context nor do they mean the same thing to every person in the same context.

Modern researchers have concentrated on identifying nonverbal elements that communicate meaning. Although attempts have been made, no one has progressed very far in codifying or standardizing meanings for various nonverbal cues. The obstacles are staggering. To use body movements for example, Mario Pei estimates that people can produce some 700,000 distinct and elementary physical signs. 5 Furthermore, nonverbal behavior appears to be partly 
instinctive, partly learned, and partly imitated. Some evidence suggests that certain nonverbal behaviors are universal, while others are definitely cultural. 6 Meanings can vary from culture to culture, subculture to subculture and, in some cases, from family to family. Additionally, context seems to be more important in nonverbal communication than in verbal communication. These factors, and many others, make the task of standardizing meaning almost overwhelming.

This is not to say that people should ignore nonverbal signals; it simply implies that this wordless language is not--as yet--subject to exact and universaliy agreed upon interpretations. However, most people can apply general meaning to many nonverbal signals with reasonable accuracy but, when they act upon their interpretations with rote certainty, their behavior becomes unrealistic and problems can, and do, arise.

The scholars currently conducting research in the field of nonverbal communication are from a multitude of disciplines (anthropology, communicology, psychiatry, psychology, sociology) and tend to concentrate their energies on one particular aspect of the field. An example of this would be Ray Birdwhistell--an anthropologist by training--whose main interest is kinesics (a word he coined). One of his particular areas of inquiry is the human face and how emotions are conveyed via the different 
movements of the eyes, eyebrows, chin, mouth, cheeks, and forehead during the course of an interaction with another human being.

\section{COMPONENTS OF NONVERBAL COMMUNICATION}

The field of nonverbal communication should be divided into nine components to be studied scientifically. These are:

1. Adornment: the dress, accessories, and cosmetics that provide a clue to the personal characteristics, preferences, personality, and attitudes of the wearer.

2. Chronemics: the use and meaning of time in relation to how people perceive, structure, and react to time, as well as the messages interpreted from the usage.

3. Haptics: the way in which touch is used in communication, including both the external and internal sensations experienced.

4. Kinesics: the meaning of the visual aspects of behavior in terms of movement (both action and static), posture, gestures, facial expressions, and eye behavior.

5. Objects and Environment: the messages that are conveyed by the living, working, and social spaces which people inhabit and the effects and influences these have on a communicative encounter.

6. Olfactory: the study of odor and how it affects communication. 
7. Paralanguage: how the voice is used in communication with the focus on how something is said, not what is said. The vocal, not the verbal, element of speech is given primary consideration.

8. Physical Appearance: the size and shape of the human body in relation to natural body features as well as perceived attractiveness. This is usually the first nonverbal code to have an impact on an interaction. It activates the visual sense and may activate the senses of touch and smell.

9. Proxemics: the way in which space is structured and used in communication, emphasizing territoriality and the concepts of personal and intimate space.

FUNCTIONS OF NONVERBAL COMMUNICATION

Additionally, nonverbal communication also serves the following functions in all human interaction:

1. Accentuation: this highlights or emphasizes a verbal message, e.g., an instructor pounding their fist on a desk to accentuate the meaning of the statement she/he was making.

2. Complementation: this modifies or expands the verbal message, e.g., a person's smile when welcoming someone toward whom they feel affection.

3. Contradiction: the verbal message is contradicted by nonverbal behavior, e.g., sarcasm. 
4. Redundancy: this repeats or supports what is being said verbally, e.g., an instructor tells the class they have five minutes to finish a test and holds up five fingers as the verbal message is being conveyed.

5. Regulation: this regulates the flow of verbal communication, e.g., turning away from someone with whom a person doesn't want to communicate, i.e., "giving them the cold shoulder."

6. Substitution: this substitutes or replaces a verbal message, e.g., a glare from an instructor when a student comes to class late.?

Although the study of nonverbal communication can be broken down into nine different components along with the six functions they serve, it must be noted that none of the components are exclusive unto themselves. All the components of nonverbal communication overlap and interact with one another and should be viewed from this standpoint. The context of the communication also dictates meaning and is a factor that must be given major consideration when studies of the nonverbal aspects of communication are being conducted. Otherwise, the researcher will have severely limited the accuracy of perceptions and conclusions she/he is attempting to draw from her/his work. 
Chapter 2--Notes

I Philip W. Jackson, "Technology and the Teacher," in Communication for Economic Development: The School and the Challenge of Innovation (New York: Hill Book Co., 1969), p. 130 .

${ }^{2}$ David B. Guralnik and Joseph H. Friend, eds., Webster's New World Dictionary of the American Language (New York: World Publishing Co., 1966), p. 440.

3 Interview with Ben Padrow, Professor of Speech Communication, Portland State University, Portland, Oregon, May 31, 1981.

${ }^{4}$ Mark I. Knapp, Essentials of Nonverbal Communication (San Francisco: Holt, Rinehart, and Winston, 1980), pp. iii-iv.

5 Mario Pei, The Story of Language (Philadelphia: J. B. Lippincott, 1949), p. 13 .

${ }^{6}$ Jack G. McAuley, People to People: Essentials of Personal and Public Communication (Belmont, CA: Wadsworth Pub. Co., 1979), pp. 201-225.

7 Michael Burgoon, Approaching Speech Communication (New York: Holt, Rinehart, and Winston, 1974), pp. 115-116. 


\section{CHAPTER III}

\section{DEVELOPMENT OF THE EVALUATION FORM FOR}

NONVERBAL COMMUNICATION TEXTS

When reviewing the textbooks that have been written on the subject of nonverbal communication, it is necessary to develop a format for the evaluation of the texts. This should be based on the criteria which has been deemed the most important in terms of the purposefor the evaluation as well as for the needs that the text would be required to fulfill. The text could then be viewed as objectively as possible.

In 1975, Theresa B. Handley of the Washington State Equal Educational Opportunities Section conducted a study on bias content in instructional texts. It is her contention that some basic principles concerning the purpose of instructional materials should be given consideration when undertaking research of this nature. They are:

1. Instructional materials shall enrich and support the curriculum, taking into consideration the varied instructional needs, abilities, interests and maturity levels of the students served.

2. Instructional materials shall be of sufficient variety so as to present opposing views of controversial issues in order that students may develop the skills of critical analysis and informed decision making. 
3. Instructional materials shall stimulate student growth in conceptual thinking, factual knowledge, literary appreciation, aesthetic values and the development of ethical standards.

4. Instructional materials should contribute to the development of an understanding of the ethnic, cultural, political and occupational diversity of American life.

A. Instructional materials shall objectively present the concerns of all facets of society. Schools should recognize that, under certain circumstances, biased materials may represent appropriate resources in the presentation of different points of view.

B. Instructional materials shall provide models which may be used as a vehicle for the development of self-respect, ethnic pride and appreciation of cultural differences, based on respect for the worth, dignity and personal values of every individual. 1

With this as the base, the Handley study also concludes that the criteria for picking useful textbooks is dependent upon several important items--such as, but not Iimited to:

A. Content in terms of:

1. Learning transferability.

2. Comprehension and reading levels.

3. Appropriate work exercises.

4. Sufficient detail.

5. Useful illustrations.

B. Style in terms of:

1. Concept organization.

3. Smooth transitions.

This list, while hardly complete, provides a beginning to which additional qualifications can be added, thereby 
allowing the evaluator to look for the production and organization details of textbook construction. An expansion should include such details as:

A. Format of the book:

1. General appearance.

2. Readability of type.

3. Durability and flexibility of the binding.

4. Appeal of page layouts.

5. Appropriateness of the illustrations.

6. Usefulness of chapter headings and subheadings.

7. Usability of the index/indexes.

8. Quality of the paper.

B. Organization and Content:

1. Consistency of the organization and content with the teaching and learning standards of the school or department adopting the material.

2. Consistency of the point of view of the book with the basic principles of the subject area for which the book is being considered.

3. Usefulness in providing situations for problem solving.

4. Aid in stimulating students toward forming their own goals and toward self-evaluation.

5. Usefulness in furthering the systematic and sequential program of the course of study.

6. Clarity and succinctness of the explanations.

7. Interest appeal.

8. Provision for measuring student achievement--if applicable.

9. Adequacy of the chapter organization.

10. Adaptability of content to classroom situations and to varying abilities of individual students.

11. Degree of challenge for the reasonably well prepared students.

12. Usefulness for the more able or gifted students.

13. Usefulness for the slow learners. 
14. Adequacy of the quality and quantity of skilis assignments.

15. Provision for review and maintenance of skills previously taught. 3

Thus far, in determining the criteria for an evaluation scale of nonverbal textbooks, two main areas have been covered: (1) content, and (2) the technical quality of textbook construction. The last area that needs to be taken into consideration is teaching effectiveness because an instructor will undoubtedly be using the text as the basis for the information supplied in the context of the course. Research has indicated that there are three avenues of approach which could be applied to the evaluation of conventional texts. ${ }^{4}$ Therefore, texts should be evaluated against the following set of criteria:

1. Evaluation of the success of the text in achieving its objectives.

2. Evaluation of a text in comparison to some other teaching method (usually conventional instruction, i.e., lecturing).

3. Manipulation of variables within a text in order to see what impact this has on the achievement of a text's objectives.

Additionally, research has proven that texts can often teach as well as instructors, sometimes better. They can often do this in the same amount of time, sometimes faster. Texts and instructors working together usually produce better results than either working separately. 5 
To incorporate teaching effectiveness into the rating scale, the criteria for evaluating texts would have to take into consideration additional information that will not only cover the areas of content and technical quality but teaching effectiveness as well. Based on this, the model for a rating scale should be expanded to incorporate the aforementioned criteria. The expanded version would appear as follows:

I. Criteria for Evaluation of Texts:

A. Content

1. Learning transferability

a. Applicable to "real life situations," i.e., school, home, family, employment, interpersonal relationships, etc.

2. Comprehension and reading levels

a. Should be written for lay student rather than other people with vast experience and esoteric knowledge of the field.

b. Concepts and material should be presented in a manner that is easily understood and comprehended by students beginning the study of nonverbal communication.

3. Sufficient detail

a. The materials should define and explain the various components of nonverbal communication without overloading the student with technical, abstract details. 
b. Ideally, the material should be presented in a fashion which suits the purposes for the need of the details, i.e., definition, explanation, examples, illustrations.

4. Appropriate work exercises

a. A text should contain experiential exercises which parallel and further define various aspects of the components of nonverbal communication being studied. These should give the student a "hands on" feel of how important, and what impact, nonverbal communication has on communicative encounters.

b. Written exercises which stimulate thought while increasing understanding of nonverbal communication should be included so that students can respond in a manner which indicates an increased awareness has occurred.

5. Useful illustrations

a. A text should contain illustrations which provide a visual picture of an example of nonverbal communication. This should be the easiest of the criteria to fulfill and could possibly provide a high degree of impact as far as creating an awareness of the different components of nonverbal communication. 
b. The visuals should be located at a place in the chapter where they can be easily related to the written material (definition, illustration).

B. Style

1. Concept organization

a. All of the nonverbal concepts should be identified, defined, explained, and illustrated.

b. The concepts under scrutiny should be presented in a straightforward, linear fashion in order to alleviate the confusion that can arise when new, sometimes abstract, material is being studied.

2. Smooth transitions

a. Each point, or paragraph, should easily and smoothly flow into the following one. The reader should be aware of the successive stages of the material as each idea is stated, as its importance is shown, as it is established, and as it is applied to the author's purpose. 6

3. Length of chapters

a. The material in the chapters should be clear, concise, and to the point without extraneous details that could serve to 
confuse the reader. Once a point has been made, defined, and explained, the author should move on to the next point so as not to bog down the reader with a plethora of insignificant data. On the other hand, all points should be identified, defined, explained, and clarified in such a way that the reader would have no doubt as to the purpose of the material.

b. Exercises, pertinent visual aids, and discussion questions should be included--if applicable.

c. A list should be included of what the student will gain by reading the material contained in the chapter, prior to the actual body of the material. The format of the chapter should follow, step by step, this simple outline. Example: "After reading this chapter, the student should be able to..."

d. A summary or conclusion should be included at the end of each chapter.

e. A list of additional readings or resources should be included when appropriate.

f. A bibliography should be included at the end of each chapter that would contain the 
names and works from which the information was acquired.

4. Indexes

a. An author index should be included after the last chapter in the text listing the various authors who have contributed the information used in the text. The pages on which the information can be found should also be listed.

b. A subject index listing the various topics covered should be included after the author index. This index should list the name of the topic as well as the pages on which the information can be found. 
Chapter 3--Notes

$I_{\text {Theresa B. Handley, Models for the Evaluation of }}$ Bias Content in Instructional Materials (Olympia, WA: Equal Educational Opportunities Section, 1975), pp. ii-iii.

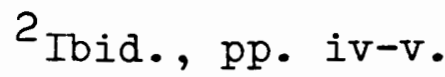

3 James Hartley, Designing the Instructional Text (London: Nichols Publishing Co., 1978), p. 102 .

${ }^{4}$ Richard I. Lester, "Try Out This Checklist for Evaluating New Textbooks," Nation's Schools, 85 (January 1970), p. 97, 122.

5 Ibid.

${ }^{6}$ Ben Padrow, Oral Communication: Preparation and Presentation (Portland, OR: Portland State University Copy Center, n.d.), p. 22. 


\section{CHAPTER IV}

ESSENTIAL COMPONENTS OF AN IDEAL

NONVERBAI COMMUNICATION TEXT

Dale Leathers reports that the most important criteria to fulfill when writing and constructing a nonverbal communication textbook (based on feedback from other nonverbal communication instructors) are the following:

1. The book must be designed so that a course can be readily developed to parallel the treatment of the subject matter in the book.

2. The book must be designed to promote the students' active involvement in testing and developing their own capacity to communicate nonverbally.

3. The book mustclearly delineate and analyze the functional capacity of the different systems which comprise nonverbal communication.

4. The book must provide an integrated treatment of the functional relationships between, and among, the nonverbal communication systems and of the interaction of these systems with the verbal communication system.

5. The book should be extensively and creatively illustrated with appropriate, applicable pictures and illustrations to facilitate the intensive examination of nonverbal communication behaviors. 1

There are two main categories to take into consideration when designing a text that is to serve as a tool for aiding in the teaching effectiveness of an instructor. The first is content and the second is layout. 
Content consists of the actual material that is used to support the author's purpose for writing the text. For example, if the text is to be written about nonverbal communication in terms of human interaction, or communication, then the content must be limited to nonverbal communication as it relates to communication on an interpersonal level. In this case, it is essential for the author to clearly delineate the direction the text is to take and then compile material that develops, supports, clarifies, and expands the concepts under consideration.

Layout is the actual manner in which the text is constructed. This category includes the means by which the material is presented to the reader in order to insure an accurate, comprehensive understanding of the printed work. To be effective, it must be tightly organized, clearly laid out, and practical for both the instructor and the student.

If the content and the layout do not work in conjunction with one another, much of the potential effectiveness of the material will, consequently, be lost. As an aid to this, the following outline is submitted. The outline is designed to detail the various components of nonverbal communication which have been deemed most important for acquiring a comprehensive understanding of the subject as well as for portraying the actual layout of an ideally constructed text. 


\section{CONTENT}

A text needs to be composed of a sufficient number of chapters to comprehensively cover all the components of nonverbal communication. This could be accomplished by dealing with the various nonverbal components individually or in an integrated format, both of which can be effective. With the purpose of a text being to inform, the material should be presented in such a way that it is defined, expanded, and clarified for the reader. The content should include, but not be limited to, the following:

\section{Introductory Material}

A. Definition of nonverbal communication.

B. Issues involved in defining and classifying nonverbal communication.

1. Environmental

2. Cultural

3. Contextual

C. Relationship between sending and reciving skills.

D. Developing sending and receiving skills.

E. Definition of specific nonverbal communication components.

1. Adornment

2. Chronemics

3. Haptics

4. Kinesics

5. Objects and Environment

6. Olfactory 
7. Paralanguage

8. Physical Appearance

9. Proxemics

F. Definition of the functions of nonverbal communication.

1. Accentuation

2. Complementation

3. Contradiction

4. Redundancy

5. Regulation

6. Substitution

G. Relationship between verbal and nonverbal communication.

H. Brief history of the study of nonverbal communication (optional).

II. Adornment

A. Definition of adornment.

B. Communicative effects of clothes.

C. Communicative effects of accessories.

D. Communicative effects of cosmetics.

E. Cultural differences.

F. Gender differences.

III. Chronemics

A. Definition of chronemics.

B. Communicative function of chronemics.

C. American concept of time. 
D. Time orientations.

1. Psychological

2. Biological

3. Cultural

IV. Haptics

A. Definition of haptics.

B. Communicative function of haptics (tactile communication).

C. Tactile communication and human development.

D. Different types of touching behavior.

1. Functional-professional

2. Social-polite

3. Friendship-warmth

4. Love-intimacy

5. Sexual arousal ${ }^{2}$

E. Needs for touch.

1. Biological

2. Psychological

3. Sociological

F. The skin as a communication system.

G. Touch norms.

H. Gender differences.

I. Cultural differences.

V. Kinesics

A. Definition of kinesics. 
B. Communicative function of kinesics.

1. Adaptors

2. Affect displays

3. Emblems

4. Illustrators

5. Regulators

C. Kinesic channels.

1. Whole head

2. Whole body

3. Face only

4. Eyes and eyebrows only

5. Hands and arms

6. Legs and feet

7. Dyad (whole body with another person)

D. Gender differences.

E. Cultural differences.

VI. Objects and Environment

A. Definition of objects and environment.

B. Communicative effects of objects (artifacts).

C. Communicative effects of environmental features.

1. Size or volume of artifacts

2. Arrangement of artifacts within an environment

3. Types of materials in use

4. Iighting and shading

5. Color 


\section{Temperature \\ 7. Noise}

D. Cultural differences.

E. Gender differences.

\section{Olfactory}

A. Definition of olfactory communication.

B. Types of smells and messages communicated.

C. Cultural differences.

D. Gender differences.

\section{Paralanguage}

A. Definition of paralanguage.

B. Communicative function of paralanguage.

C. Sound attributes which give vocal cues their unique characteristics.

D. Vocal cues in relation to:

1. Speaker recognition

2. Personality judgments

3. Personal characteristics

4. Judgments of emotions

5. Comprehension and persuasion

6. Hesitations and pauses (turn taking) 3

E. Gender differences.

F. Cultural differences.

IX. Physical Appearance

A. Definition of physical appearance.

B. Communicative potential of physical appearance. 
C. Body types.

1. Endomorph

2. Mesomorph

3. Ectomorph

D. Traits associated with body types.

E. Indicators of attractiveness.

1. General attractiveness

2. Body shape

3. Body color

4. Smell

5. Hair (cranial, facial, body)

6. Clothes and artifacts

F. Gender differences.

G. Cultural differences.

X. Proxemics

A. Definition of proxemics.

B. Communicative functions of proxemics.

C. Factors relating to individual space preferences.

1. Age

2. Sex

3. Ethnic and cultural background

4. Topic or subject matter

5. Setting for the interaction

6. Physical characteristics

7. Attitudinal orientation

8. Emotional orientation 
9. Characteristics of the interpersonal relationship.

10. Personality characteristics ${ }^{4}$

D. Territoriality.

1. Intimate/personal space

2. Private space

3. Public space

\section{General Summary Material}

A. Brief review of the material in the chapters in terms of the usage and importance of nonverbal communication.

B. Characteristics of a skilled nonverbal sender/ encoder.

C. Characteristics of a skilled nonverbal receiver/ decoder.

D. Relationship between sending and receiving skills.

\section{IAYOUT}

To facilitate ease in understanding the actual means by which the material will be presented to the reader, the text will be divided into three parts: (1) front matter section, (2) individual chapters, and (3) back matter section. The front matter section includes all the material presented prior to the first chapter. This includes the title page, dedication, forward, preface, acknowledgments, contents, and an introduction. The body of the text is the 
individual chapters and all the information contained within each chapter. The back matter, or final section, would contain the appendix, bibliography, glossary, and author and subject indexes.

The importance of a useful, functional layout with regard to textbook formation cannot be overemphasized. A tightly organized, aesthetically pleasing, functional layout takes careful planning and painstaking attention to detail. If done right, the content will be enhanced and the text's teaching effectiveness will be increased, thereby expanding its value as a learning tool. The purpose of the textbook is to teach while creating awareness, understanding, and an appreciation of the material being presented.

In keeping with the criteria advocated by Leathers, an ideally organized textbook should appear as follows:

I. Front Matter Section

A. The cover should be as aesthetically pleasing as possible. The title must be prominently displayed so that it is easily readable. The appearance of the text should not intimidate students, but inspire them to want to discover what is contained within the covers.

B. If applicable, a page (or more) can be devoted to the person to whom the author desires to dedicate the text. According to the whim of the 
author, this may vary from the full blown poesy of Shakespeare's publisher, "To the onlie begettor of these sonnets" to, "For Mom." 5

C. The forward is a short introduction by a recognized authority in the field which points out the special features and importance of the work. 6

D. A preface section tells of the author's purpose for writing the text and the direction he/she intends to take with the material. This provides justification for the work and gives the reader a sense of what to expect from the material. The author can also use this section to present background about herself/himself or to make a statement about her/his feelings on the subject under consideration and then tell the reader why, and how, she/he has come to the conclusions that have been reached. A brief statement about the author(s) could also be included in this section. Pertinent information about the profession, degrees earned, major publications, or areas of interest, and the current place of employment would enhance the credibility of the text.

E. If applicable, the section for acknowledgments can follow the preface. In this section, the author acknowledges the people who have provided assistance while the book was being formed. 
Acknowledgments usually occupy one or two pages, depending on the contributions of assistants and colleagues.

F. The table of contents must indicate what is contained in the body of the text. To be most effective, this section should be broken down into outline form, listing the major components of the text along with a list of the chapter names and page numbers in each section. Additionally, the specific parts of each chapter should be listed along with the pages on which the information can be found. This is vitally important to the reader in that it makes referral to material quick and easy while providing information as to what aspects of the various nonverbal components are to be developed.

II. Individual Chapters

The material in the chapters must promote the educational goals and objectives of the text by:

(1) being appropriate to the level of instruction intended; (2) using a vocabulary that is easily understood and comprehended by the reader; (3) presenting concepts that are appropriate to the ability of the students using the text; (4) developing the concepts in a logical scope and sequence that is readable and clear; and (5) using material that will 
appeal to the readers while stimulating their

curiosity. This can be accomplished in the following manner:

A. The section at the beginning of each chapter should contain an outline prior to the start of the written material which lists the major components of the chapter in the order they are addressed.

B. The section at the beginning of each chapter should contain a list of what is to be learned prior to the start of the written material. This can be in the form of questions students would be expected to answer after they have read the material or direct statements about the content of the material. This part can be related to the concepts presented as well as to the new terminology contained in the chapter.

C. The pagination throughout the text should be easily identifiable in order to provide uncomplicated access to the material.

D. The typography, or printed words, must be easy to read while not impeding the reader's comprehension of the material.

E. All sections and paragraphs should be written with the central idea in the first or second sentence. The remainder of the material will be 
used to expand, support, and clarify the central idea. This aids in the organization and balance while presenting the information as clearly and simply as possible. By utilizing this style, the reader is aided in his/her conception of the subject matter, thereby helping the author to achieve the stated purpose for writing the text.

F. All concepts should be presented in a straightforward, linear fashion from simple to complex. The idea is to present the material as clearly and simply as possible while providing the reader with the opportunity to grasp the scope, range, and depth of the material and to relate it to other concepts. Continuity would, thus, be maintained.

G. The material should stay within the main thrust of the text. If the thrust is interpersonal, the material should be limited to nonverbal communication in human interaction. Extraneous information must be omitted if it does not apply to the topic at hand, because it can serve to confuse the reader. Continuity must be maintained at all times.

H. The major chapter titles and subtitles must be clearly delineated to provide easy access to the formation contained therein. These are to follow 
the order of presentation listed in the table of contents and in the chapter outline.

I. All material should be presented from an unbiased viewpoint. If this is not the case, it is imperative that the author notify the reader as to his/her expressed opinion on the topic. The sources, purposes, and points of view must be readily identifiable.

J. Pertinent exercises and activities which relate directly to the material should be included in each chapter. These provide an experiential aspect to the material and are an excellent learning tool (sometimes the most effective) that can serve to enhance a student's comprehension of the subject matter under consideration.

K. Written or visual examples should be included, where appropriate, to help readers in their conceptualization of the material.

I. Visual aids should be extensively used throughout the text to clarify the material or to serve as a visual example for readers. These should include charts, graphs, cartoons, pictures, diagrams, models, etc. Each visual aid should contain an accompanying interpretation or explanation of what it is representing while being clear, concise, and to the point. It should 
serve as a visual extension of the material and must depict an element or aspect of the material being discussed while contributing to the overall development of the text.

M. A summary or review should be the last part of each chapter. In this section, all the major points made in the chapter would be listed in the order they were presented. The purpose is to summarize the work as simply as possible. This relates directly to the list of, "What a student should know . .", that is located at the beginning of each chapter.

N. The section at the end of each chapter should contain a list of discussion questions that are based on the material in the chapters. These can be used by: (1) individual students to test their acquired knowledge of the materials; (2) groups of students studying the material together;

(3) and/or the instructor to stimulate discussion or to test the student's knowledge.

O. The section at the end of each chapter should contain a glossary of the key words which are used in the material as well as their meanings. This would serve to facilitate an increased understanding of the material by providing easy access to the terminology used in its presentation. A student needs to grasp the meaning of 
what is written before she/he can adequately comprehend the material itself.

P. The section at the end of each chapter should contain a list of additional activities which relate to the material in the chapter. This is an excellent learning tool because it provides the student (and instructor) the opportunity to actually experience an aspect of the material being discussed, thereby reinforcing the concepts under study.

Q. The section at the end of each chapter should contain a list of the footnoted sources, if any, for students' perusal. If further clarification is desired, the students would be provided with access to the original source from which the information was extrapolated.

R. The section at the end of each chapter should contain a bibliography that lists the contributing authors as well as the sources from which the information was obtained. This information would be of significant importance to those students or instructors desiring additional data on the topic.

S. The section at the end of the chapter should contain a list of additional readings that relate to the chapter topic. This would provide a 
resource from which the student could expand her/his knowledge of the subject--if so desired.

III. Back Matter Section

A. An appendix should be included, if appropriate, so the author can provide additional supplementary material of a different, but related, nature to that contained in the body of the text. Rather than having exercises and activities relating to particular components of nonverbal communication, the appendix may include activities which deal with the whole realm of nonverbal communication. Such an activity might be a journal where students chart their increased awareness of how nonverbal communication is used in their daily lives throughout the duration of the class.

B. A bibliography that lists the names of the authors and the works from which the information was extracted is an important resource that should be part of the back matter section of the text. It would provide information for anyone (student or instructor) desiring to further her/his knowledge of the topic by independent research.

C. A glossary should be included which lists the important, unfamiliar words and their meanings that are contained in the text. This should include all the words from the glossaries at the 
end of each chapter as well as any others that are deemed significant by the author.

D. An author index is a necessary facet of all texts. Each author referred to must be listed, along with the page(s) on which the references are made. This expedites referral to the works of the various contributors who have been instrumental in providing information for the text.

E. A subject index should also be included in this section of the text. The index would provide a listing of all the topics covered in the text in addition to providing the pages on which the material can be found. 
Chapter 4--Notes

${ }^{I}$ Dale G. Leathers, Nonverbal Communication Systems (Boston:, Allyn and Bacon, 1976), p. xi.

${ }^{2}$ Mark I. Knapp, Essentials of Nonverbal Communication (New York: Holt, Rinehart and Winston, 1980), pp. 153-155.

3 Ibid., pp. 204-222 passim.

${ }^{4}$ Ibid., pp. 82-86.

${ }^{5}$ Adrian Wilson, The Design of Books (Salt Lake City: Peregrine Smith Inc., 1974), p. 62 .

6 Ibid. 


\section{CHAPTER V}

\section{NONVERBAL COMMUNICATION TEXT}

\section{EVALUATION FORM}

James Hartley, in his book, Designing the Instructional Text, states:

Instructional texts must be planned very carefully. The two main reasons for this are: (I) instructional texts are usually much more complex in structure and appearance than is continuous prose, thus they require greater care in the design and presentation; and (2) technical developments in print and information processing mean more and more non-specialists are producing instructional materials. Today more control by authors over the layout of instructional texts is both necessary and possible if the material is to be effective. 1

An evaluator must be as objective as possible when rating textbooks. The person doing the rating must take into consideration such factors as the school's policy for textbook selection, the department's policy for textbook selection, the level of the students in the class, and the curricular needs of the class itself. As an aid to this, an evaluation form can serve as a necessary and effective tool for adequately comparing the overall strengths and weaknesses of the various texts submitted for approval.

Evaluating a textbook is, at best, a difficult task for instructors. The selection of textbooks does not exist in an educational vacuum. It is a process that takes place within the context of other interests, needs, concerns, 
and issues. The most common way to, increase objectivity and provide satisfactory coverage is to use a checklist of some sort but, on the college level, few, if any, schools use a standardized evaluation form ${ }^{2}$ even though the selection, evaluation, and adoption of textbooks is one of a college professor's most important tasks.

Iinda Kunder, of the Educational Research Service, conducted a study in 1976 which explored the various methods for textbook selection in use throughout the United States by the individual states. 3 The purpose of the study was to compile definitive, comprehensive literature on what the different evaluators look for when they are examining the texts which have been submitted for consideration. Although the study was targeted for public school systems, 4 the information is applicable to this study because colleges and universities have a great deal more latitude in selecting texts than do public school systems in that they seldom use a standardized method for evaluating the texts. On the college level, textbooks are most often chosen by a department head, a committee, or the person teaching the class without the use of any type of evaluation form and without any clear-cut, objective requirements. The choice is usually highly subjective with regard to the perceived needs of each individual instructor and each individual class. 
In the Kunder study, surveys were sent to 1275 districts in the thirty-three states which permit local districts (sometimes in conjunction with the state) to select their own textbooks. Of those districts, 414 responded with an explanation of the methods that are used to select the various texts and many also included copies of the evaluation forms they use. 5

The evaluation form that is most applicable to the needs of this thesis, and the one that appears to be the most comprehensive form in use throughout the United States, is the one used by the Westminster School District in Carroll County, Maryland. 6 As stated previously, with the proliferation of available materials, along with the sometimes intense marketing pressure exerted on professors, it is advisable to have a well-defined procedure for selecting textbooks. The Westminster School District Evaluation Form will provide a thorough, if not efficient, way to analyze each text in order to insure that appropriate works are selected. It will serve as an excellent model under which the main components of textbook evaluation (content analysis, technical quality, and teaching effectiveness) fall. The broad base used in the scale will provide an overall description of the different elements covered in each text and can easily be applied to the specific needs of this study (see the Appendix). 
It should be noted that the major weakness of the Westminster Evaluation Form is the double-, triple-, and sometimes quadruple-pronged questions that are asked of the evaluator. A prong is the direction the question points the person doing the evaluating. An example of a quadruplepronged question can be found in section V-A of the General Evaluation Form (see Appendix). In this case, the question relates to the content of a text and asks if the material is "well presented by providing adequate scope, range, depth, and continuity." If broken down into individual components, the question could be considered four separate questions. The first would relate to adequate scope, the second to adequate range, the third to adequate depth, and the fourth to adequate continuity. A question of this nature would, therefore, force the evaluator to make a general, rather than a specific evaluation of the material. One way to alleviate a problem such as this is to rewrite or omit all pronged questions. If that is not feasible, then the material should be judged by a number of people, each of whom could evaluate the text independently and then compare their findings in order to determine the accuracy of the evaluation form.

Each subject is unique, therefore it has been necessary to develop an addendum to the Westminster School District Evaluation Form. The expanded version is designed to evaluate the specific criteria which should be included 
in nonverbal communication textbooks. The expanded form is more specific in that it is designed to determine which nonverbal components are present in each text as well as what aspects of the different components are covered. The material that has provided the basis for the addendum is that which was mentioned in Chapter 4 as being necessary for inclusion in all comprehensive, introductory nonverbal communication textbooks. The form has been adjusted to meet the needs of this particular study and will provide a definitive answer as to what topics are contained in each nonverbal communication textbook (see Appendix). 
Chapter 5--Notes

${ }^{I}$ James Hartley, Designing the Instructional Text (New York: Nichols Publishing Co., 1978), p. 7.

${ }^{2}$ Conversations with colleagues at the Western Speech Communication Association Convention, Portland Hilton Hotel, Winter, 1980.

${ }^{3}$ Iinda Kunder, Procedures for Textbook and Instructional Materials Selection (Arlington, VA: Educational Research Service, 1976), p. 1.

${ }^{4}$ Ibid., p. 2. 5 Ibid.

6Ibid., pp. 42-58. 
CHAPTER VI

\section{DESCRIPTION AND EVALUATION OF NINE NONVERBAL COMMUNICATION TEXTS}

In this chapter, the evaluation forms will be applied to nine nonverbal communication textbooks that are available in the Portland State University libraries (regular and reserve).

Each text was selected because it was written by a prominent researcher in the field of nonverbal communication $^{l}$ and because each author claims her/his work is comprehensive and covers all the different components of nonverbal communication, thus making it suitable for use in an introductory nonverbal communication class. All the texts have been widely circulated by the various publishers and are being, or have been, used at numerous other colleges and universities. ${ }^{2}$ 
The Rhetoric of Nonverbal Communication. 1971. Haig A. Bosmajian. Glenview, II: Scott, Foresman and Co. The text is divided into two parts: (1) Nonverbal Communication: Interpersonal and Intercultural, and (2) Nonverbal Communication: An Agent of Political and Social Change.

Part 1 contains the following articles: ( 1 ) How to Read Body Language by Davis; (2) Symbolism by Krout; (3) Tactile Communication by Frank; (4) Rhythm in Babies and Adults by Meerloo; (5) Communication in Africa by Doobi; (6) Adumbration as a Feature of Intercultural Communication by Hall; (7) Music as Symbolic Behavior by Merriam; (8) Why Do Kids Dig Rock by Goldstein; and (9) Topless Dancing as a Form of Expression and Communication from In re Gianini, 72 Ca. Rptr. 655 (1968).

Part 2 contains the following articles: (1) The Miranda of Power by Merriam; (2) Symbolic Conduct by the Columbia Law Review; (3) Oppression and Nonviolence by M. L. King, Jr.; (4) Picketing and the Communication of Ideas by Jones; (5) The Persuasiveness of Nazi Marching and Der Kampf Um Die Strasse by Bosmajian; (6) Can Government Force Expression Through the Flag Salute by the West Virginia State Board of Education vs. Barnette, 319 U.S. 624 (1943); and (7) Wearing the Black Armband to School to Protest War from Tinker vs. Des Moines School District, 393 U.S. 503 (1969).3 
The components of nonverbal communication not covered, or covered in a cursory manner are: adornment, chronemics, olfactory, paralanguage, physical appearance, and proxemics. 
GENERAL EVALUATION SCALE FOR NONVERBAL TEXTS

Text: The Rhetoric of Nonverbal Communication: Readings Author: Bosmajian, Haig. 1971.

YES NO NA

I. Purpose

A. Does the author accomplish the overall purpose of the text?

B. Is the purpose accomplished in good literary style?
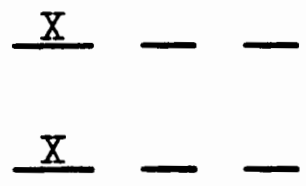

II. Author

A. Is there pertinent, factual information about the educational background, profession, and qualifications of the author?

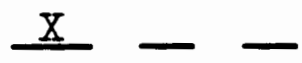

III. Authenticity

A. Is the material factually accurate and objective in its presentation?

B. Is the material up-to-date? $\underline{x}-$

C. Are the information sources well documented?

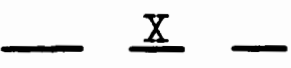

$\underline{\mathrm{X}}-$

IV. Appropriateness

A. Does the material promote the educational goals and objectives of the curriculum?

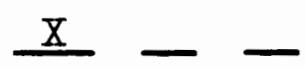

B. Is the material appropriate to the level of instruction intended?

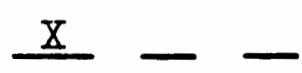

C. Is the interest level appropriate to the user?

1. Will the material stimulate the curiosity of the user?

$\underline{x}-$

2. Will the material appeal to many students?
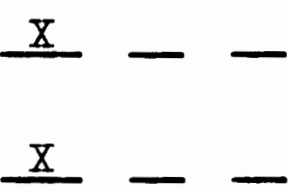
YES NO NA

V. Content

A. Is the content of the material well presented by providing adequate scope, range, depth, and continuity?

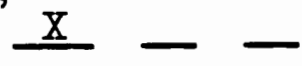

B. Is the material well organized and well balanced?

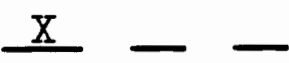

C. Is the material presented as clearly and simply as possible for the level intended?

D. Does the material aid conceptualization of the subject matter?

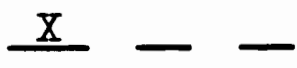

E. Does the material achieve its stated purpose?

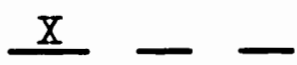

F. Are the transitions from one point to another, or one section to another, smooth and clear?

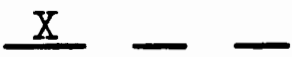

G. Does the text present information not otherwise available?

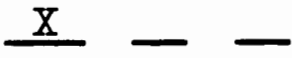

H. Does the material give a new dimension to the subject?

I. Are the sources, purposes, and points of view readily identifiable?

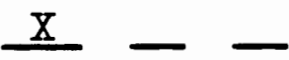

VI. Technical Quality

A. Is the text hardcover?

B. Is the text softcover?

$\underline{X}-$

C. Is the typography clear and easy to read?

D. Are the page layouts well designed?

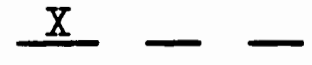

E. Is the pagination definite and clear?

F. Are aids to learning provided?

1. Is there a table of contents?

$\underline{x}-$

2. Is there an outline listing the contents of each chapter? 
a. Is this at the beginning of each chapter?

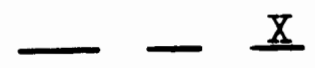

b. Is this in the table of contents?

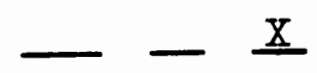

3. Are the major titles and subtitles

of each section delineated in each chapter?

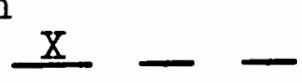

4. Is there a list of priorities at the beginning of each chapter?

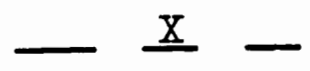

5. Are internal summaries and reviews provided where appropriate?

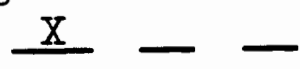

6. Is there a list of related exercises or activities contained in each chapter?

7. Is there a list of additional readings in each chapter?

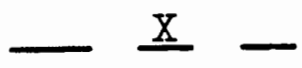

8. Does the text contain an appendix?

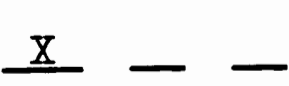

a. Is the appended material useful?

$\underline{\mathrm{X}}$

$-\underline{X}$

9. Does the text contain a glossary? - $\underline{\underline{X}}-$

a. Is it at the end of each chapter?

$-\underline{X}$

b. Is it at the end of the text?

$-\underline{X}$

10. Does the text contain a subject index?

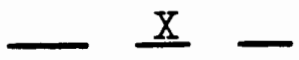

11. Does the text contain an author index?

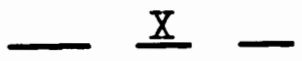

12. Does the text contain a bibliography?

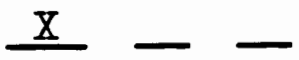

a. Is it at the end of each chapter?

$\underline{\mathrm{X}}-$

b. Is it at the end of the text? _ $\underline{\underline{X}}$ 
13. Are the chapters footnoted or endnoted?

G. Are visual aids used?

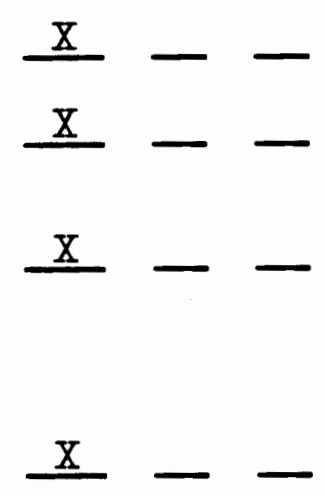

1. Do they contribute to the development of the text?

2. Is the art of photographic quality of the visual aid acceptable (sharpness, composition, color)?

3. Is there a good balance between artistic technique and educational need?

4. Are the captions readable?

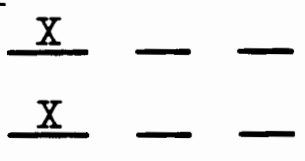

5. Are the captions a good interpretation of the material, yet not distracting?

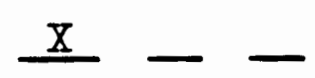

6. Are the illustrations and captions suitable for teaching and learning purposes?

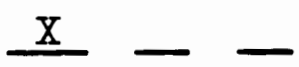

7. Are the visual aids located properly for greatest usefulness?

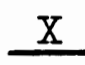

8. Are the visual aids adequate in number?

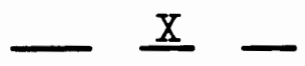

9. Is the content of the visual aid well organized and well balanced? $\mathrm{X}$ -

10. Is explanatory material provided? $\mathrm{X}$ -

\section{SPECIFIC EVALUATION FORM FOR NONVERBAL TEXTS}

I. Introductory Material

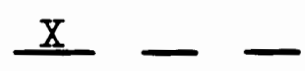

A. Definition of nonverbal communication $\underline{X}-$

B. Issues involved in defining and classifying nonverbal communication

1. Environmental

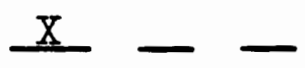


YES NO NA

2. Cultural

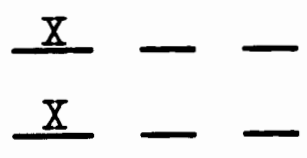

C. Relationship between sending and receiving skills

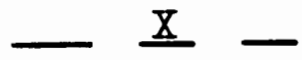

D. Developing sending and receiving skills

$-\underline{X}-$

E. Components of nonverbal communication mentioned in the text

1. Adornment

2. Chronemics

3. Haptics

4. Kinesics

5. Objects and Environment

6. Olfactory

7. Paralanguage

8. Physical Appearance

9. Proxemics

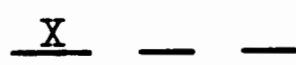

$-\underline{X}-$

$\underline{X}-$

- $\underline{X}-$

$\underline{X}-$

X -

$\underline{\underline{X}}-$

$\underline{\underline{X}}$

- $\underline{X}$

- $\underline{X}-$

F. Definition of the functions of nonverbal communication

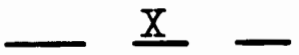

1. Accentuation

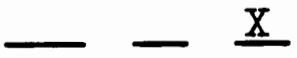

2. Complementation

$-\underline{\underline{X}}$

3. Contradiction

$-\underline{\underline{X}}$

4. Redundancy

$-\underline{\underline{X}}$

5. Regulation

$-\underline{X}$

6. Substitution

- - I

G. Relationship between verbal and nonverbal communication 
YES NO NA

H. Brief history of the study of nonverbal communication (optional)

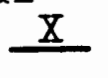

II. Adornment

A. Definition of adornment

$-\underline{X}-$

B. Communicative effects of clothes

$-\underline{X}$

C. Communicative effects of accessories

$-\underline{\underline{X}}$

D. Communicative effects of cosmetics

E. Cultural differences

$-\underline{X}$

F. Gender differences

$-\underline{X}$

$-\underline{X}$

III. Chronemics

A. Definition of chronemics

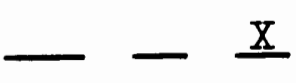

B. Communicative function of chronemics

C. American concept of time

D. Effects of time orientations

1. Psychological

2. Biological

3. Cultural

IV. Haptics

A. Definition of haptics

B. Communicative function of haptics

- $\underline{X}-$

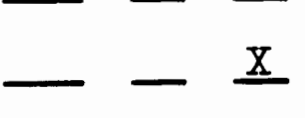

$-\underline{x}$

$-\underline{x}$

$-\underline{-} \underline{\underline{x}}$

C. Tactile communication and human development

D. Different types of touching behavior

1. Functional-professional

2. Social-polite

3. Friendship-warmth
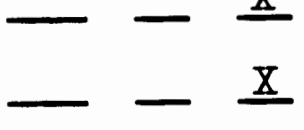

$-\underline{\underline{X}}$

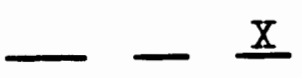

$\underline{x}--$

$\underline{x}-$

$\underline{X}-$

X - -

X -

$\underline{x}-$

$\underline{X}-$

X - - 
YES NO NA

4. Love-intimacy

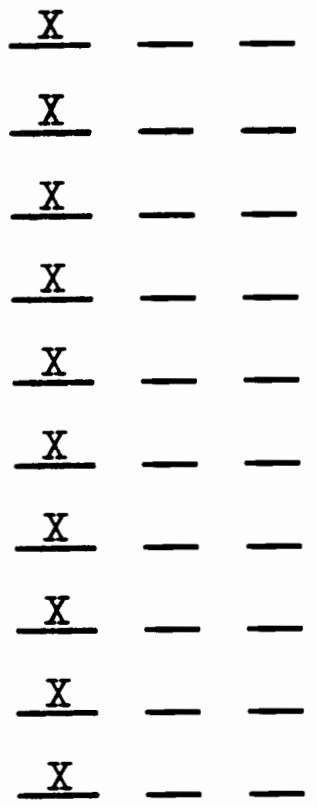

V. Kinesics

5. Sexual arousal

E. Needs for human touch

1. Biological

2. Psychological

3. Sociological

F. The skin as a communication system

G. Touch norms and the reason for norms

H. Gender differences

I. Cultural differences

A. Definition of kinesics

B. Communicative function of kinesics

C. Kinesic channels

1. Whole head

2. Whole body

3. Face only

4. Eyes and eyebrows only

- $\underline{\mathrm{X}}-$

$--\frac{x}{x}$

$-\underline{x}$

$-\underline{x}$

5. Hands and arms

$-\underline{x}$

6. Legs and feet

7. Dyad (whole body with another person)

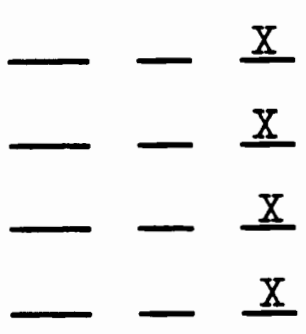

$--\underline{\underline{X}}$

D. Gender differences

$-\underline{\underline{x}}$

E. Cultural differences

- - $\underline{X}$

VI. Objects and Environment

$\underline{x}-$

A. Definition of objects and environment $\underline{X}-$ 
YES NO NA

B. Communicative effects of objects

(artifacts)

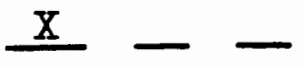

C. Communicative effects of environmental

features

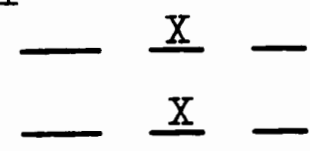

1. Size or volume of artifacts

2. Arrangement of artifacts within an environment

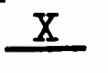

3. Types of materials in use

- $\underline{\mathrm{X}}-$

4. Lighting and shading

$\underline{\underline{X}}-$

5. Color

$-\underline{\mathrm{X}}-$

6. Temperature

$-\underline{X}-$

7. Noise

$-\underline{X}-$

D. Cultural differences

$-\underline{X}-$

E. Gender differences

$-\underline{X}-$

VII. OIfactory

$-\underline{X}-$

A. Definition of olfactory communication

$-\underline{X}$

B. Communicative function of odor

$-\underline{X}$

C. Types of smells and messages communicated

$-\underline{X}$

D. Cultural differences

$-\underline{X}$

E. Gender differences

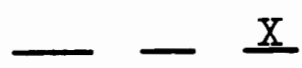

VIII. Paralanguage

A. Definition of paralanguage

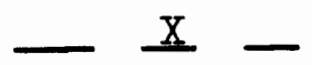

B. Communicative function of paralanguage
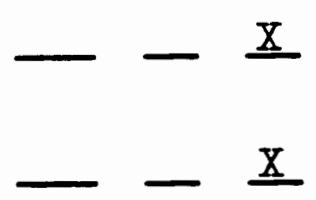

C. Sound attributes which give vocal cues their unique characteristics

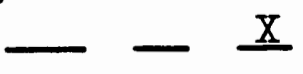

D. Vocal cues in relation to:

1. Speaker recognition

$-\underline{X}$ 
2. Personality judgments

3. Personal characteristics

4. Judgments of emotion

5. Comprehension and persuasion

6. Hesitations and pauses

E. Gender differences

F. Cultural differences

IX. Physical Appearance

A. Definition of physical appearance

B. Communicative potential of physical appearance

C. Body types

1. Endomorph

2. Mesomorph

3. Ectomorph

D. Traits associated with body types

E. Indicators of attractiveness

1. General attractiveness

2. Body shape

3. Body color

4. Smell

5. Hair (cranial, facial, body)

6. Clothes and artifacts

F. Cultural differences

G. Gender differences
YES NO NA

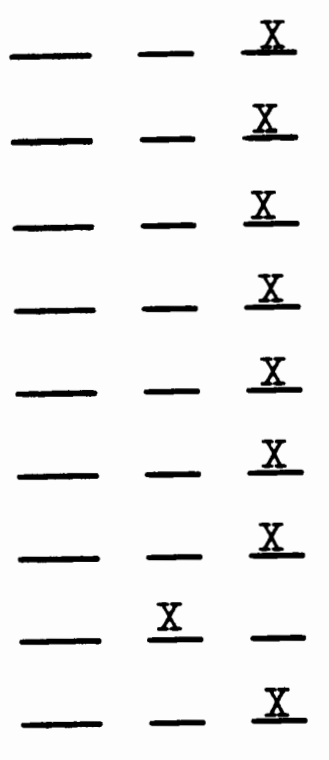

- - $\underline{x}$

$-\underline{x}$

$-\underline{x}$

$--\underline{x}$

$-\underline{\underline{X}}$

$--\underline{x}$

- - $\underline{x}$

$--\underline{x}$

$--\underline{\underline{x}}$

$--\underline{x}$

- - $\underline{x}$

- - I

- - $\underline{x}$

- $-\underline{X}$

$-\underline{\underline{x}}$ 
YES NO NA

X. Proxemics

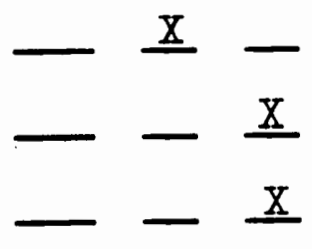

C. Factors relating to individual space preference

1. Age

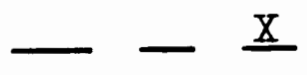

2. Sex

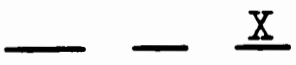

3. Ethnic and cultural background

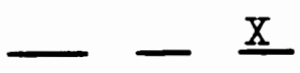

4. Topic or subject matter

$-\underline{X}$

5. Setting of the interaction

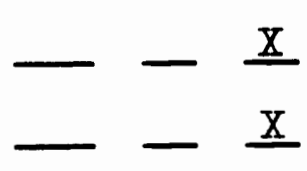

6. Physical characteristics of the interactants

$-\underline{X}$

7. Attitudinal orientation

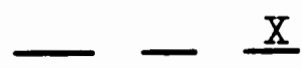

8. Emotional orientation

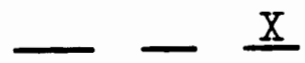

9. Characteristics of the interpersonal relationship

$-\underline{X}$

10. Personality characteristics

D. Territoriality

1. Intimate/Personal space
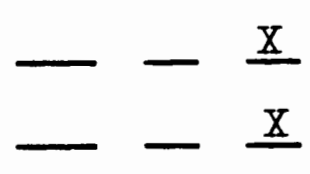

2. Private space

$-\underline{X}$

3. Public space

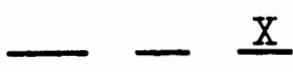

$-\underline{X}$

XI. General Summary Material

A. Brief review of the material in the chapters in terms of the usage and importance of nonverbal communication

$-\underline{X}-$ 
D. Relationship between nonverbal sending and receiving skills

$-\underline{\underline{X}}$ 
Nonverbal Communication in Human Interaction. 1972. Mark L. Knapp. New York: Holt, Rinehart and Winston. The text is divided into seven chapters which cover the following topics: (1) Basic Perspectives of Nonverbal Communication; (2) Effects of Environment and Space on Human Communication; (3) Effects of Physical Appearance and Dress on Human Communication; (4) Effects of Physical Behavior on Human Communication; (5) Effects of the Face and Eyes on Human Communication; (6) Effects of Vocal Cues Which Accompany Spoken Words; and (7) Observing and Recording Nonverbal Behavior. 4

The components of nonverbal communication not covered, or covered in a cursory manner are: chronemics and olfactory. 


\section{GENERAL EVALUATION SCALE FOR NONVERBAI TEXTS}

Text: Nonverbal Communication in Human Interaction Author: Knapp, Mark I. 1972.

YES NO NA

I. Purpose

A. Does the author accomplish the overall purpose of the text?

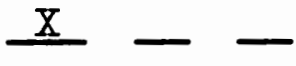

B. Is the purpose accomplished in good literary style?

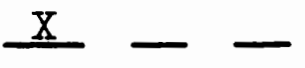

II. Author

A. Is there pertinent, factual information about the educational background, profession, and qualifications of the author?

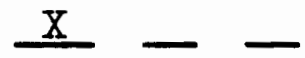

III. Authenticity

A. Is the material factually accurate and objective in its presentation?

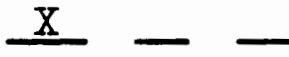

B. Is the material up-to-date?

$\underline{x}-$

C. Are the information sources well documented?

$\underline{x}-$

IV. Appropriateness

A. Does the material promote the educational goals and objectives of the curriculum?

B. Is the material appropriate to the level of instruction intended?

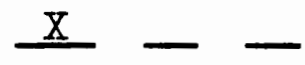

C. Is the interest level appropriate to the user?

1. Will the material stimulate the curiosity of the user?

$\underline{X}-$

2. Will the material appeal to many students?

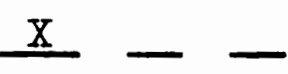

$\underline{X}-$

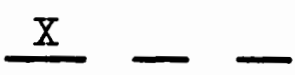


YES NO NA

\section{Content}

A. Is the content of the material well presented by providing adequate scope, range, depth, and continuity?

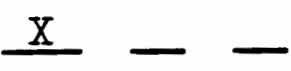

B. Is the material well organized and well balanced?

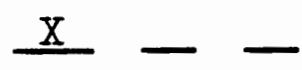

C. Is the material presented as clearly and simply as possible for the level intended?

D. Does the material aid conceptualization of the subject matter?

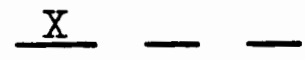

E. Does the material achieve its stated purpose?

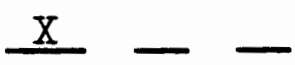

F. Are the transitions from one point to another, or one section to another, smooth and clear?

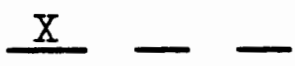

G. Does the text present information not otherwise available?

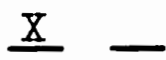

H. Does the material give a new dimension to the subject?

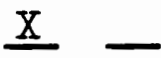

I. Are the sources, purposes, and points of view readily identifiable?

VI. Technical Quality

A. Is the text hardcover?

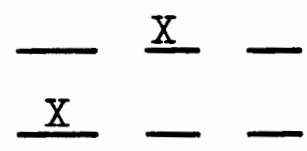

B. Is the text softcover?

C. Is the typography clear and easy to read?

D. Are the page layouts well designed? $\underline{X}$

E. Is the pagination definite and clear? $\mathbb{X}$

F. Are aids to learning provided?

1. Is there a table of contents?

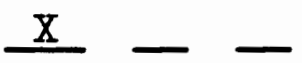

2. Is there an outline listing the contents of each chapter? 
a. Is this at the beginning of each chapter?

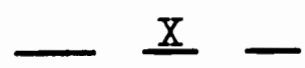

b. Is this in the table of contents?

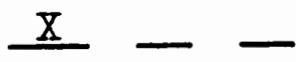

3. Are the major titles and subtitles of each section delineated in each chapter?

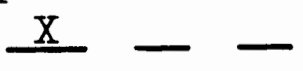

4. Is there a list of priorities at the beginning of each chapter?

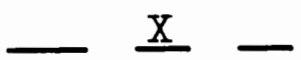

5. Are internal summaries and reviews provided where appropriate?

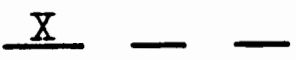

6. Is there a list of related exercises or activities contained in each chapter?

7. Is there a list of additional readings in each chapter?

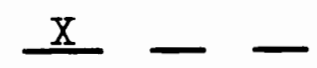

8. Does the text contain an appendix?

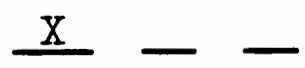

a. Is the appended material
useful?

a. Is the appended material
useful?

$-\underline{X}-$

9. Does the text contain a glossary? _- $\underline{\mathrm{X}}$ -

a. Is it at the end of each chapter?

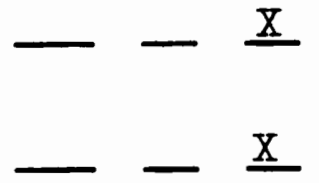

b. Is it at the end of the text?

$-\underline{X}$ 
YES NO NA

13. Are the chapters footnoted or endnoted?

G. Are visual aids used?

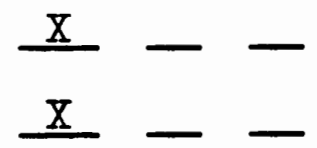

1. Do they contribute to the development of the text?

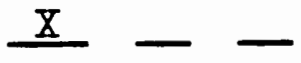

2. Is the art of photographic quality of the visual aid acceptable (sharpness, composition, color)?

$\underline{\mathrm{X}}-$

3. Is there a good balance between artistic technique and educational need?

4. Are the captions readable?

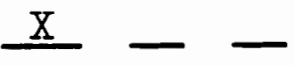

5. Are the captions a good interpretations of the material, yet not distracting?

6. Are the illustrations and cap-

tions suitable for teaching and learning purposes?
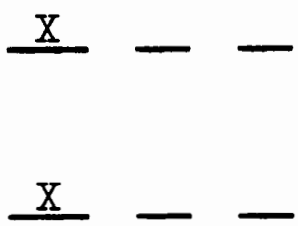

7. Are the visual aids located properly for greatest usefulness?

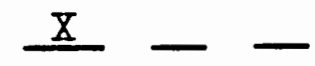

8. Are the visual aids adequate in number?
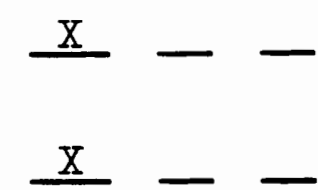

9. Is the content of the visual aid well organized and well balanced? $\mathrm{X}$ -

10. Is explanatory material provided? $\underline{\mathrm{X}}-$

\section{SPECIFIC EVALUATION FORM FOR NONVERBAL TEXTS}

I. Introductory Material

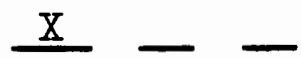

A. Definition of nonverbal communication $\underline{X}$

B. Issues involved in defining and classifying nonverbal communication

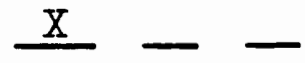

1. Environmental 
YES NO NA

2. Cultural

$\frac{x}{x}--$

3. Contextual

$-\underline{X}-$ receiving skills

D. Developing sending and receiving skills

$-\underline{X}-$

E. Components of nonverbal communication mentioned in the text

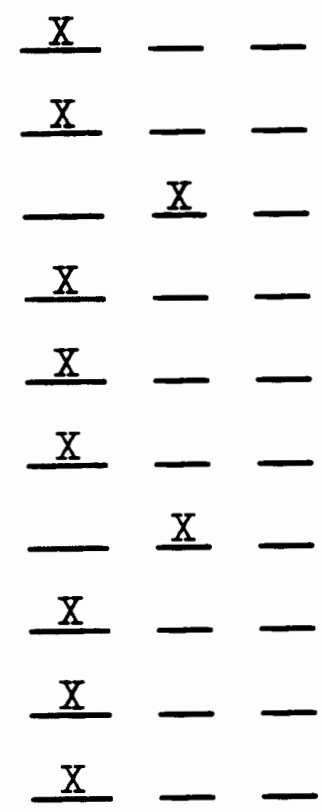

F. Definition of the functions of nonverbal communication

1. Accentuation

2. Complementation

3. Contradiction

4. Redundancy

5. Regulation

6. Substitution

$\underline{X}-$

$\underline{\mathrm{X}}-$

$\underline{\mathrm{X}}-$

$\underline{X}-$

$\underline{x}-$

$\underline{\mathrm{X}}-$

$\underline{X}-$

G. Relationship between verbal and nonverbal communication 
YES NO NA

H. Brief history of the study of nonverbal communication (optional)

$\underline{\mathrm{X}}$

II. Adornment

A. Definition of adornment

B. Communicative effects of clothes

C. Communicative effects of accessories

D. Communicative effects of cosmetics

E. Cultural differences

F. Gender differences

III. Chronemics

A. Definition of chronemics

B. Communicative function of chronemics

C. American concept of time

D. Effects of time orientations

1. Psychological

2. Biological

3. Cultural

IV. Haptics

A. Definition of haptics

B. Communicative function of haptics

C. Tactile communication and human development

D. Different types of touching behavior

1. Functional-professional

2. Social-polite

3. Friendship-warmth

4. Love-intimacy
X - -

$-\underline{X}-$

$\underline{x}-$

X - -

- $\underline{X}-$

- $\underline{X}-$

$-\underline{X}-$

$-\underline{X}-$

$-\underline{X}$

$-\underline{X}$

- - X

$-\underline{X}$

$-\underline{x}$

$-\underline{X}$

- -

$\underline{X}-$

X - -

X -

X -

- I -

$-\underline{X}$

$-\underline{X}$

$-\underline{X}$

$-\underline{X}$ 
5. Sexual arousal

YES NO NA

E. Needs for human touch

$--\underline{X}$

1. Biological

2. Psychological

3. Sociological

F. The skin as a communication system

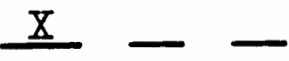

G. Touch norms and the reason for norms

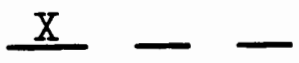

H. Gender differences

I. Cultural differences

V. Kinesics

A. Definition of kinesics

B. Communicative function of kinesics

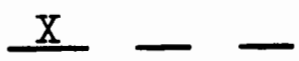

$\underline{x}--$

- $\underline{\mathrm{X}}-$

$\underline{X}-$

- $\underline{x}-$

- $\underline{x}-$

$\underline{\mathrm{X}}-$

$\underline{\mathrm{X}}-$

$\underline{X}-$

C. Kinesic channels

$\underline{X}-$

1. Whole head

$\underline{X}--$

2. Whole body

- $\underline{\mathrm{X}}-$

3. Face only

4. Eyes and eyebrows only

$\underline{x}$

$\underline{x}-$

5. Hands and arms

- $\underline{\underline{X}}-$

6. Legs and feet

7. Dyad (whole body with another person)

- $\underline{X}-$

$\underline{\mathrm{X}}--$

D. Gender differences

$\underline{X}--$

E. Cultural differences

- $\underline{\underline{X}}-$

VI. Objects and Environment

$\underline{X}-$

A. Definition of objects and environment $\underline{X}-$

B. Communicative effects of objects (artifacts) 
YES NO NA

C. Communicative effects of environmental features

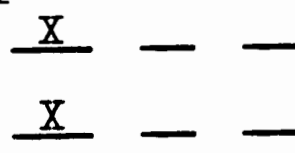

2. Arrangement of artifacts within an environment

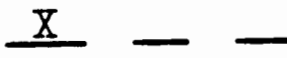

3. Types of materials in use

$\longrightarrow$ X

4. Lighting and shading

$\underline{X}-$

5. Color

$\underline{x}-$

6. Temperature

$\underline{x}-$

7. Noise

D. Cultural differences

- $\underline{x}-$

E. Gender differences

$\underline{x}-$

$-\underline{x}-$

VII. Olfactory

$-\underline{\underline{X}}-$

A. Definition of olfactory communication - -

B. Communicative function of odor

$-\underline{X}$

C. Types of smells and messages communicated

$-\underline{X}$

D. Cultural differences

$-\underline{X}$

E. Gender differences

$-\underline{X}$

VIII. Paralanguage

A. Definition of paralanguage

$\underline{X}-$

B. Communicative function of paralanguage

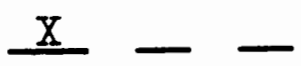

$\underline{X}-$

C. Sound attributes which give vocal cues

their unique characteristics

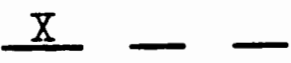

D. Vocal cues in relation to:

1. Speaker recognition

$\underline{X}-$

2. Personality judgments 
3. Personal characteristics

YES NO NA

4. Judgments of emotion

5. Comprehension and persuasion

6. Hesitations and pauses

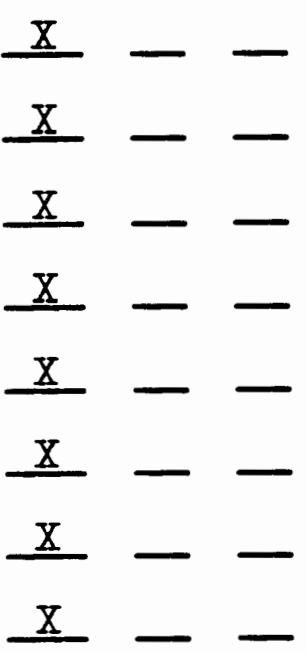

A. Definition of physical appearance

$\underline{x}-$

B. Communicative potential of physical appearance

$\frac{x}{x}--$

C. Body types

1. Endomorph

X - -

2. Mesomorph

3. Ectomorph

D. Traits associated with body types

E. Indicators of attractiveness

1. General attractiveness

2. Body shape

3. Body color

X

$\underline{\mathrm{X}}-$

$\underline{x}-$

$\underline{x}--$

$\underline{x}-$

$\underline{x}-$

$\underline{x}-$

4. Smell

5. Hair (cranial, facial, body)

6. Clothes and artifacts

F. Cultural differences

$\underline{X}$

$\underline{X}-$

$\underline{X}-$

$-\underline{\mathrm{X}}-$

G. Gender differences

- $\underline{\underline{X}}-$

X. Proxemics

X

A. Definition of proxemics

- I - 
B. Communicative function of proxemics

C. Factors relating to individual space preference

1. Age

2. Sex

3. Ethnic and cultural background

4. Topic or subject matter

5. Setting of the interaction

6. Physical characteristics of the interactants

7. Attitudinal orientation

8. Emotional orientation

9. Characteristics of the interpersonal relationship

10. Personality characteristics

D. Territoriality

1. Intimate-Personal space

2. Private space

3. Public space

XI. General Summary Material
- $\underline{X}-$

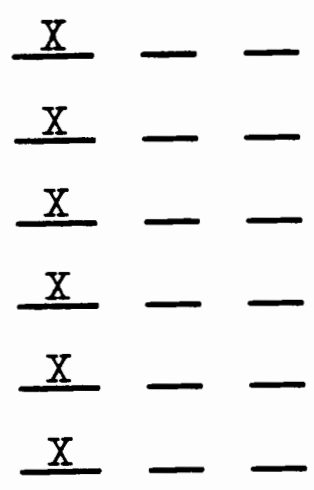

$\underline{X}-$

$\underline{X}-$

- $\underline{X}-$

$\underline{\mathrm{X}}-$

$\underline{\mathrm{X}}-$

$\underline{X}--$

X -

$\underline{x}-\underline{-}$

$\underline{X}-$

$-\underline{\mathrm{X}}-$

A. Brief review of the material in the chapters in terms of the usage and importance of nonverbal communication

$-\underline{X}$

B. Characteristics of a skilled nonverbal receiver/decoder

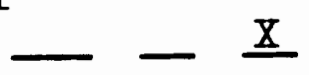

C. Characteristics of a skilled nonverbal sender/encoder

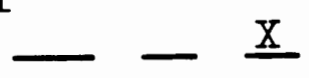

D. Relationship between nonverbal sending and receiving skills

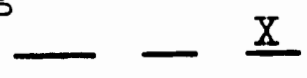


Beyond Words: An Introduction to Nonverbal Communication. 1974 .

Randall P. Harrison. Englewood Cliffs, N.J.: PrenticeHall, Inc.

The text is divided into four parts which comprise twelve chapters and four appendices.

Part 1: Introduction contains the following two chapters: (1) Nonverbal Cues; and (2) Nonverbal Communication.

Part 2: Systems contains the following three chapters: (1) Communication Systems; (2) Code Systems; and (3) Systems for Prediction.

Part 3: Codes contains the following five chapters:

(1) Human Sounds; (2) The Human Face; (3) Hands and Body;

(4) Time, Space, and Object; and (5) Messages of Media.

Part 4: Conclusion contains the following two chapters: (1) -plications: im-, ap-, con-; and (2) Epilog.

The four appendices contain the following information: Appendix A: answers to the "right-right" test; Appendix B: information processing test; Appendix C: who touches whom, where; Appendix D: a glossary of key terms. ${ }^{5}$

The only component of nonverbal communication missing from this text is olfactory although adornment, haptics, objects and environment, paralanguage, physical appearance, and proxemics are only cursorily examined. 


\section{GENERAI EVAIUATION SCAIE FOR NONVERBAI TEXTS}

Text: Beyond Words: An Introduction to Nonverbal Communication.

Author: Harrison, Randall P. 1974.

YES NO NA

I. Purpose

A. Does the author accomplish the overall purpose of the text?

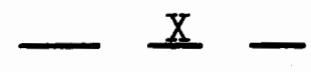

B. Is the purpose accomplished in good literary style?

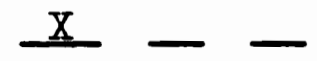

II. Author

A. Is there pertinent, factual information about the educational background, profession, and qualifications of the author?

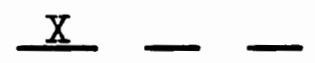

III. Authenticity

A. Is the material factually accurate and objective in its presentation?

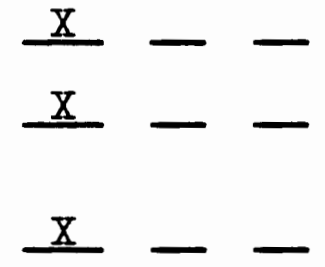

IV. Appropriateness

A. Does the material promote the educational goals and objectives of the curriculum?

B. Is the material appropriate to the level of instruction intended?

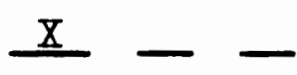

C. Is the interest level appropriate to the user?

1. Will the material stimulate the curiosity of the user?
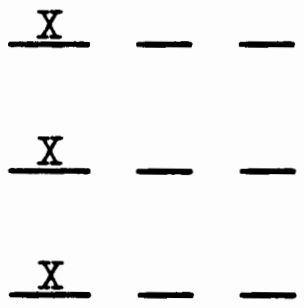

2. Will the material appeal to many students?

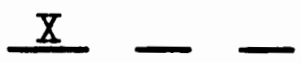


YES NO NA

V. Content

A. Is the content of the material well presented by providing adequate scope, range, depth, and continuity?

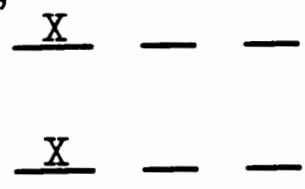

B. Is the material well organized and well balanced?

C. Is the material presented as clearly and simply as possible for the level intended?

D. Does the material aid conceptualization of the subject matter?
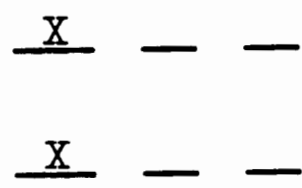

E. Does the material achieve its stated purpose?

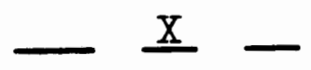

F. Are the transitions from one point to another, or one section to another, smooth and clear?

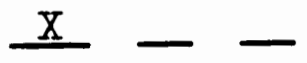

G. Does the text present information not otherwise available?

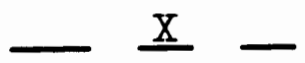

H. Does the material give a new dimension to the subject?

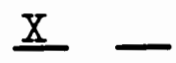

I. Are the sources, purposes, and points of view readily identifiable?

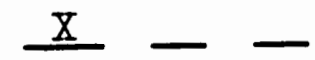

VI. Technical Quality

A. Is the text hardcover?

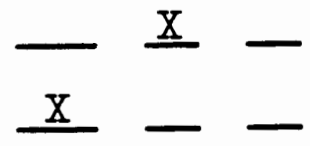

B. Is the text softcover?

C. Is the typography clear and easy to read?

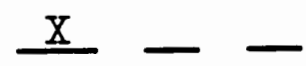

D. Are the page layouts well designed? $\underline{\mathrm{X}}-$

E. Is the pagination definite and clear? $\underline{X}-$

F. Are aids to learning provided? $\underline{X}-$

1. Is there a table of contents? $\underline{X}-$

2. Is there an outline listing the contents of each chapter? 
a. Is this at the beginning of each chapter?

$\underline{x}-$

b. Is this in the table of contents?

X -

3. Are the major titles and subtitles of each section delineated in each chapter?

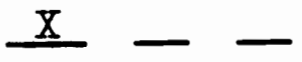

4. Is there a list of priorities at the beginning of each chapter?

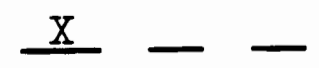

5. Are internal summaries and reviews provided where appropriate?

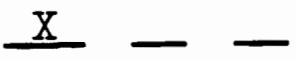

6. Is there a list of related exercises or activities contained in each chapter?

7. Is there a list of additional readings in each chapter?

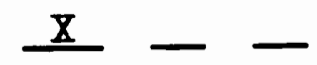

8. Does the text contain an appendix?

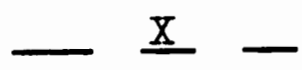

a. Is the appended material useful?

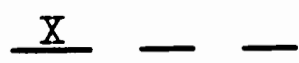

9. Does the text contain a glossary? $\mathrm{X}$ -

a. Is it at the end of each chapter?

$-\underline{X}-$

b. Is it at the end of the text?

X -

10. Does the text contain a subject index?

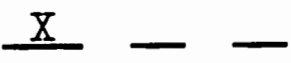

11. Does the text contain an author index?

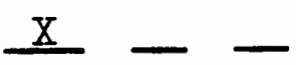

12. Does the text contain a bibliography?

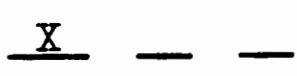

a. Is it at the end of each chapter?

$-\underline{X}-$

b. Is it at the end of the text? $\underline{X}-$ 
YES NO NA

13. Are the chapters footnoted or endnoted?

G. Are visual aids used?

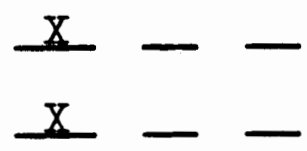

1. Do they contribute to the development of the text?

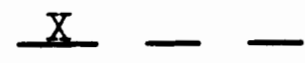

2. Is the art of photographic quality of the visual aid acceptable (sharpness, composition, color)?

3. Is there a good balance between artistic technique and educational need?

4. Are the captions readable?

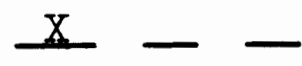

5. Are the captions a good interpretation of the material, yet not distracting?

6. Are the illustrations and caplearning purposes?

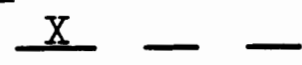
$\underline{\mathrm{X}}-$

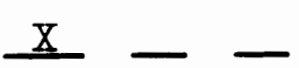

\section{tions suitable for teaching and}

7. Are the visual aids located properly for greatest usefulness?

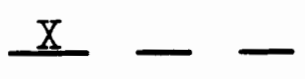

8. Are the visual aids adequate in

number?

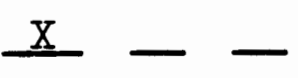

9. Is the content of the visual aid well organized and well balanced? $\mathrm{X}$ -

10. Is explanatory material provided? $\mathrm{X}-$

\section{SPEC IFIC EVALUATION FORM FOR NONVERBAL TEXTS}

I. Introductory Material

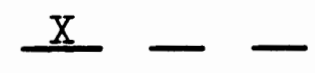

A. Definition of nonverbal communication $\underline{X}-$

B. Issues involved in defining and classifying nonverbal communication

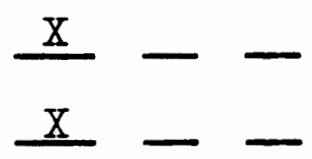


YES NO NA

2. Cultural

X - -

3. Contextual

$\underline{x}-$

C. Relationship between sending and receiving skills

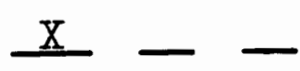

D. Developing sending and receiving skills

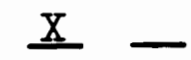

E. Components of nonverbal communication mentioned in the text

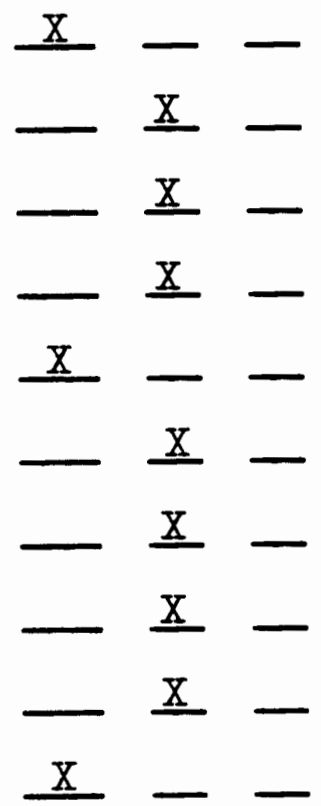

F. Definition of the functions of nonverbal communication

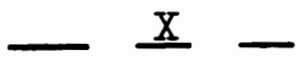

1. Accentuation

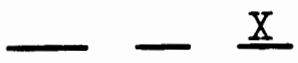

2. Complementation

$-\underline{\underline{X}}$

3. Contradiction

$--\underline{X}$

4. Redundancy

$-\underline{\underline{x}}$

5. Regulation

$-\underline{\underline{X}}$

6. Substitution

$-\underline{x}$

G. Relationship between verbal and nonverbal communication 
YES NO NA

H. Brief history of the study of nonverbal communication (optional)

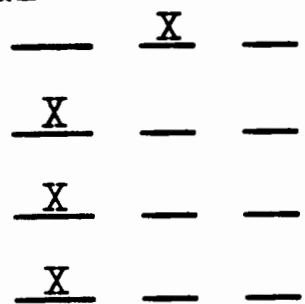

B. Communicative effects of clothes

$\underline{X}$

C. Communicative effects of accessories

$-\underline{X}-$

D. Communicative effects of cosmetics

- $\underline{X}-$

E. Cultural differences

$-\underline{X}-$

F. Gender differences

III. Chronemics

A. Definition of chronemics

$-\underline{X}-$

B. Communicative function of chronemics

C. American concept of time

D. Effects of time orientations

1. Psychological

2. Biological

3. Cultural

IV. Haptics

A. Definition of haptics

$\mathrm{X}$

$\underline{\mathrm{X}}$

X -

X - -

X -

X -

X - -

$\underline{X}-$

X -

X - -

B. Communicative function of haptics

X -

C. Tactile communication and human development

$-\underline{X}-$

D. Different types of touching behavior $-\underline{X}-$

1. Functional-professional

$-\underline{\underline{X}}$

2. Social-polite

3. Friendship-warmth

$-\underline{\underline{X}}$

4. Love-intimacy

$-\underline{X}$

- $-\underline{\underline{X}}$ 
YES NO NA

5. Sexual arousal

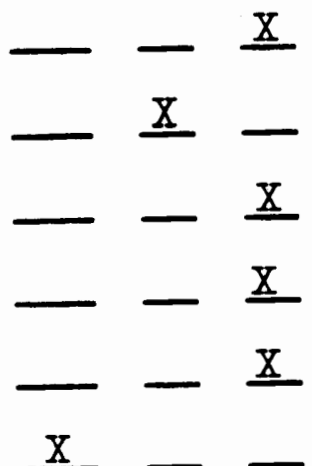

F. The skin as a communication system

G. Touch norms and the reason for norms

H. Gender differences

I. Cultural differences

V. Kinesics

A. Definition of kinesics

B. Communicative function of kinesics

C. Kinesic channels

1. Whole head

2. Whole body

3. Face only

4. Eyes and eyebrows only

5. Hands and arms

$\underline{x}-$

$-\underline{x}-$

$\underline{x}-$

$\underline{x}-$

$\underline{x}-$

$\underline{x}--$

$\underline{x}--$

$\underline{x}--$

6. Legs and feet

7. Dyad (whole body with another

person)

$\underline{x}$

$\underline{x}-$

$\underline{\mathrm{X}}-$

$\underline{\mathrm{X}}-$

- $\underline{x}-$

D. Gender differences

$\underline{X}-$

E. Cultural differences

$-\underline{x}-$

$-\underline{X}-$

VI. Objects and Environment

$\underline{X}-$

A. Definition of objects and environment $\underline{X}-$

B. Communicative effects of objects (artifacts) 
C. Communicative effects of environmental features

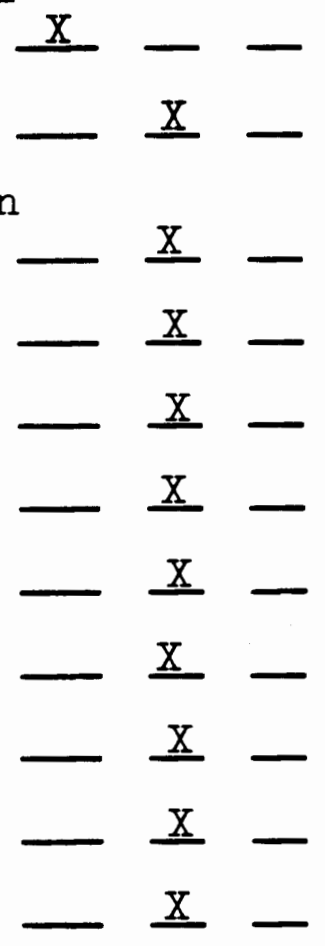

VII. Olfactory

1. Size or volume of artifacts

2. Arrangement of artifacts within an environment

3. Types of materials in use

4. Lighting and shading

5. Color

6. Temperature

7. Noise

D. Cultural differences

E. Gender differences

A. Definition of olfactory communication

B. Communicative function of odor

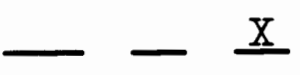

C. Types of smells and messages communicated

$-\underline{X}$

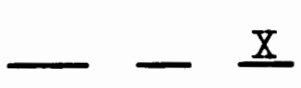

D. Cultural differences

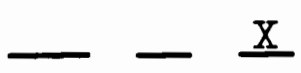

E. Gender differences

VIII. Paralanguage

A. Definition of paralanguage

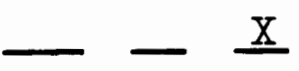

B. Communicative function of paralanguage

C. Sound attributes which give vocal cues their unique characteristics

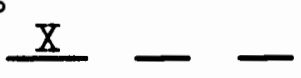

D. Vocal cues in relation to:

I. Speaker recognition

- $\underline{X}$

2. Personality judgments

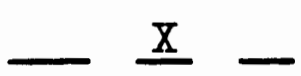


3. Personal characteristics

4. Judgments of emotion

5. Comprehension and persuasion

6. Hesitations and pauses

E. Gender differences

F. Cultural differences

IX. Physical Appearance

A. Definition of physical appearance

B. Communicative potential of physical appearance

C. Body types

1. Endomorph

2. Mesomorph

3. Ectomorph

D. Traits associated with body types

E. Indicators of attractiveness

1. General attractiveness

2. Body shape

3. Body color

4. Smell

5. Hair (cranial, facial, body)

6. Clothes and artifacts

F. Cultural differences

G. Gender differences

X. Proxemics

A. Definition of proxemics
YES NO NA

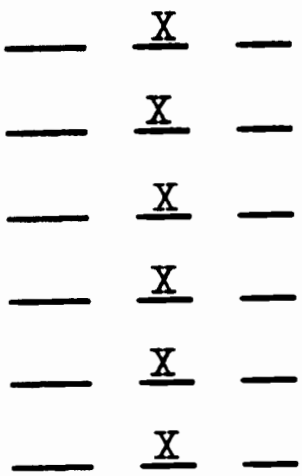

$\underline{x}-$

$\underline{x}-$

X -

- $\underline{x}-$

$-\underline{\underline{X}}$

$-\underline{\underline{x}}$

$-\underline{\underline{X}}$

- $\underline{x}-$

- $\underline{x}-$

- - $\underline{x}$

- - $\underline{x}$

$--\underline{x}$

- - $\underline{x}$

$--\underline{x}$

- - $\underline{x}$

- I -

- $\underline{I}-$

X -

X - 
B. Communicative function of proxemics $\mathrm{X}$ -

C. Factors relating to individual space preference

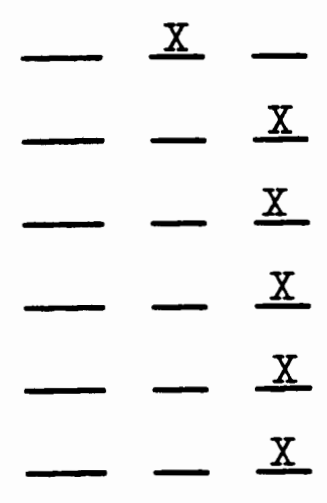

6. Physical characteristics of the interactants

7. Attitudinal orientation

8. Emotional orientation

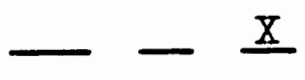

1. Age

2. Sex

3. Ethnic and cultural background

4. Topic or subject matter

5. Setting of the interaction

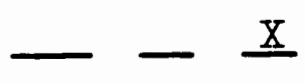

9. Characteristics of the interpersonal relationship

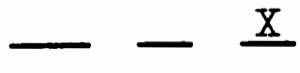

10. Personality characteristics

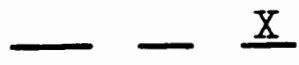

D. Territoriality

1. Intimate-Personal space

2. Private space

3. Public space

XI. General Summary Material
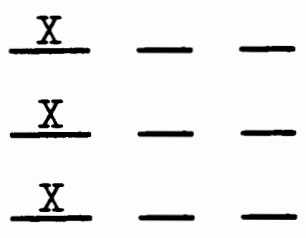

$\underline{X}-$

$\underline{x}-$

A. Brief review of the material in the chapters in terms of the usage and importance of nonverbal communication $X$

B. Characteristics of a skilled nonverbal receiver/decoder

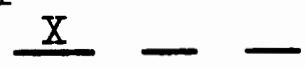

c. Characteristics of a skilled nonverbal sender/encoder

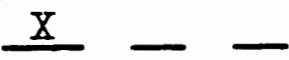

D. Relationship between nonverbal sending and receiving skills 
Nonverbal Communication: Readings with Commentary. 1974. Shirley Weitz. New York: Oxford University Press.

The text is divided into the following five major sections: (I) Facial Expression and Visual Interaction; (2) Paralanguage; (3) Body Movement and Gestures; (4) Spatial Behavior; and (5) Multichannel Communication.

Section 1 contains the following four articles:

(1) Similarities and Differences Between Cultures in Expressive Moments by Eibl-Eibesfeldt; (2) Facial Affect Scoring Technique by Ekman, Friesen, and Tompkins; (3) Communication of Affect Through Facial Expressions in Humans by Buck, Savin, Miller, and Caul; and (4) Visual Interaction: The Glances of Power and Preference by Exline.

Section 2 contains the following four articles:

(1) Communication of Feelings by Content Free Speech by Davitz and Davitz; (2) Acoustic Concomitants of Emotional Dimensions by Scherer: (3) The Doctor's Voice: Postdictor of Successful Referral of Alcoholic Patients by Milmoe, Rosenthal, Blanc, Chafetz, and Wolf; (4) The Mother's Voices: Postdictor of Aspects of Her Baby's Behavior by Milmoe, Novey, Kagan, and Rosenthal.

Section 3 contains the following five articles:

(1) Toward Analyzing American Movement by Birdwhistell;

(2) Masculinity and Feminity as Display by Birdwhistel1;

(3) Movement Coordination in Social Interaction by Kendon; (4) The Body Movement-Speech Rhythm Relationship as a Cue 
to Speech Encoding by Dittman; and (5) Quasi-Courtship Behavior in Psychotherapy by Scheflen. Section 4 contains the following four articles: (1) Proxemics by Hall; (2) Conflicts and Directions in Proxemic Research by Watson; (3) Small Group Ecology by Sommer; and (4) Territorial Defense and the Good Neighbor by Sommer and Becker.

Section 5 contains the following five chapters: (1) Nonverbal Leakage and Clues to Deception by Ekman and Friesen; (2) Inference of Attitudes from Nonverbal Communication in Two Channels by Mehrabian and Ferris; (3) Some Signals and Rules for Taking Speaking Turns in Conversations by Duncan; and (4) Some Determinants of Social Interaction by Mehrabian and Ksionzky; and (5) Displays and Messages in Intraspecific Communication by Smith. 6 The components of nonverbal communication not covered in this text are adornment, chronemics, haptics, objects and environment, olfactory, and physical appearance. 


\section{GENERAL EVALUATION SCALE FOR NONVERBAL TEXTS}

Text: Nonverbal Communication: Readings with Commentary. Author: Weitz, Shirley. 1974.

YES NO NA

I. Purpose

A. Does the author accomplish the overall purpose of the text?

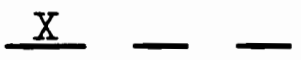

B. Is the purpose accomplished in good literary style?

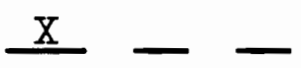

II. Author

A. Is there pertinent, factual information about the educational background, profession, and qualifications of the author?

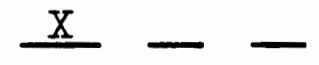

III. Authenticity

A. Is the material factually accurate and objective in its presentation?

B. Is the material up-to-date?

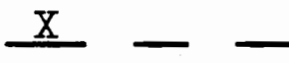

C. Are the information sources well documented?

IV. Appropriateness

A. Does the material promote the educational goals and objectives of the curriculum?

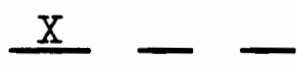

B. Is the material appropriate to the level of instruction intended?

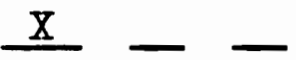

C. Is the interest level appropriate to the user?

1. Will the material stimulate the curiosity of the user?

$\underline{X}-$

$\underline{X}-$

2. Will the material appeal to many students?

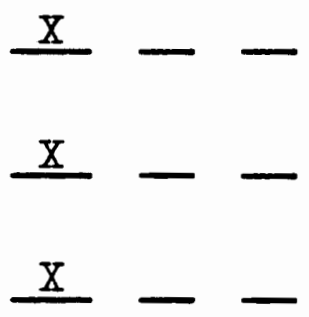


YES NO NA

\section{Content}

A. Is the content of the material well presented by providing adequate scope, range, depth, and continuity?

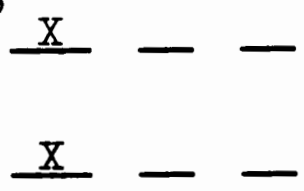

B. Is the material well organized and well balanced?

C. Is the material presented as clearly and simply as possible for the level intended?

D. Does the material aid conceptualiza-

tion of the subject matter?

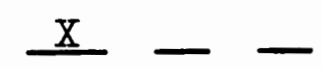

E. Does the material achieve its stated purpose?

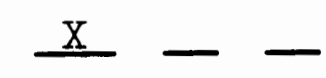

F. Are the transitions from one point to another, or one section to another, smooth and clear?

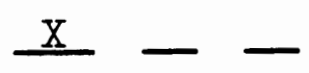

G. Does the text present information not otherwise available?

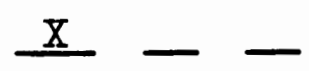

H. Does the material give a new dimension to the subject?
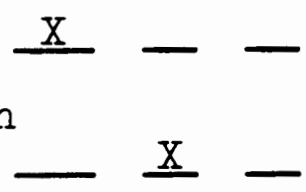

I. Are the sources, purposes, and points of view readily identifiable?

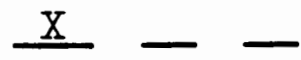

\section{Technical Quality}

A. Is the text hardcover?

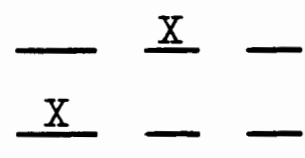

B. Is the text softcover?

C. Is the typography clear and easy to read?

D. Are the page layouts well designed?

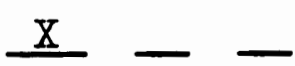

E. Is the pagination definite and clear?

F. Are aids to learning provided?

1. Is there a table of contents?

X

$\mathrm{X}$

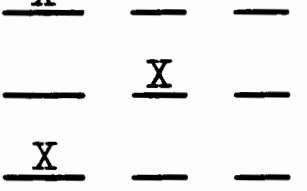

2. Is there an outline listing the contents of each chapter? 
YES NO NA

a. Is this at the beginning of each chapter?

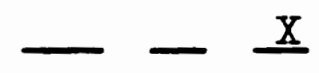

b. Is this in the table of contents?

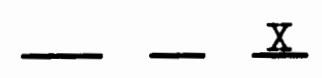

3. Are the major titles and subtitles of each section delineated in each chapter?

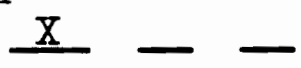

4. Is there a list of priorities at the beginning of each chapter?

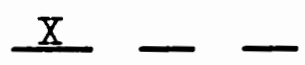

5. Are internal summaries and reviews provided where appropriate?

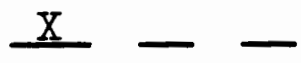

6. Is there a list of related exercises or activities contained in each chapter?

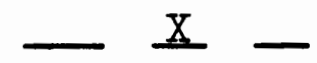

7. Is there a list of additional readings in each chapter?

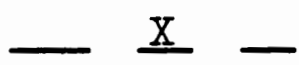

8. Does the text contain an appendix?

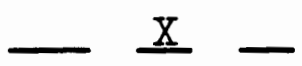

a. Is the appended material useful?

$-\underline{X}$

9. Does the text contain a glossary? _ $\underline{X}-$

a. Is it at the end of each chapter?

$-\underline{Z}$

b. Is it at the end of the text?

$-\underline{X}$

10. Does the text contain a subject index?

$\underline{X}-$

11. Does the text contain an author index?

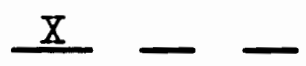

12. Does the text contain a bibliography?

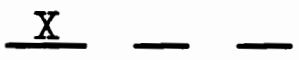

a. Is it at the end of each chapter?

$\underline{X}-$

b. Is it at the end of the text? _ $\underline{X}$ - 
YES NO NA

13. Are the chapters footnoted or endnoted?

G. Are visual aids used?

1. Do they contribute to the development of the text?
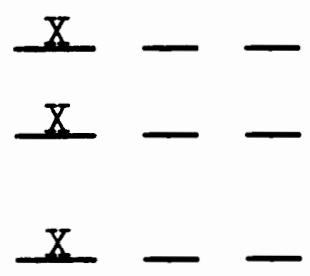

2. Is the art of photographic quality of the visual aid acceptable (sharpness, composition, color)?

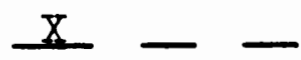

3. Is there a good balance between artistic technique and educational need?

4. Are the captions readable?

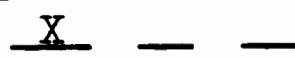

5. Are the captions a good interpretation of the material, yet not distracting?

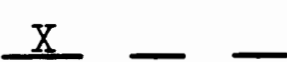

Are the illustrations and captions suitable for teaching and learning purposes?

7. Are the visual aids located properly for greatest usefulness?

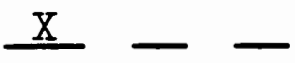

8. Are the visual aids adequate in number?

9. Is the content of the visual aid well organized and well balanced? $\underline{\mathrm{X}}-$

10. Is explanatory material provided? $\mathrm{X}$ -

SPEC IFIC EVALUATION FORM FOR NONVERBAL TEXTS

I. Introductory Material

$\underline{\mathrm{X}}-$

A. Definition of nonverbal communication $\mathrm{X}-$

B. Issues involved in defining and classifying nonverbal communication

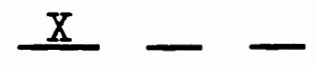

1. Environmental 
YES NO NA

2. Cultural

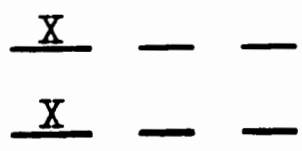

C. Relationship between sending and receiving skills

$-\underline{X}-$

D. Developing sending and receiving skills

$\underline{\underline{X}}-$

E. Components of nonverbal communication mentioned in the text

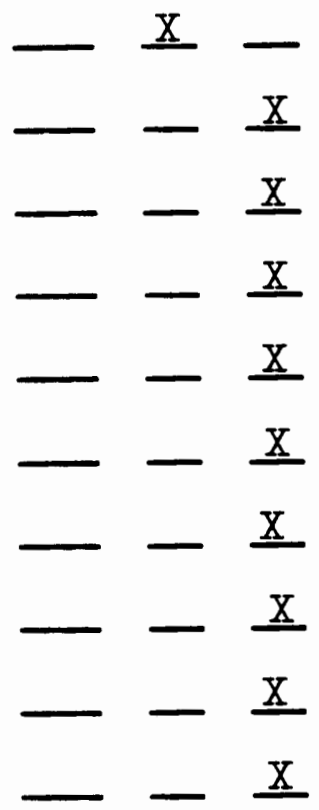

1. Adornment

2. Chronemics

3. Haptics

4. Kinesics

5. Objects and Environment

6. Olfactory

7. Paralanguage

8. Physical Appearance

9. Proxemics

F. Definition of the functions of nonverbal communication

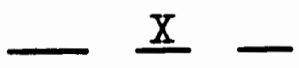

1. Accentuation

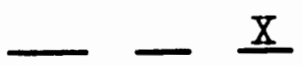

2. Complementation

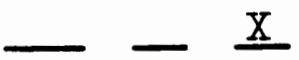

3. Contradiction

4. Redundancy

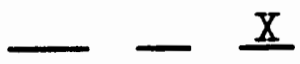

5. Regulation

$-\underline{X}$

6. Substitution

$-\underline{X}$

$-\underline{X}$

G. Relationship between verbal and nonverbal communication 
YES NO NA

H. Brief history of the study of nonverbal communication (optional)

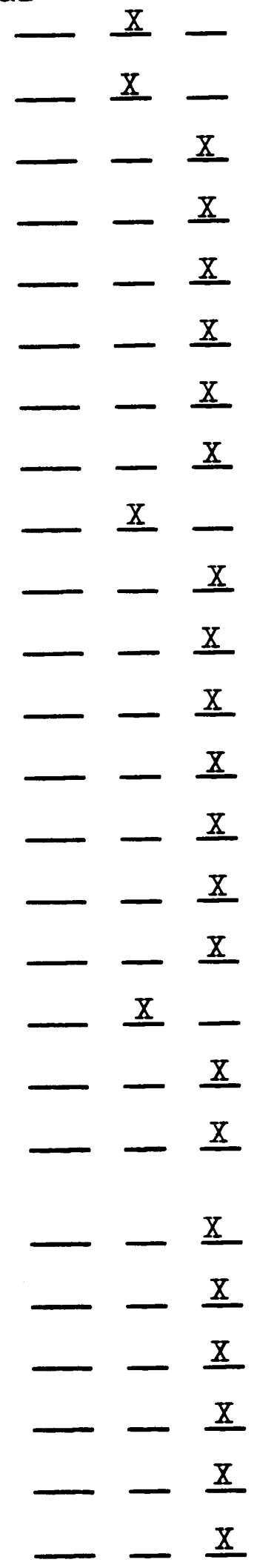

IV. Haptics

A. Definition of haptics

B. Communicative function of haptics

C. Tactile communication and human development

A. Definition of adornment

B. Communicative effects of clothes

C. Communicative effects of accessories

D. Communicative effects of cosmetics

E. Cultural differences

F. Gender differences

III. Chronemics

A. Definition of chronemics

B. Communicative function of chronemics

C. American concept of time

D. Effects of time orientations

1. Psychological

2. Biological

3. Cultural

D. Different types of touching behavior

1. Functional-professional

2. Social-polite

3. Friendship-warmth

4. Love-intimacy

\section{政}

- $\underline{X}-$

$-\underline{x}$

- -

- - $\underline{x}$

- $-\underline{\underline{x}}$

$-\underline{\underline{x}}$

$--\underline{x}$

$-\underline{x}-$

- $-\underline{x}$

$-\underline{\underline{x}}$

- - $\underline{x}$

$-\underline{\underline{x}}$

$-\underline{x}$

- - I

$--\underline{x}$

- $\underline{x}-$

- - $\underline{X}$ 
YES NO NA

5. Sexual arousal

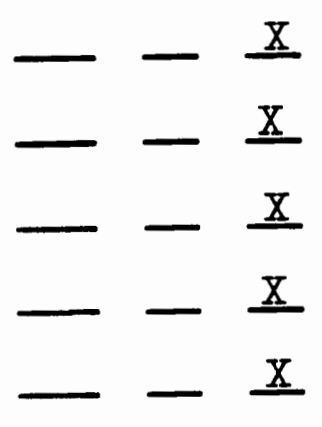

F. The skin as a communication system

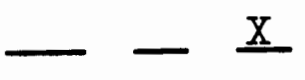

G. Touch norms and the reason for norms

H. Gender differences

I. Cultural differences

$-\underline{X}$

$-\underline{\underline{X}}$

$-\underline{x}$

V. Kinesics

A. Definition of kinesics

B. Communicative function of kinesics

$\underline{x}--$

C. Kinesic channels

$\underline{x}--$

X -

$\underline{x}-$

1. Whole head

$\underline{x}--$

2. Whole body

3. Face only

4. Eyes and eyebrows only

5. Hands and arms

$\underline{x}-$

6. Legs and feet

$\underline{x}-$

$\underline{\mathrm{x}}-$

$\underline{x}-$

7. Dyad (whole body with another
person)

D. Gender differences

$\underline{x}-$

E. Cultural differences

$\underline{x}-$

$\underline{X}-$

$-\underline{\underline{x}}-$

VI. Objects and Environment

- $\underline{\underline{X}}-$

A. Definition of objects and environment - -

B. Communicative effects of objects (artifacts) 
YES NO NA

C. Communicative effects of environmental features

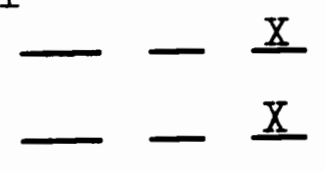

2. Arrangement of artifacts within an environment

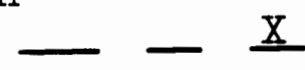

3. Types of materials in use

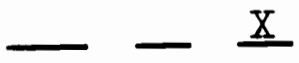

4. Lighting and shading

5. Color

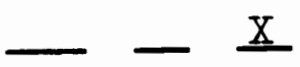

6. Temperature

$-\longrightarrow$ X

7. Noise

D. Cultural differences

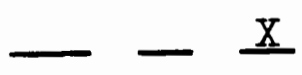

E. Gender differences

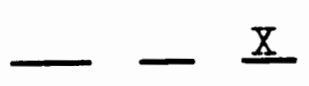

$-\underline{x}$

$-\underline{x}$

VII. Olfactory

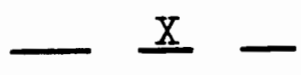

A. Definition of olfactory communication - - $\underline{X}$

B. Communicative function of odor

$-\underline{X}$

C. Types of smells and messages communicated

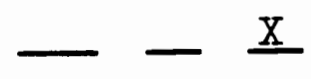

D. Cultural differences

$-\underline{X}$

E. Gender differences

$-\underline{X}$

VIII. Paralanguage

$\underline{X}-$

A. Definition of paralanguage

$\underline{X}$

B. Communicative function of paralanguage

C. Sound attributes which give vocal cues their unique characteristics

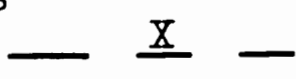

D. Vocal cues in relation to:

1. Speaker recognition

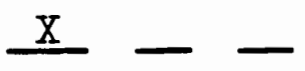

2. Personality judgments 
YES NO NA

3. Personal characteristics

4. Judgments of emotion

5. Comprehension and persuasion

6. Hesitations and pauses

E. Gender differences

F. Cultural differences

IX. Physical Appearance

A. Definition of physical appearance

B. Communicative potential of physical appearance

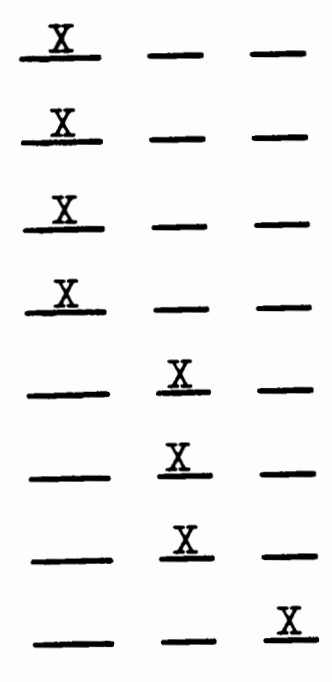

$--\underline{x}$

c. Body types

1. Endomorph

$-\underline{\underline{X}}$

2. Mesomorph

$-\underline{\underline{X}}$

3. Ectomorph

$-\underline{\underline{X}}$

$-\underline{x}$

D. Traits associated with body types - - $\underline{\underline{X}}$

E. Indicators of attractiveness - - $\underline{X}$

1. General attractiveness - - $\underline{X}$

2. Body shape

$-\underline{\underline{X}}$

3. Body color

4. Smell

$-\underline{x}$

5. Hair (cranial, facial, body)

6. Clothes and artifacts

$-\underline{x}$

$-\underline{x}$

$-\underline{X}$

F. Cultural differences

$-\underline{X}$

G. Gender differences

$-\underline{x}$

X. Proxemics

A. Definition of proxemics

$\frac{x}{\underline{x}}--$ 
YES NO NA

B. Communicative function of proxemics $\underline{X}-$

C. Factors relating to individual space preference

1. Age

2. Sex

3. Ethnic and cultural background

4. Topic or subject matter

5. Setting of the interaction

6. Physical characteristics of the interactants

7. Attitudinal orientation

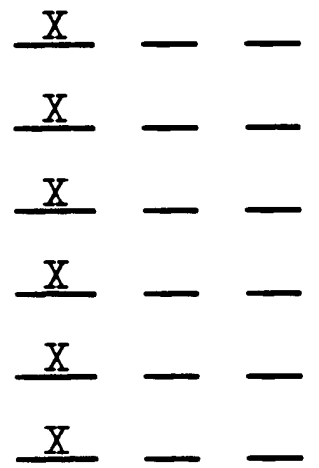

8. Emotional orientation

9. Characteristics of the interpersonal relationship

10. Personality characteristics

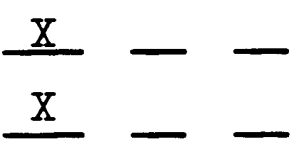

D. Territoriality

1. Intimate-Personal space

2. Private space

$\underline{X}$

3. Public space

XI. General Summary Material

A. Brief review of the material in the chapters in terms of the usage and importance of nonverbal communication $\mathrm{X}$ -

B. Characteristics of a skilled nonverbal receiver/decoder

C. Characteristics of a skilled nonverbal sender/encoder

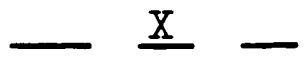

D. Relationship between nonverbal sending and receiving skills

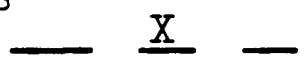


With Words Unspoken. 1976.

Lawrence Rosenfeld and Jean Civikly. New York: Holt, Rinehart and Winston.

The text is divided into five sections which comprise sixteen chapters.

Section 1: Tuning In is designed to orient the reader to the field of nonverbal communication by providing definitions, examples, and exercises which focus on the role nonverbal communication plays in the total communication process.

Section 2: Tuning In to Ourselves contains chapters on the Senses; Biorhythms; and the Body Image.

Section 3: Tuning In to Others contains chapters on Hair; Clothing and Other Artifacts; Facial Expressions; Looking: Who, Why, and Where; Body Movement; Touch; Voice; and Territoriality and Personal Space.

Section 4: Tuning In to the Environment contains chapters on the Physical Environment; Music; and Time.

Section 5: Tuning In to the Nonverbal Experience consists of two chapters entitled: (1) The American City: A Case Study; and (2) Cross Cultural Considerations. Both chapters provide examples of the impact nonverbal communication has on communicative interactions.?

This is the only text which contains information on all the components of nonverbal communication. 


\section{GENERAL EVALUATION SCALE FOR NONVERBAL TEXTS}

Text: With Words Unspoken.

Author: Rosenfeld, Lawrence and Civikly, Jean. 1976.

YES NO NA

I. Purpose

A. Does the author accomplish the overall purpose of the text?

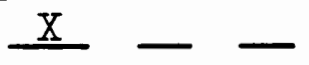

B. Is the purpose accomplished in good literary style?

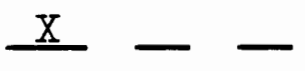

II. Author

A. Is there pertinent, factual information about the educational background, profession, and qualifications of the author?

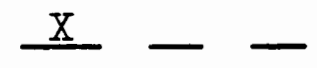

III. Authenticity

A. Is the material factually accurate and objective in its presentation?

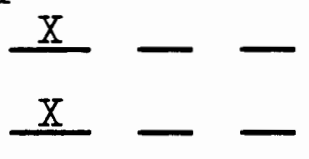

B. Is the material up-to-date?

C. Are the information sources well documented?

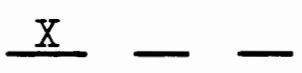

IV. Appropriateness

A. Does the material promote the educational goals and objectives of the curriculum?

B. Is the material appropriate to the level of instruction intended?

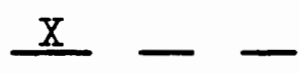

C. Is the interest level appropriate to the user?

1. Will the material stimulate the curiosity of the user?
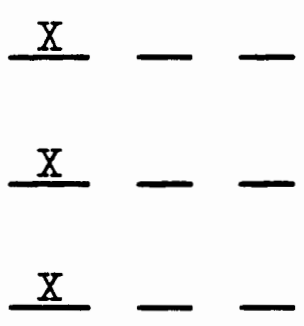

2. Will the material appeal to many students? 
YES NO NA

V. Content

A. Is the content of the material well presented by providing adequate scope, range, depth, and continuity?

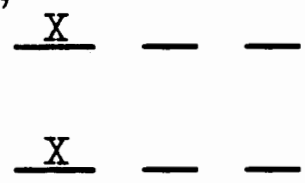

B. Is the material well organized and well balanced?

C. Is the material presented as clearly and simply as possible for the level intended?

D. Does the material aid conceptualization of the subject matter?

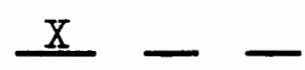

E. Does the material achieve its stated purpose?

F. Are the transitions from one point to another, or one section to another, smooth and clear?

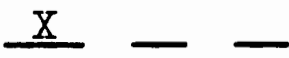

G. Does the text present information not otherwise available?
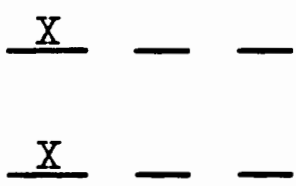

H. Does the material give a new dimension to the subject?

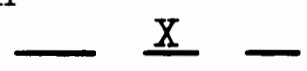

I. Are the aources, purposes, and points of view readily identifiable?

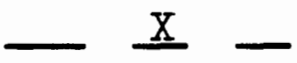

VI. Technical Quality

A. Is the text hardcover?

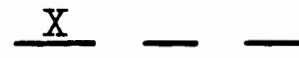

B. Is the text softcover?

$-\underline{X}-$

C. Is the typography clear and easy to read?

D. Are the page layouts well designed?

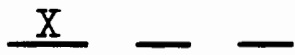

E. Is the pagination definite and clear?

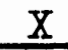

F. Are aids to learning provided?

1. Is there a table of contents?

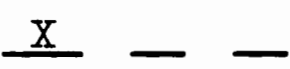

2. Is there an outline listing the contents of each chapter? 
YES NO NA

a. Is this at the beginning of each chapter?

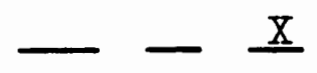

b. Is this in the table of contents?

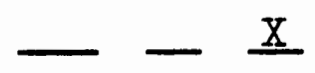

3. Are the major titles and subtitles of each section delineated in each chapter?

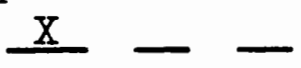

4. Is there a list of priorities at the beginning of each chapter?

$-\underline{X}-$

5. Are internal summaries and reviews provided where appropriate?

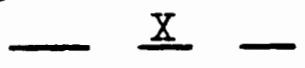

6. Is there a list of related exercises or activities contained in each chapter?

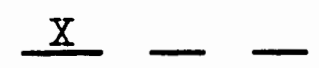

7. Is there a list of additional readings in each chapter?

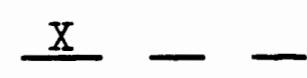

8. Does the text contain an appendix?

$\underline{X}-$

a. Is the appended material useful?

$-\underline{X}$

9. Does the text contain a glossary? _- $\underline{X}$ -

a. Is it at the end of each chapter?

$-\underline{\underline{X}}$

b. Is it at the end of the text?

$-\underline{\underline{X}}$

10. Does the text contain a subject index?

11. Does the text contain an author index?

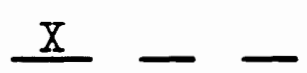

12. Does the text contain a bibliography?

a. Is it at the end of each chapter?

$\underline{x}-$

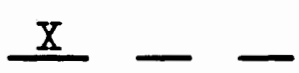

- I -

b. Is it at the end of the text? 


\section{YES NO NA}

13. Are the chapters footnoted or endnoted?

G. Are visual aids used?

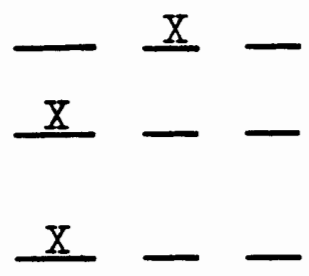

1. Do they contribute to the development of the text?

2. Is the art of photographic quality of the visual aid acceptable (sharpness, composition, color)?

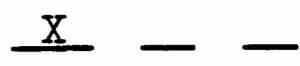

3. Is there a good balance between artistic technique and educational need?

4. Are the captions readable?

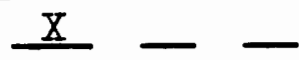

5. Are the captions a good interpretation of the material, yet not distracting?

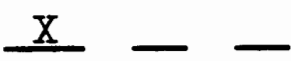

6. Are the illustrations and captions suitable for teaching and learning purposes?

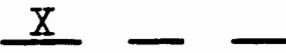

7. Are the visual aids located properly for greatest usefulness?

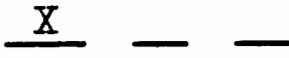

8. Are the visual aids adequate in number?

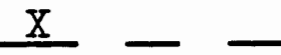

9. Is the content of the visual aid well organized and well balanced? $\mathrm{X}$ -

10. Is explanatory material provided? $\mathrm{X}$ -

\section{SPEC IFIC EVALUATION FORM FOR NONVERBAL TEXTS}

I. Introductory Material

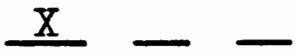

A. Definition of nonverbal communication $\mathbf{X}-$

B. Issues involved in defining and classifying nonverbal communication

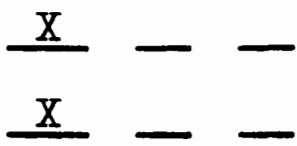


YES NO NA

2. Cultural

$\underline{\underline{x}}-$

3. Contextual

C. Relationship between sending and receiving skills

$\underline{x}--$

D. Developing sending and receiving skills

$-\underline{X}-$

E. Components of nonverbal communication mentioned in the text

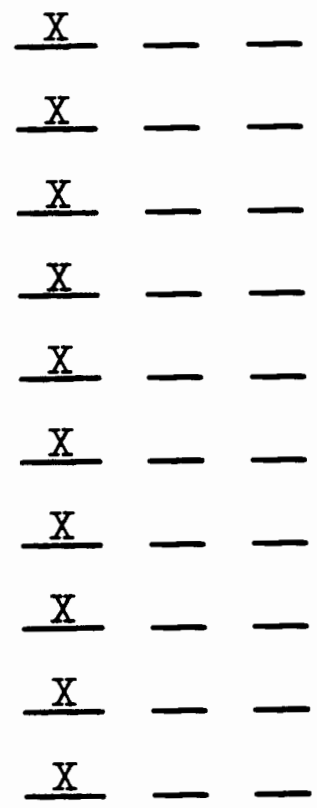

F. Definition of the functions of nonverbal communication

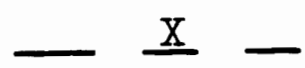

1. Accentuation

2. Complementation

$-\underline{X}$

3. Contradiction

$-\underline{\underline{Z}}$

4. Redundancy

$-\underline{X}$

5. Regulation

$-\underline{X}$

5. Regulation

$-\underline{X}$

6. Substitution

$-\underline{X}$

G. Relationship between verbal and nonverbal communication 
YES NO NA

H. Brief history of the study of nonverbal communication (optional)

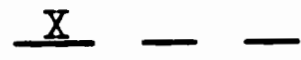

II. Adornment

A. Definition of adornment

B. Communicative effects of clothes

$\underline{X}-$

C. Communicative effects of accessories

D. Communicative effects of cosmetics

X

E. Cultural differences

F. Gender differences

III. Chronemics

A. Definition of chronemics

B. Communicative function of chronemics

C. American concept of time

D. Effects of time orientations

1. Psychological

2. Biological

3. Cultural

IV. Haptics

A. Definition of haptics

B. Communicative function of haptics

X -

X - -

$\underline{X}-$

- $\underline{X}-$

$\underline{X}-$

$\underline{X}-$

$\underline{x}--$

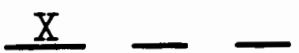

$\underline{x}-$

$\underline{\mathrm{x}}-$

$\underline{x}-$

$\underline{x}--$

$\underline{x}-$

$x-1$

$\underline{x}--$

$\underline{\mathrm{X}}-$

C. Tactile communication and human

development

D. Different types of touching behavior

1. Functional-professional

$\underline{\mathrm{X}}-$

2. Social-polite

3. Friendship-warmth

X

- X -

$\underline{X}-$

4. Love-intimacy 
5. Sexual arousal

YES NO NA

E. Needs for human touch

1. Biological

2. Psychological

3. Sociological

F. The skin as a communication system

X - -

G. Touch norms and the reason for norms

H. Gender differences

I. Cultural differences

V. Kinesics

A. Definition of kinesics

B. Communicative function of kinesics

$\mathrm{X}-$

$\underline{X}-$

$\underline{\mathrm{X}}-\mathrm{C}$

C. Kinesic channels

1. Whole head

2. Whole body

3. Face only

X -

4. Eyes and eyebrows only

5. Hands and arms

$\underline{\mathrm{X}}$

$\underline{\mathrm{X}}-$

X -

$-\underline{\mathrm{X}}-$

$\underline{X}-$

$\underline{x}-$

X -

X - -

$\underline{\mathrm{X}}-$

6. Iegs and feet

$\underline{\mathrm{X}}-$

X -

7. Dyad (whole body with another person)

$\underline{X}-$

$\underline{X}-$

$-\underline{X}-$

$\underline{\mathrm{X}}-$

D. Gender differences

X -

E. Cultural differences

- $\underline{\underline{x}}-$

VI. Objects and Environment

$\underline{\mathrm{X}}-$

A. Definition of objects and environment $\underline{X}-$

B. Communicative effects of objects

(artifacts) 
YES NO NA

C. Communicative effects of environmental features

1. Size or volume of artifacts

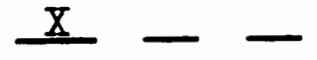

2. Arrangement of artifacts within an environment

$\underline{x}-$

3. Types of materials in use

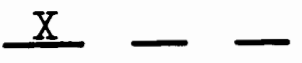

4. Lighting and shading

5. Color

6. Temperature

7. Noise

D. Cultural differences

$-\underline{x}-$

$\underline{X}-$

$\underline{x}--$

E. Gender differences

$\underline{x}-$

$\underline{x}-$

$-\underline{x}-$

$\underline{x}-$

VII. Olfactory

$\underline{x}-$

A. Definition of olfactory communication $X$

B. Communicative function of odor

$\underline{X}--$

C. Types of smells and messages communicated

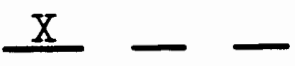

D. Cultural differences

$\underline{\underline{X}}-$

E. Gender differences

$\underline{X}-$

VIII. Paralanguage

A. Definition of paralanguage

$\underline{x}-$

B. Communicative function of paralanguage

$\underline{I}-$

$\underline{X}--$

C. Sound attributes which give vocal cues their unique characteristics

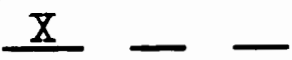

D. Vocal cues in relation to:

1. Speaker recognition

$\underline{x}-$

2. Personality judgments 


\section{YES NO NA}

3. Personal characteristics

4. Judgments of emotion

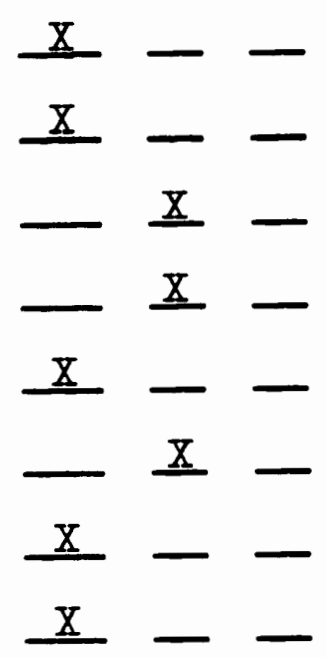

A. Definition of physical appearance

$\underline{X}$

B. Communicative potential of physical appearance

C. Body types

1. Endomorph

2. Mesomorph

3. Ectomorph

D. Traits associated with body types

E. Indicators of attractiveness

1. General attractiveness

2. Body shape

3. Body color

4. Smell

5. Hair (cranial, facial, body)

6. Clothes and artifacts

F. Cultural differences

G. Gender differences

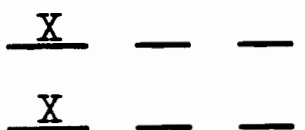

$\underline{x}--$

X - -

X - -

X - -

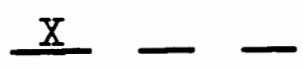

$\underline{x}--$

$\underline{\mathrm{X}}-$

$\underline{x}--$

$\underline{\mathrm{X}}-$ -

$\underline{\mathrm{X}}-$

$\underline{x}--$

X -

- $\underline{x}-$

$\underline{X}-$

X. Proxemics

$\underline{x}-$

A. Definition of proxemics

$\underline{X}-$ 
YES NO NA

B. Communicative function of proxemics

X -

C. Factors relating to individual space preference

1. Age

2. Sex

3. Ethnic and cultural background

4. Topic or subject matter

5. Setting of the interaction

6. Physical characteristics of the interactants

7. Attitudinal orientation

8. Emotional orientation

9. Characteristics of the interpersonal relationship

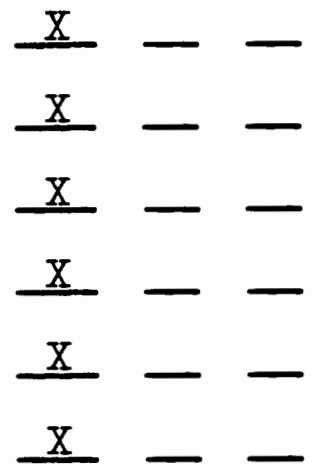

10. Personality characteristics

D. Territoriality

1. Intimate-Personal space

2. Private space

3. Public space

XI. General Summary Material

A. Brief review of the material in the chapters in terms of the usage and importance of nonverbal communication $\mathrm{X}-$

B. Characteristics of a skilled nonverbal receiver/decoder

C. Characteristics of a skilled nonverbal sender/encoder

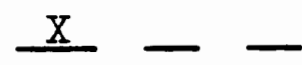

$\underline{\mathrm{X}}--$

X -

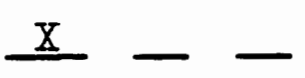

$\underline{X}-$

$\underline{\mathrm{X}}-$

$\underline{X}-$

$\underline{\mathrm{X}}-$

$\underline{x}-$

X - - 
Nonverbal Communication Systems. 1976

Dale G. Leathers. Boston: Allyn and Bacon, Inc.

The text is divided into ten chapters which cover the following topics: (1) Introduction to the Study of Nonverbal Communication; (2) Kinesics; (3) Proxemics in Relation to Man's Proximate Environment; (4) Proxemics in Relation to the Urban Environment; (5) Artifactual Communication; (6) Vocalics (paralanguage); (7) Tactile and Olfactory Communication; (8) Telepathic Communication; (9) Observing, Classifying, and Measuring the Quality of Nonverbal Communication; and (10) The Relation of the Nonverbal Systems to the Verbal Systems. Two appendices relating to the Kinesic Communication system and the Vocalic (paralanguage) Communication System are also included. 8

The only component of nonverbal communication not covered in the text is chronemics. 


\section{GENERAL EVALUATION SCALE FOR NONVERBAL TEXTS}

Text: Nonverbal Communication Systems.

Author: Leathers, Dale G. 1976.

YES NO NA

I. Purpose

A. Does the author accomplish the overall purpose of the text?

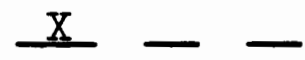

B. Is the purpose accomplished in good literary style?

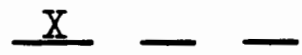

II. Author

A. Is there pertinent, factual information about the educational background, profession, and qualifications of the author?

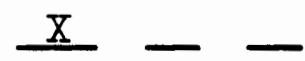

\section{Authenticity}

A. Is the material factually accurate and objective in its presentation?

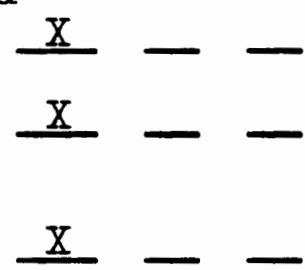

IV. Appropriateness

A. Does the material promote the educational goals and objectives of the curriculum?

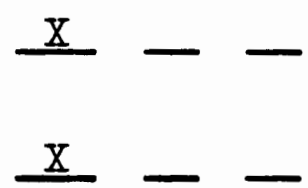

C. Is the interest level appropriate to the user?

1. Will the material stimulate the curiosity of the user?

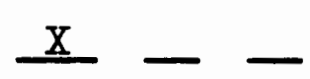

Is the material appropriate to the level of instruction intended?

2. Will the material appeal to many students?
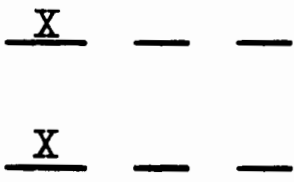
YES NO NA

V. Content

A. Is the content of the material well presented by providing adequate scope, range, depth, and continuity?

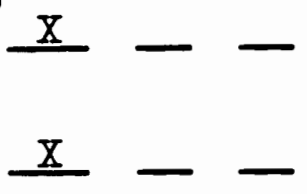

B. Is the material well organized and well balanced?

C. Is the material presented as clearly and simply as possible for the level intended?

D. Does the material aid conceptualization of the subject matter?

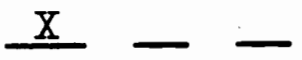

E. Does the material achieve its stated purpose?
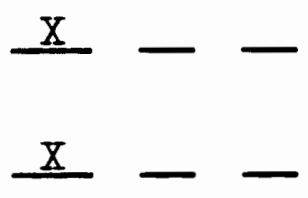

F. Are the transitions from one point to another, or one section to another, smooth and clear?

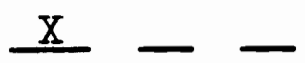

G. Does the text present information not otherwise available?

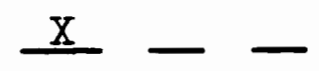

H. Does the material give a new dimension to the subject?

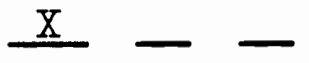

I. Are the sources, purposes, and points of view readily identifiable?

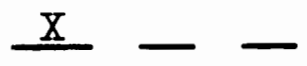

VI. Technical Quality

A. Is the text hardcover?

B. Is the text softcover?

$-\underline{\mathrm{X}}-$

C. Is the typography clear and easy to read?

D. Are the page layouts well designed?

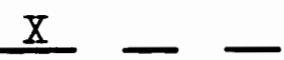

E. Is the pagination definite and clear? $\mathbb{X}$

F. Are aids to learning provided?

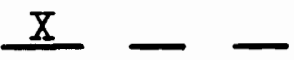

1. Is there a table of contents?

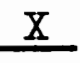

2. Is there an outline listing the contents of each chapter? 
YES NO NA

a. Is this at the beginning of each chapter?

b. Is this in the table of contents?

$-\mathrm{X}-$

$\underline{X}-$

3. Are the major titles and subtitles of each section delineated in each chapter?

4. Is there a list of priorities at the beginning of each chapter?

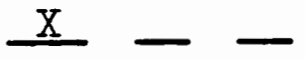

5. Are internal summaries and reviews provided where appropriate?

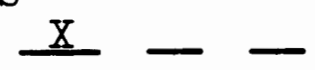

6. Is there a list of related exercises or activities contained in each chapter?

7. Is there a list of additional readings in each chapter?

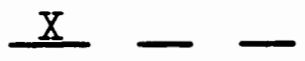

8. Does the text contain an appendix?

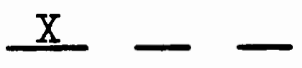

a. Is the appended material useful?

$\underline{x}--$

9. Does the text contain a glossary? X -

a. Is it at the end of each chapter?

$-\underline{\underline{X}}$

b. Is it at the end of the text? - -

10. Does the text contain a subject index?

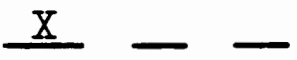

11. Does the text contain an author index?

$\underline{x}-$

12. Does the text contain a bibliography?

a. Is it at the end of each chapter?

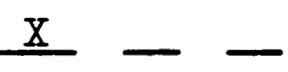

b. Is it at the end of the text?

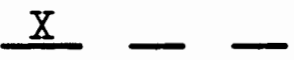


13. Are the chapters footnoted or endnoted?

G. Are visual aids used?

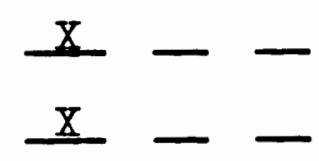

1. Do they contribute to the development of the text?

$\underline{X}-$

2. Is the art of photographic

quality of the visual aid acceptable (sharpness, composition, color)?

$\underline{x}-$

3. Is there a good balance between artistic technique and educational need?

4. Are the captions readable?

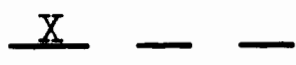

5. Are the captions a good interpretation of the material, yet not distracting?

6. Are the illustrations and captions suitable for teaching and learning purposes?
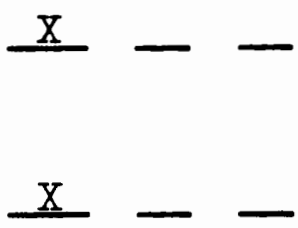

7. Are the visual aids located properly for greatest usefulness?

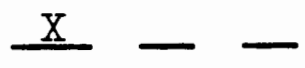

8. Are the visual aids adequate in number?

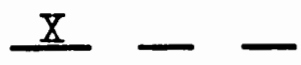

9. Is the content of the visual aid well organized and well balanced? $\mathrm{X}$ -

10. Is explanatory material provided? $\underline{X}-$

\section{SPEC IFIC EVALUATION FORM FOR NONVERBAL TEXTS}

I. Introductory Material

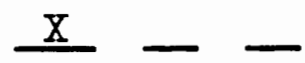

A. Definition of nonverbal communication $\mathrm{X}-$

B. Issues involved in defining and classifying nonverbal communication

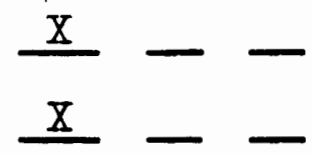


YES NO NA

2. Cultural

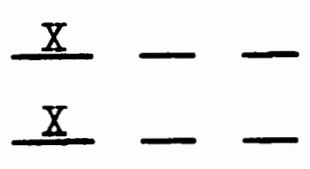

C. Relationship between sending and receiving skills

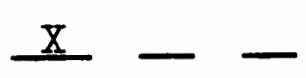

D. Developing sending and receiving skills

E. Components of nonverbal communication mentioned in the text

1. Adornment

2. Chronemics

3. Haptics

4. Kinesics

5. Objects and Environment

6. Olfactory

7. Paralanguage

8. Physical Appearance

9. Proxemics
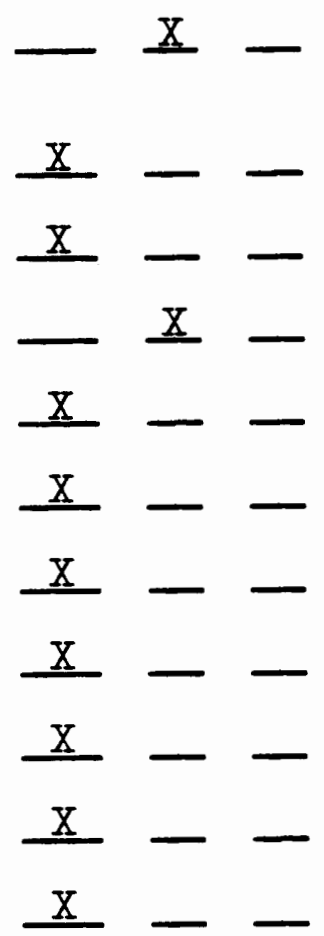

F. Definition of the functions of nonverbal communication

$\underline{X}-$

1. Accentuation

$\underline{X}-$

2. Complementation

I

3. Contradiction

$-\underline{X}-$

4. Redundancy

5. Regulation

6. Substitution

$-\underline{X}-$

$-\underline{x}-$

- I -

G. Relationship between verbal and nonverbal communication 
YES NO NA

H. Brief history of the study of nonverbal communication (optional)

II. Adornment

A. Definition of adornment

B. Communicative effects of clothes

$-\mathrm{X}-$

C. Communicative effects of accessories

D. Communicative effects of cosmetics

$\underline{x}-$

E. Cultural differences

F. Gender differences

III. Chronemics

A. Definition of chronemics

B. Communicative function of chronemics

C. American concept of time

D. Effects of time orientations

1. Psychological

2. Biological

3. Cultural

IV. Haptics

A. Definition of haptics

B. Communicative function of haptics

$\underline{x}--$

$\underline{X}-$

$\mathrm{X}-$

$\underline{X}-$

- $\underline{X}$

- $\underline{x}-$

- $\mathrm{X}-$

- -

$--\underline{X}$

$--\frac{x}{x}$

$--\underline{x}$

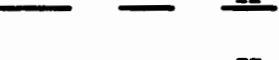

- $-\underline{X}$

- - $-\underline{X}$

$-\underline{X}$

X - -

X - -

X -

C. Tactile communication and human development

D. Different types of touching behavior

1. Functional-professional

2. Social-polite

3. Friendship-warmth

4. Love-intimacy

$\underline{X}-$

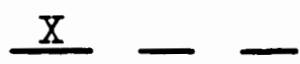

$\underline{\mathrm{X}}-$

X -

X -

$\underline{\mathrm{x}}-$ 
YES NO NA

5. Sexual arousal

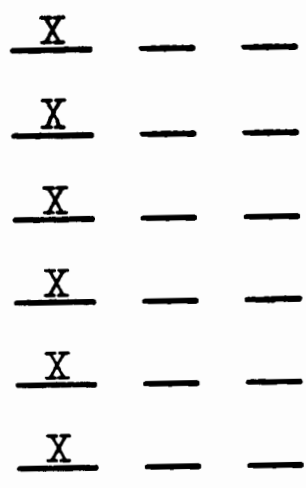

F. The skin as a communication system

G. Touch norms and the reason for norms

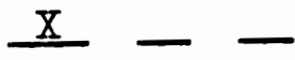

H. Gender differences

I. Cultural differences

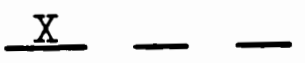

V. Kinesics

A. Definition of kinesics

B. Communicative function of kinesics

C. Kinesic channels

1. Whole head

2. Whole body

3. Face only

4. Eyes and eyebrows only

5. Hands and arms

- I -

$\underline{X}--$

$\underline{X}-$

$\underline{x}-$

6. Legs and feet

$\underline{X}$

$\underline{X}-$

$\underline{x}-$

$\underline{x}-$

$\underline{x}-$

X -

7. Dyad (whole body with another person)

$-\underline{X}-$

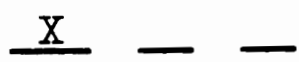

D. Gender differences

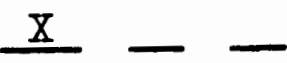

E. Cultural differences

- $\underline{x}-$

VI. Objects and Environment

X -

A. Definition of objects and environment $\underline{X}-$

B. Communicative effects of objects (artifacts) 
YES NO NA

C. Communicative effects of environmental

features

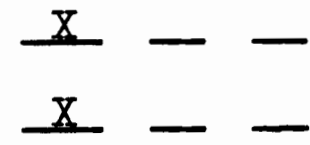

1. Size or volume of artifacts

2. Arrangement of artifacts within an environment

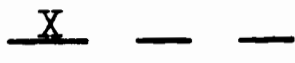

3. Types of materials in use

X -

4. Lighting and shading

$\underline{x}--$

5. Color

6. Temperature

X -

7. Noise

$\underline{x}--$

$\underline{x}-$

D. Cultural differences

$-\underline{X}-$

E. Gender differences

- $\underline{x}-$

VII. Olfactory

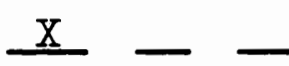

A. Definition of olfactory communication $\mathrm{X}-$

B. Communicative function of odor

$\underline{\mathrm{X}}-$

C. Types of smells and messages communicated

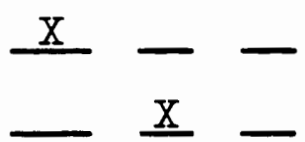

D. Cultural differences

E. Gender differences

VIII. Paralanguage

A. Definition of paralanguage

B. Communicative function of paralanguage

$\underline{x}--$

$\underline{x}--$

X -

$\underline{x}--$

C. Sound attributes which give vocal cues their unique characteristics

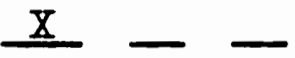

D. Vocal cues in relation to:

1. Speaker recognition

$\underline{x}--$

2. Personality judgments

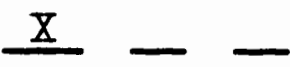


YES NO NA

3. Personal characteristics

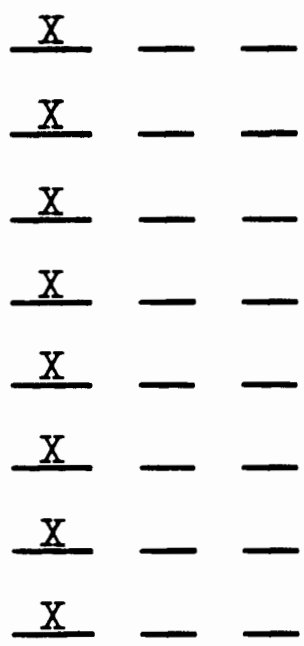

B. Communicative potential of physical appearance

C. Body types

1. Endomorph

2. Mesomorph

3. Ectomorph

D. Traits associated with body types

E. Indicators of attractiveness

1. General attractiveness

2. Body shape

3. Body color

4. Smell

5. Hair (cranial, facial, body)

6. Clothes and artifacts

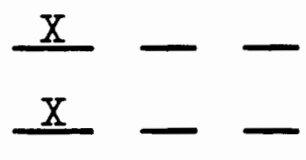

$\underline{X}-$

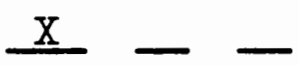

$\underline{x}-$
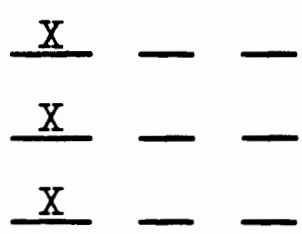

X -

X -

$\underline{\mathrm{X}}-$
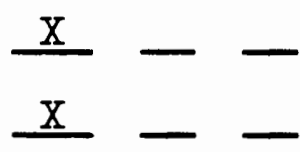

F. Cultural differences

$-\underline{\mathrm{X}}-$

G. Gender differences

X -

X. Proxemics

A. Definition of proxemics 


\section{YES NO NA}

B. Communicative function of proxemics

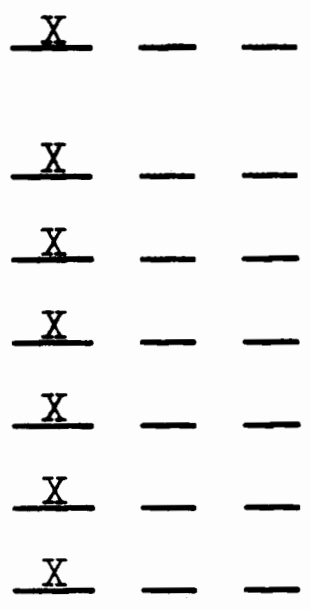

6. Physical characteristics of the interactants

7. Attitudinal orientation

8. Emotional orientation

9. Characteristics of the interpersonal relationship

10. Personality characteristics
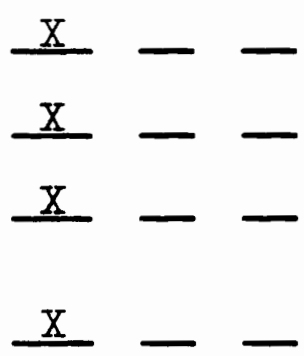

$\underline{X}-$

D. Territoriality

1. Intimate-Personal space

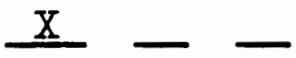

2. Private space

3. Public space

XI. General Summary Material
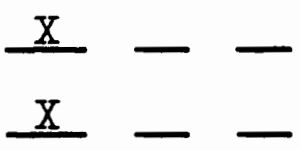

$\underline{\mathrm{X}}-$

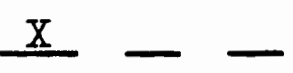

A. Brief review of the material in the chapters in terms of the usage and importance of nonverbal communication $\mathrm{X}-$

B. Characteristics of a skilled nonverbal receiver/decoder

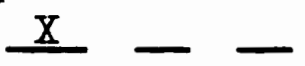

C. Characteristics of a skilled nonverbal sender/encoder

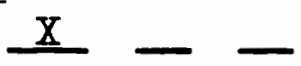

D. Relationship between nonverbal sending and receiving skills

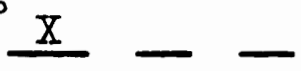


The Unspoken Dialogue: An Introduction to Nonverbal Communication. 1976. Judee Burgoon and Thomas Saine. Boston: Houghton Mifflin Co.

The text is divided into two major sections:

(1) The Components of Nonverbal Communication; and (2) The Functions of Nonverbal Communication.

Section 1: The Components of Nonverbal Communication is divided into five chapters which define important aspects of the study of nonverbal communication. Chapter 1 defines the term nonverbal communication and provides material on the relationship between verbal and nonverbal communication. Chapter 2 defines the five different approaches to the study of nonverbal communication, i.e., Body Language, Ethological, Linguistic, Psychoanalytic, Physiological, and Functional approaches. Chapter 3 defines the Codes (components) relating to the human body, i.e., Kinesics, Haptics, Physical Appearance, and Vocalics (paralanguage). Chapter 4 defines nonverbal communication in relation to space, Time, and Artifacts, i.e., Proxemics, Chronemics, and Objects and Environment. Chapter 5 presents material on individual differences, subcultural differences, sex differences, and personality differences.

Section 2: The Functions of Nonverbal Communication is composed of six chapters which provide information on how nonverbal communication functions in the total communication process. Chapter 6 examines first impressions in relation to physical, sociocultural, and psychological 
features. Chapter 7 illustrates the relational messages such as Attraction and Liking, Credibility, Status, and Power. Chapter 8 studies the communication of affect in relation to myths surrounding the study of emotions, the acquisition of emotional expressions, dimensions underlying affect displays, the roles of body parts, sending and judging vocalic cues, sending and judging facial cues, and the problems of research. Chapter 9 concentrates on the regulation of interaction by examining how interactions are regulated when initiating interaction, structuring interaction, and terminating interaction. Chapter 10 reports on how the self is presented to others nonverbally. Chapter 11 focuses on how nonverbal communication is used to manipulate others through comprehension and retention, attitude change, and changes in overt and communicative behaviors. 9

The one component of nonverbal communication that is missing from this text is olfactory. 


\section{GENERAL EVALUATION SCALE FOR NONVERBAL TEXTS}

Text: The Unspoken Dialogue: An Introduction to Nonverbal Communication.

Author: Burgoon, Judee and Saine, Thomas. 1976.

YES NO NA

I. Purpose

A. Does the author accomplish the overall purpose of the text?

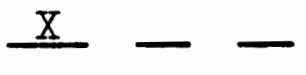

B. Is the purpose accomplished in good literary style?

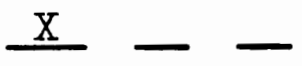

II. Author

A. Is there pertinent, factual information about the educational background, profession, and qualifications of the author?

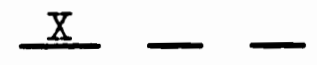

III. Authenticity

A. Is the material factually accurate and objective in its presentation?

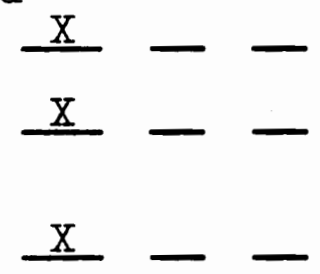

IV. Appropriateness

A. Does the material promote the educational goals and objectives of the curriculum?

B. Is the material appropriate to the level of instruction intended?

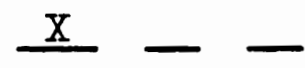

C. Is the interest level appropriate to the user?

1. Will the material stimulate the curiosity of the user?
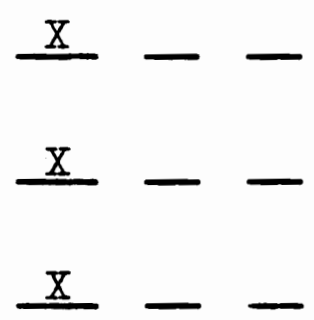

2. Will the material appeal to many students?

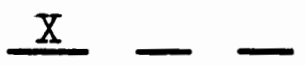


YES NO NA

V. Content

A. Is the content of the material well presented by providing adequate scope, range, depth, and continuity?

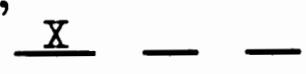

B. Is the material well organized and well balanced?

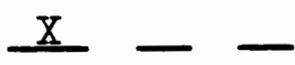

C. Is the material presented as clearly and simply as possible for the level intended?

D. Does the material aid conceptualization of the subject matter?

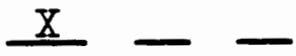

E. Does the material achieve its stated purpose?

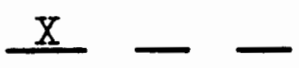

F. Are the transitions from one point to another, or one section to another, smooth and clear?

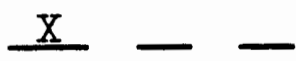

G. Does the text present information not otherwise available?

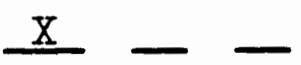

H. Does the material give a new dimension to the subject?

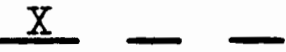

I. Are the sources, purposes, and points of view readily identifiable?

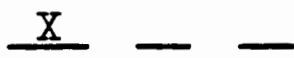

VI. Technical Quality

A. Is the text hardcover?

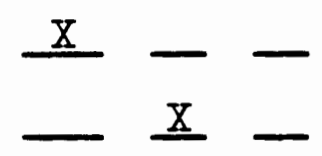

C. Is the typography clear and easy to read?

D. Are the page layouts well designed? $\underline{\mathrm{X}}-$

E. Is the pagination definite and clear? $\mathbb{X}-$

1. Is there a table of contents?

$\underline{X}-$

2. Is there an outline listing the contents of each chapter? 


\section{YES NO NA}

a. Is this at the beginning of each chapter?

$-\underline{x}-$

b. Is this in the table of contents?

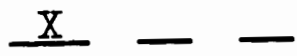

3. Are the major titles and subtitles of each section delineated in each chapter?

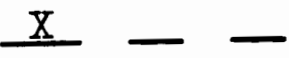

4. Is there a list of priorities at the beginning of each chapter?

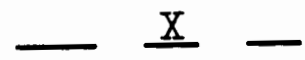

5. Are internal summaries and reviews provided where appropriate?

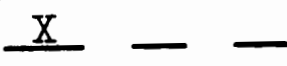

6. Is there a list of related exercises or activities contained in each chapter?

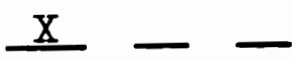

7. Is there a list of additional readings in each chapter?

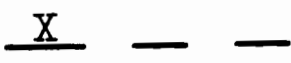

8. Does the text contain an appendix?

a. Is the appended material useful?

$-\underline{X}$

9. Does the text contain a glossary?

$\underline{X}$

a. Is it at the end of each chapter?

$-\underline{X}$

b. Is it at the end of the text? - - $\underline{X}$

10. Does the text contain a subject index?

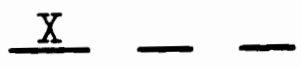

11. Does the text contain an author index?

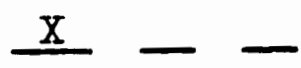

12. Does the text contain a bibliography?

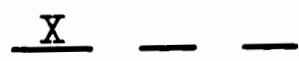

a. Is it at the end of each chapter?

$\underline{\mathrm{X}}-$

b. Is it at the end of the text? 
YES NO NA

13. Are the chapters footnoted or endnoted?

G. Are visual aids used?

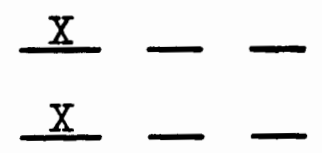

1. Do they contribute to the development of the text?

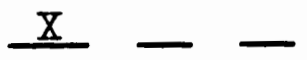

2. Is the art of photographic quality of the visual aid acceptable (sharpness, composition, color)?

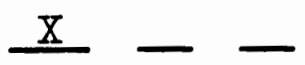

3. Is there a good balance between artistic technique and educational need?

4. Are the captions readable?

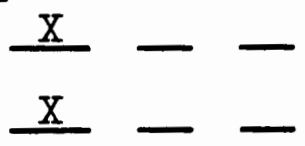

5. Are the captions a good interpretation of the material, yet not distracting?

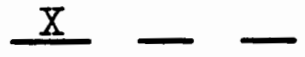

6. Are the illustrations and captions suitable for teaching and learning purposes?

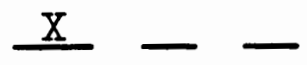

7. Are the visual aids located properly for greatest usefulness?

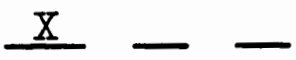

8. Are the visual aids adequate in number?

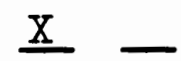

9. Is the content of the visual aid well organized and well balanced? $\mathrm{X}$ -

10. Is explanatory material provided? $\underline{X}-$

SPECIFIC EVALUATION FORM FOR NONVERBAL TEXTS

I. Introductory Material

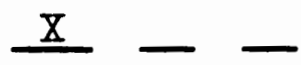

A. Definition of nonverbal communication $\underline{Z}$

B. Issues involved in defining and classifying nonverbal communication

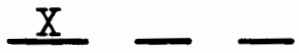

1. Environmental 
YES NO NA

2. Cultural

3. Contextual

$\frac{x}{x}--$

C. Relationship between sending and receiving skills

X - -

D. Developing sending and receiving skills

- $\underline{x}-$

E. Components of nonverbal communication mentioned in the text

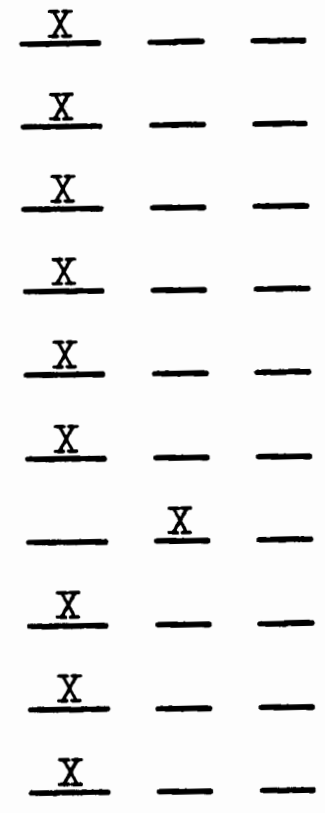

F. Definition of the functions of nonverbal communication

1. Accentuation

2. Complementation

3. Contradiction

$\underline{x}-$

$\underline{x}-$

$\underline{x}-$

4. Redundancy

5. Regulation

6. Substitution

$\underline{x}-$

$\underline{x}-$

$\underline{x}-$

$\underline{x}-$

G. Relationship between verbal and nonverbal communication

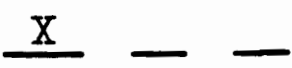




\section{YES NO NA}

H. Brief history of the study of nonverbal communication (optional)

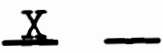

II. Adornment

A. Definition of adornment

B. Communicative effects of clothes

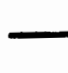

C. Communicative effects of accessories

D. Communicative effects of cosmetics

E. Cultural differences

F. Gender differences

\section{Chronemics}

A. Definition of chronemics

B. Communicative function of chronemics

C. American concept of time

D. Effects of time orientations

1. Psychological

2. Biological

3. Cultural

IV. Haptics

A. Definition of haptics

B. Communicative function of haptics

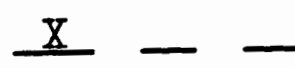

X - -

X -

X - -

$\underline{x}-$

$\mathrm{X}-\mathrm{C}$

$\underline{x}-$

$\underline{X}-$

$\underline{x}-$

$\underline{x}--$

$\underline{X}-$

$\underline{X}-$

$\underline{x}-$

$\underline{x}--$

$\underline{x}--$

$\underline{x}-$

$\underline{x}-$

$\underline{x}-$

C. Tactile communication and human development

$\underline{\mathrm{X}}-$

D. Different types of touching behavior

1. Functional-professional

$\underline{x}-$

2. Social-polite

3. Friendship-warmth

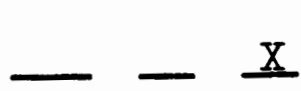

$-\underline{x}$

4. Love-intimacy

$-\underline{x}$

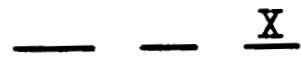


YES NO NA

5. Sexual arousal

$-\underline{\mathrm{X}}$

E. Needs for human touch

1. Biological

2. Psychological

3. Sociological

X -

X -

$\underline{X}-$

$\underline{\mathrm{X}}-$

F. The skin as a communication system

X -

G. Touch norms and the reason for norms

$\underline{x}-$

H. Gender differences

$\underline{X}-$

I. Cultural differences

V. Kinesics

A. Definition of kinesics

B. Communicative function of kinesics

$\underline{X}-$

C. Kinesic channels

X -

$\underline{\mathrm{X}}-$

$\underline{x}-$

$\underline{X}-$

1. Whole head

$\underline{X}-$

2. Whole body

3. Face only

4. Eyes and eyebrows only

X - -

5. Hands and arms

$\underline{X}-$

6. Legs and feet

$\underline{X}-$

$\underline{x}-$

7. Dyad (whole body with another person)

$\underline{\mathrm{X}}$

$\underline{X}-$

D. Gender differences

X - -

E. Cultural differences

$\underline{x}-$

VI. Objects and Environment

$\underline{X}-$

A. Definition of objects and environment $\mathrm{X}-$

B. Communicative effects of objects

(artifacts) 
YES NO NA

C. Communicative effects of environmental features

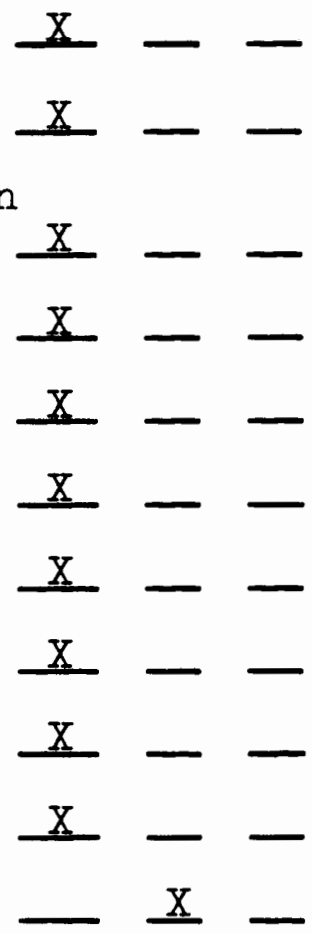

VII. Olfactory

1. Size or volume of artifacts

2. Arrangement of artifacts within an environment

3. Types of materials in use

4. Lighting and shading

5. Color

6. Temperature

7. Noise

D. Cultural differences

E. Gender differences

A. Definition of olfactory communication

B. Communicative function of odor

$-\underline{x}$

C. Types of smells and messages communicated

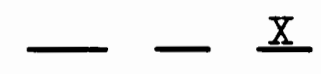

D. Cultural differences

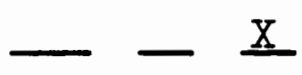

E. Gender differences

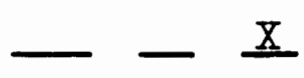

VIII. Paralanguage

A. Definition of paralanguage

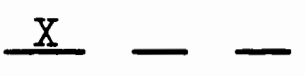

B. Communicative function of paralanguage

$\underline{x}-$

$\underline{\mathrm{X}}-$

C. Sound attributes which give vocal cues their unique characteristics

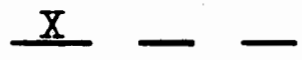

D. Vocal cues in relation to:

1. Speaker recognition

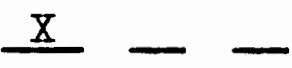

2. Personality judgments 
3. Personal characteristics

4. Judgments of emotion

5. Comprehension and persuasion

YES NO NA

6. Hesitations and pauses

E. Gender differences

F. Cultural differences

IX. Physical Appearance

A. Definition of physical appearance

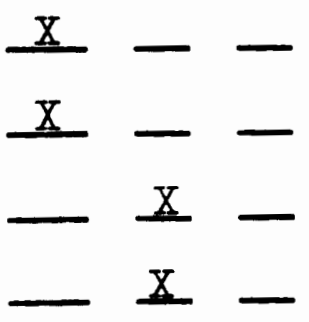

B. Communicative potential of physical appearance

$\underline{x}-$

X - -

$\underline{x}--$

$\underline{x}-$

C. Body types

1. Endomorph

2. Mesomorph

3. Ectomorph

D. Traits associated with body types

E. Indicators of attractiveness

1. General attractiveness

$\underline{x}--$

$\underline{x}-$

2. Body shape

$\underline{\mathrm{X}}-$

3. Body color

$\underline{\mathrm{X}}$

$\underline{\mathrm{X}}$

4. Smell

5. Hair (cranial, facial, body)

$\underline{X}-$

$\underline{x}-$

$\underline{x}-$

$\underline{x}-$

$\underline{X}-$

$\underline{X}-$

6. Clothes and artifacts

F. Cultural differences

G. Gender differences

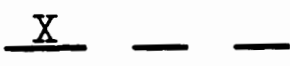

$\underline{x}-$

$\underline{x}-$

$\underline{x}-$

X. Proxemics

$\underline{X}-$

A. Definition of proxemics 
YES NO NA

B. Communicative function of proxemics $\mathrm{X}$ -

C. Factors relating to individual space preference

1. Age

2. Sex

3. Ethnic and cultural background

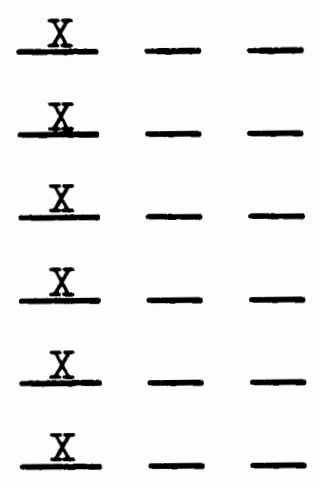

6. Physical characteristics of the interactants

7. Attitudinal orientation

8. Emotional orientation

9. Characteristics of the interpersonal relationship

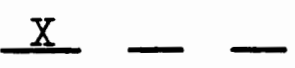

$\underline{x}--$

$\underline{x}-$

10. Personality characteristics

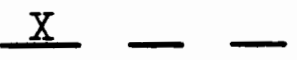

$\underline{x}-$

D. Territoriality

1. Intimate-Personal space

2. Private space

3. Public space

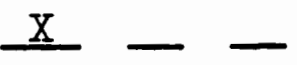

$\underline{x}-$

$\underline{x}-$

$\underline{x}-$

XI. General Summary Material

$\underline{x}-$

A. Brief review of the material in the chapters in terms of the usage and importance of nonverbal communication $\mathrm{X}$

B. Characteristics of a skilled nonverbal receiver/decoder

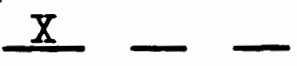

C. Characteristics of a skilled nonverbal sender/encoder

D. Relationship between nonverbal sending and receiving skills
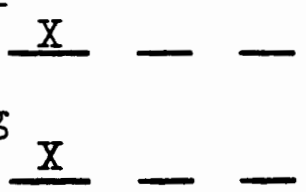
Moving Bodies: Nonverbal Communication in Social Relationships. 1978.

Marianne LaFrance and Clara Majo. Monterey, CA: West Publishing Co.

The text is divided into fourteen chapters which cover the following topics: (1) Meaning and Function of Nonverbal Communication; (2) Movement, i.e., Kinesic Channels, Perspectives, and Social Rules; (3) Motion and Emotion; (4) Personal Signatures, i.e., personality traits, expressive styles; (5) Psychopathological Indicators; (6) Positive Relationships, i.e., indicators of attraction; (7) Negative Relationship; (8) Status; (9) Influential Moves, i.e., attitudes, approval; (10) Rules and Rituals for Interpersonal Interaction; (11) Children; (12) Gender Differences; (13) Intercultural Differences; and (14) Summary Material. 10

The text does not contain information regarding the following components of nonverbal communication: adornment, chronemics, and olfactory. 
GENERAL EVALUATION SCALE FOR NONVERBAL TEXTS

Text: Moving Bodies: Nonverbal Communication in Social Relationships.

Author: IaFrance, Marianne and Mayo, Clara. 1978.

YES NO NA

I. Purpose

A. Does the author accomplish the overall purpose of the text?

B. Is the purpose accomplished in good literary style?

II. Author

A. Is there pertinent, factual information about the educational background, profession, and qualifications of the author?

III. Authenticity

A. Is the material factually accurate and objective in its presentation?

B. Is the material up-to-date?
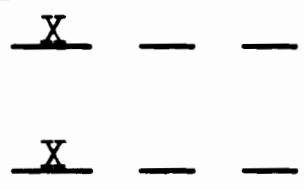

C. Are the information sources well documented?

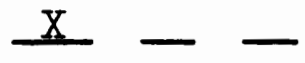


YES NO NA

V. Content

A. Is the content of the material well presented by providing adequate scope, range, depth, and continuity?

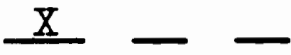

B. Is the material well organized and well balanced?

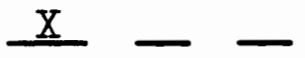

C. Is the material presented as clearly and simply as possible for the level intended?

D. Does the material aid conceptualization of the subject matter?

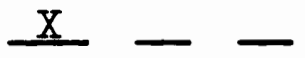

E. Does the material achieve its stated purpose?

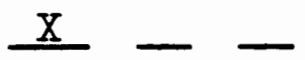

F. Are the transitions from one point to another, or one section to another, smooth and clear?

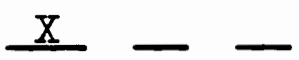

G. Does the text present information not otherwise available?

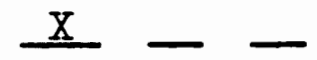

H. Does the material give a new dimension to the subject?

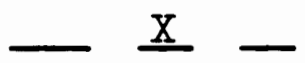

I. Are the sources, purposes, and points of view readily identifiable?

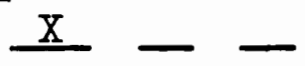

VI. Technical Quality

A. Is the text hardcover?

B. Is the text softcover?

C. Is the typography clear and easy to read?

D. Are the page layouts well designed?
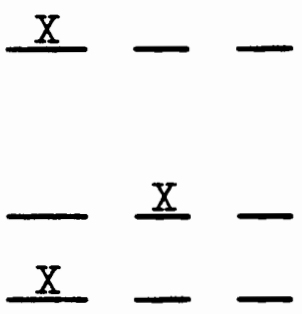

E. Is the pagination definite and clear?

1. Is there a table of contents?

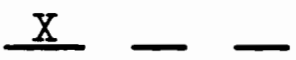

2. Is there an outline listing the contents of each chapter? 


\section{YES NO NA}

a. Is this at the beginning of each chapter?

X -

b. Is this in the table of contents?

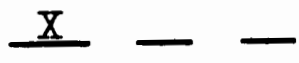

3. Are the major titles and subtitles of each section delineated in each chapter?

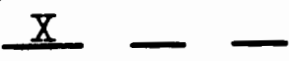

4. Is there a list of priorities at the beginning of each chapter? $\mathrm{X}$ -

5. Are internal summaries and reviews provided where appropriate?

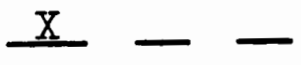

6. Is there a list of related exercises or activities contained in each chapter?

7. Is there a list of additional readings in each chapter?

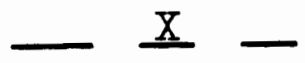

8. Does the text contain an appendix?

a. Is the appended material useful?

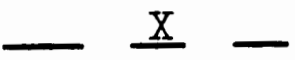
useful?

$-\underline{x}-$

$-\underline{X}$

9. Does the text contain a glossary? - $\underline{X}-$

a. Is it at the end of each chapter?

$-\underline{x}$

b. Is it at the end of the text? _- -

10. Does the text contain a subject index?

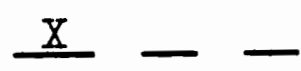

11. Does the text contain an author index?

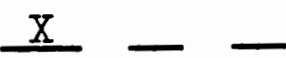

12. Does the text contain a bibliography?

a. Is it at the end of each chapter?

$\underline{X}-$

- I -

b. Is it at the end of the text? 
YES NO NA

13. Are the chapters footnoted or endnoted?

G. Are visual aids used?

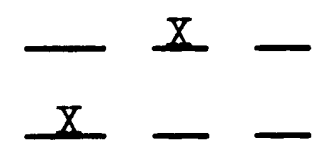

1. Do they contribute to the development of the text?

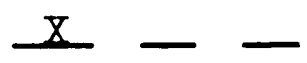

2. Is the art of photographic quality of the visual aid acceptable (sharpness, composition, color)?

3. Is there a good balance between artistic technique and educational need?

4. Are the captions readable?

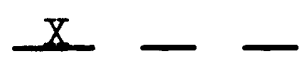

5. Are the captions a good interpretation of the material, yet not distracting?

6. Are the illustrations and captions suitable for teaching and learning purposes?
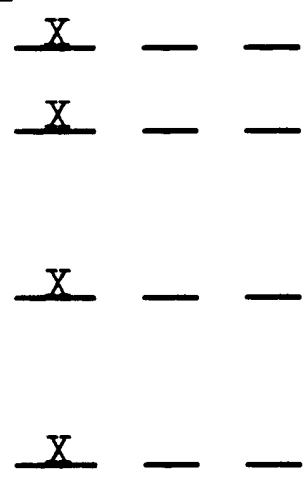

7. Are the visual aids located properly for the greatest usefulness?

8. Are the visual aids adequate in number?

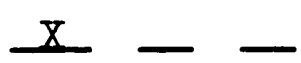

9. Is the content of the visual aid well organized and well balanced? $\mathrm{X}$ -

10. Is explanatory material provided? _ $\mathbb{X}$

\section{SPECIFIC EVALUATION FORM FOR NONVERBAL TEXTS}

I. Introductory Material

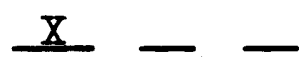

A. Definition of nonverbal communication $\underline{X}-$

B. Issues involved in defining and classifying nonverbal communication

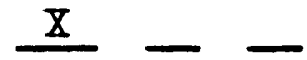

1. Environmental 


\section{YES NO NA}

2. Cultural

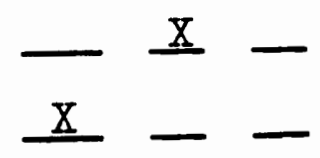

C. Relationship between sending and receiving skills

I -

D. Developing sending and receiving skills

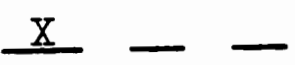

E. Components of nonverbal communication mentioned in the text

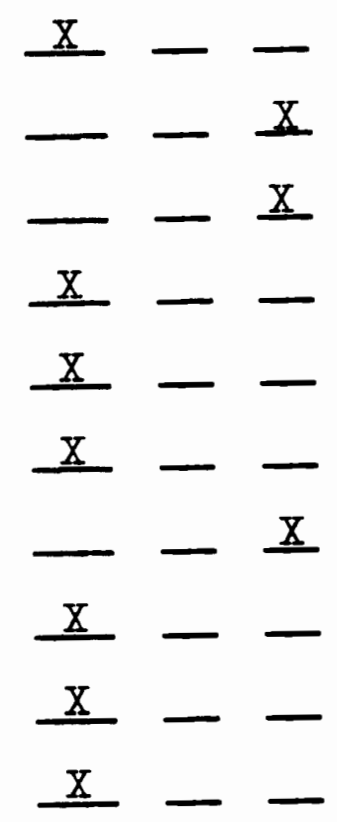

F. Definition of the functions of nonverbal communication

1. Accentuation

2. Complementation

3. Contradiction

4. Redundancy

5. Regulation

- X -

$-\underline{X}$

$-\underline{X}$

$-\underline{X}$

$-\underline{X}$

6. Substitution

$-\underline{X}$

$-\underline{X}$

G. Relationship between verbal and nonverbal communication

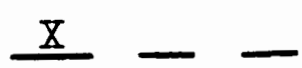


YES NO NA

H. Brief history of the study of nonverbal communication (optional)

II. Adornment

A. Definition of adornment

B. Communicative effects of clothes

C. Communicative effects of accessories

D. Communicative effects of cosmetics

E. Cultural differences

F. Gender differences

III. Chronemics

A. Definition of chronemics

B. Communicative function of chronemics

C. American concept of time

D. Effects of time orientations

1. Psychological

2. Biological

3. Cultural

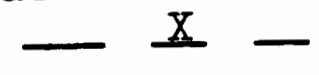

$-\underline{X}-$

$-\underline{x}$

$-\underline{X}$

$-\underline{X}$

$-\underline{X}$

$-\underline{X}$

$-\underline{X}$

- $\mathrm{X}-$

$-\underline{X}$

$-\underline{x}$

$-\underline{X}$

$-\underline{X}$

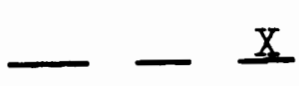

$-\underline{X}$

$-\underline{X}$

IV. Haptics

A. Definition of haptics

B. Communicative function of haptics

$\mathrm{X}$

$\underline{X}-$

C. Tactile communication and human development

X -

c. Tactile communication and human

D. Different types of touching behavior

1. Functional-professional

$-\underline{\mathrm{X}}-$

2. Social-polite

3. Friendship-warmth

4. Love-intimacy

X - -

$\mathrm{X}-$

X -

X - -

X - 
YES NO NA

5. Sexual arousal

$\underline{\mathrm{X}}-$

E. Needs for human touch

$-\underline{\mathrm{X}}-$

1. Biological

$-\underline{X}$

2. Psychological

$-\underline{X}$

3. Sociological

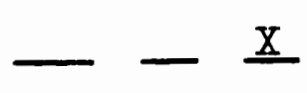

F. The skin as a communication system

$-\underline{X}-$

G. Touch norms and the reason for norms

$-\underline{X}$

H. Gender differences

$\underline{X}-$

I. Cultural differences

V. Kinesics

A. Definition of kinesics

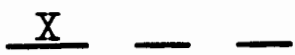

B. Communicative function of kinesics

X

C. Kinesic channels

$\underline{\mathrm{X}}$

$\underline{X}$

$\underline{X}$

1. Whole head

X

2. Whole body

$\underline{X}$

3. Face only

$\underline{X}$

4. Eyes and eyebrows only

5. Hands and arms

X

6. Legs and feet

X -

7. Dyad (whole body with another

person)

$\underline{X}-$

D. Gender differences

E. Cultural differences

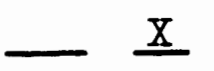

$\underline{X}-$

$-\underline{X}-$

$\mathrm{X}-$

VI. Objects and Environment

$\underline{\mathrm{X}}-$

A. Definition of objects and environment $\underline{X}-$

B. Communicative effects of objects

(artifacts) 
YES NO NA

C. Communicative effects of environmental features

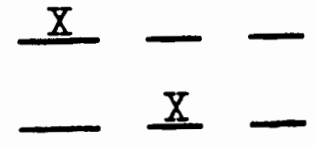

1. Size or volume of artifacts

2. Arrangement of artifacts within an environment

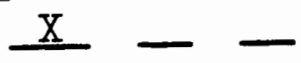

3. Types of materials in use

4. Lighting and shading

5. Color

$-\underline{x}-$

6. Temperature

7. Noise

D. Cultural differences

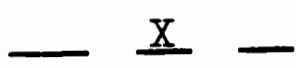

$-\underline{x}-$

E. Gender differences

VII. Olfactory

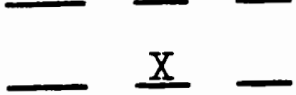

A. Definition of olfactory communication

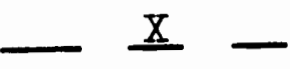

B. Communicative function of odor

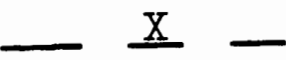

C. Types of smells and messages communicated

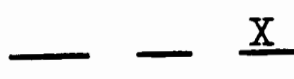

D. Cultural differences

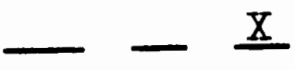

E. Gender differences

VIII. Paralanguage

A. Definition of paralanguage

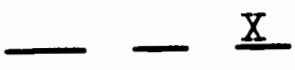

B. Communicative function of paralanguage

C. Sound attributes which give vocal cues their unique characteristics

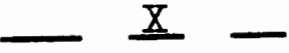

D. Vocal cues in relation to:

1. Speaker recognition

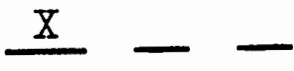

2. Personality judgments 
YES NO NA

3. Personal characteristics

4. Judgments of emotion

5. Comprehension and persuasion

6. Hesitations and pauses

E. Gender differences

F. Cultural differences

IX. Physical Appearance

A. Definition of physical appearance

B. Communicative potential of physical appearance

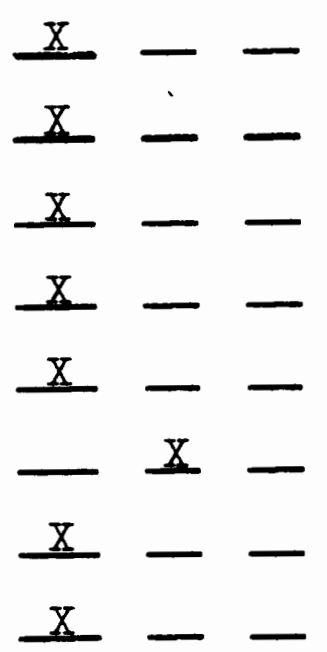

C. Body types

1. Endomorph

2. Mesomorph

3. Ectomorph

D. Traits associated with body types

E. Indicators of attractiveness

1. General attractiveness

2. Body shape

3. Body color

4. Smell

5. Hair (cranial, facial, body)

6. Clothes and artifacts

F. Cultural differences

G. Gender differences

X. Proxemics

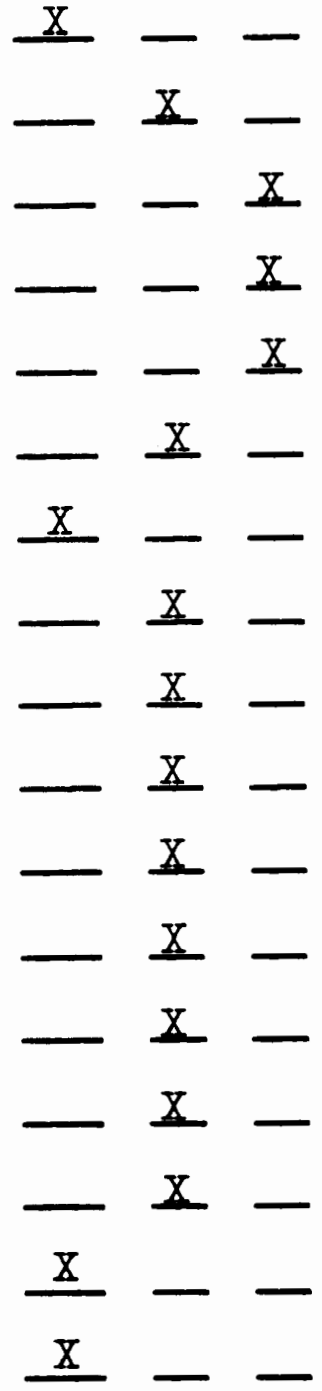

A. Definition of proxemics 
YES NO NA

B. Communicative function of proxemics

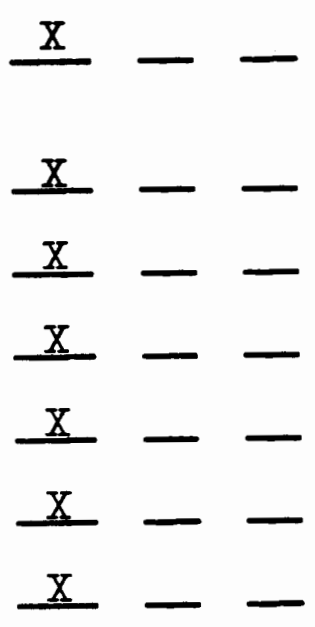

5. Setting of the interaction

space preference

1. Age

2. Sex

3. Ethnic and cultural background

4. Topic or subject matter

6. Physical characteristics of the interactants

7. Attitudinal orientation

8. Emotional orientation

9. Characteristics of the interpersonal relationship

10. Personality characteristics

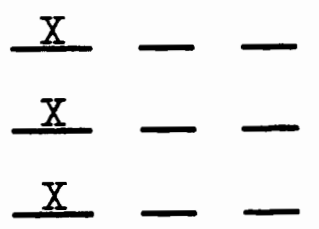

D. Territoriality

1. Intimate-Personal space

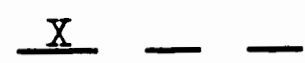

2. Private space

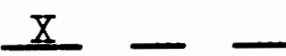

3. Public space

XI. General Summary Material

A. Brief review of the material in the

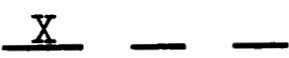

$\underline{X}-$

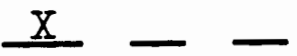

$-\underline{x}-$

- $\mathrm{x}-$ chapters in terms of the usage and importance of nonverbal communication
B. Characteristics of a skilled nonverbal receiver/decoder

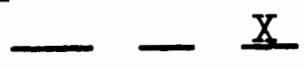
C. Characteristics of a skilled nonverbal sender/encoder

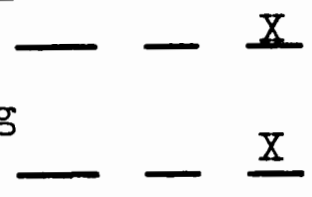


Essentials of Nonverbal Communication. 1980. Mark I. Knapp. New York: Holt, Rinehart and Winston. The text is divided into twelve chapters which cover the following topics: (1) Basic Perspectives on Defining and Classifying Nonverbal Communication in the Total Communication Process; (2) History of the Development of Nonverbal Communication; (3) Environmental Effects; (4) Territory and Personal Space; (5) Physical Appearance and Dress; (6) Body Movement and Posture; (7) Touching Behavior; (8) Facial Expressions; (9) Eye Behavior; (10) Paralanguage; (11) Nonverbal Sending and Receiving Skills; and (12) Observing and Recording Nonverbal Behavior. 11

The components of nonverbal communication this text does not cover are: chronemics and olfactory communication. 
GENERAL EVALUATION SCALE FOR NONVERBAL TEXTS

Text: Essentials of Nonverbal Communication. Author: Knapp, Mark I. 1980.

YES NO NA

I. Purpose

A. Does the author accomplish the overall purpose of the text?

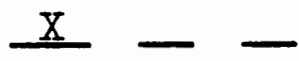

B. Is the purpose accomplished in good literary style?

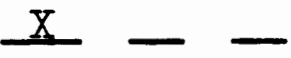

II. Author

A. Is there pertinent, factual information about the educational background, profession, and qualifications of the author?

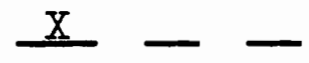

III. Authenticity

A. Is the material factually accurate and objective in its presentation?

B. Is the material up-to-date?

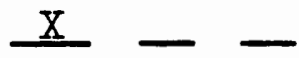

C. Are the information sources well documented?

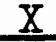

IV. Appropriateness

A. Does the material promote the educational goals and objectives of the curriculum?

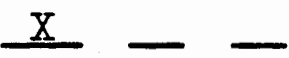

B. Is the material appropriate to the

level of instruction intended?

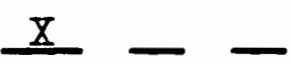

C. Is the interest level appropriate to the user?

1. Will the material stimulate the curiosity of the user?

$\underline{X}-$

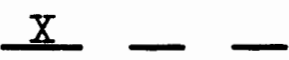

2. Will the material appeal to many students? 
YES NO NA

V. Content

A. Is the content of the material well presented by providing adequate scope, range, depth, and continuity?

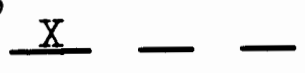

B. Is the material well organized and well balanced?

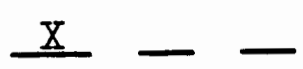

C. Is the material presented as clearly and simply as possible for the level intended?

D. Does the material aid conceptualization of the subject matter?

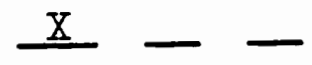

E. Does the material achieve its stated purpose?

F. Are the transitions from one point to another, or one section to another, smooth and clear?
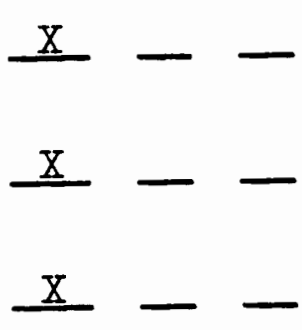

G. Does the text present information not

otherwise available?

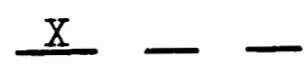

Does the material give a new dimension to the subject?

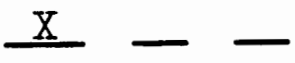

I. Are the sources, purposes, and points of view readily identifiable?

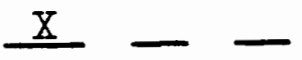

VI. Technical Quality

A. Is the text hardcover?

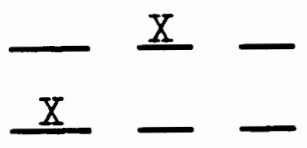

B. Is the text softcover?

C. Is the typography clear and easy to read?

D. Are the page layouts well designed?

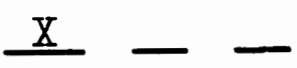

E. Is the pagination definite and clear?

1. Is there a table of contents?

X

2. Is there an outline listing the contents of each chapter? 
a. Is this at the beginning of each chapter?

$-\underline{X}-$

b. Is this in the table of contents?

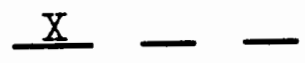

3. Are the major titles and subtitles of each section delineated in each chapter?

4. Is there a list of priorities at the beginning of each chapter?

5. Are internal summaries and reviews provided where appropriate?

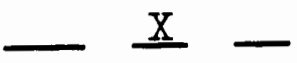

6. Is there a list of related exercises or activities contained in each chapter?

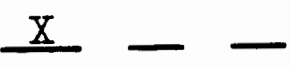

7. Is there a list of additional

readings in each chapter?

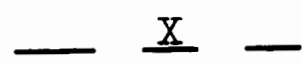

8. Does the text contain an appendix?

a. Is the appended material

useful?
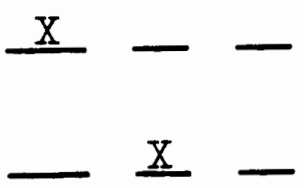

9. Does the text contain a glossary?

$-\underline{X}$

a. Is it at the end of each chapter?

$-\underline{X}$

b. Is it at the end of the text? - - $\underline{X}$

10. Does the text contain a subject index?

11. Does the text contain an author index?
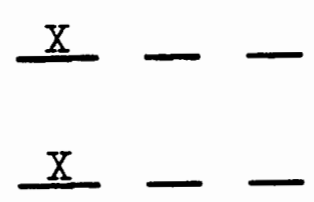

12. Does the text contain a bibliography?

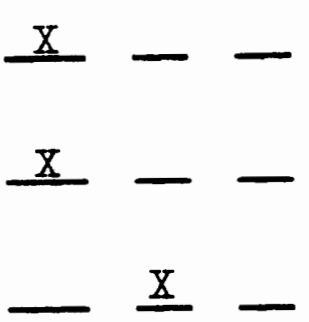


YES NO NA

13. Are the chapters footnoted or endnoted?

G. Are visual aids used?

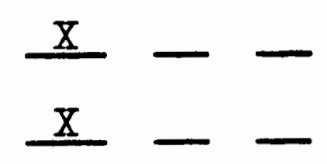

1. Do they contribute to the development of the text?

$\underline{X}-$

2. Is the art of photographic quality of the visual aid acceptable (sharpness, composition, color)?

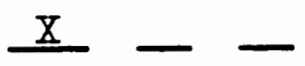

3. Is there a good balance between artistic technique and educational need?

4. Are the captions readable?

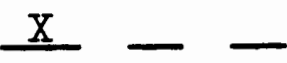

5. Are the captions a good interpretation of the material, yet not distracting?

6. Are the illustrations and captions suitable for teaching and learning purposes?

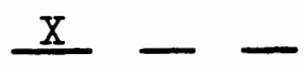

7. Are the visual aids located properly for greatest usefulness?

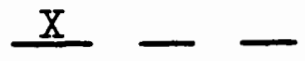

8. Are the visual aids adequate in number?

9. Is the content of the visual aid well organized and well balanced? $\mathrm{X}$ -

10. Is explanatory material provided? $\underline{X}-$

\section{SPECIFIC EVALUATION FORM FOR NONVERBAL TEXTS}

I. Introductory Material

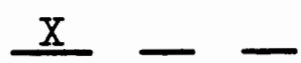

A. Definition of nonverbal communication $\underline{X}$

B. Issues involved in defining and classifying nonverbal communication

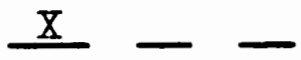

1. Environmental 
YES NO NA

2. Cultural

$\underline{x}-$

3. Contextual

X -

C. Relationship between sending and receiving skills

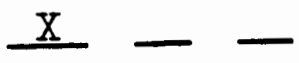

D. Developing sending and receiving skills

$\underline{X}-$

E. Components of nonverbal communication mentioned in the text

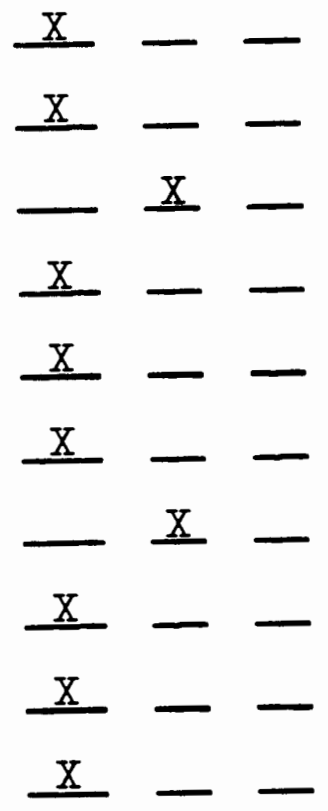

F. Definition of the functions of nonverbal communication

1. Accentuation

2. Complementation

3. Contradiction

4. Redundancy

5. Regulation

$\underline{\mathrm{X}}-$

$\underline{\mathrm{X}}-$

6. Substitution

$\underline{\mathrm{X}}-$

$\underline{x}-$

$\underline{x}-$

$\underline{\mathrm{X}}-$

$\underline{\mathrm{X}}-$

G. Relationship between verbal and nonverbal communication 


\section{YES NO NA}

H. Brief history of the study of nonverbal communication (optional)

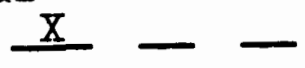

II. Adornment

A. Definition of adornment

$\underline{\mathrm{X}}-$

B. Communicative effects of clothes

$\underline{x}-$

C. Communicative effects of accessories

$\mathrm{X}-$

D. Communicative effects of cosmetics

E. Cultural differences

F. Gender differences

$\underline{X}-$

$\underline{X}-$

- $\underline{x}-$

$\underline{X}-$

III. Chronemics

A. Definition of chronemics

$-\underline{X}-$

B. Communicative function of chronemics

$-\underline{X}$

C. American concept of time

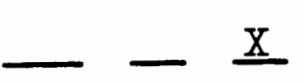

D. Effects of time orientations

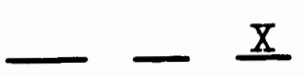

1. Psychological

2. Biological

3. Cultural

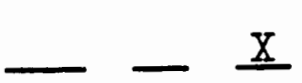

$-\underline{x}$

$-\underline{X}$

$-\underline{x}$

IV. Haptics

A. Definition of haptics

$\underline{\mathrm{X}}$

$\underline{X}$

B. Communicative function of haptics

$\underline{X}$

C. Tactile communication and human development

D. Different types of touching behavior

1. Functional-professional

2. Social-polite

3. Friendship-warmth

$\underline{X}$

$\underline{\mathrm{X}}$

X

X

X

4. Love-intimacy

X 
YES NO NA

5. Sexual arousal

$\underline{X}--$

E. Needs for human touch

1. Biological

- X -

2. Psychological

$-\mathrm{X}$

3. Sociological

F. The skin as a communication system

$-x$

G. Touch norms and the reason for norms

H. Gender differences

I. Cultural differences

V. Kinesics

A. Definition of kinesics

B. Communicative function of kinesics

$-\mathrm{X}$

- $\underline{X}-$

X - -

$\underline{x}-$

$\underline{x}-$

C. Kinesic channels

1. Whole head

2. Whole body

3. Face only

4. Eyes and eyebrows only

X - -

$\underline{x}-$

$\underline{X}-$

$\underline{X}--$

$\underline{x}-$

$\underline{x}-$

$\underline{x}--$

5. Hands and arms

$\underline{X}-$

6. Legs and feet

X - -

6. Legs and feet

$\longrightarrow$ X

7. Dyad (whole body with another person)

D. Gender differences

E. Cultural differences
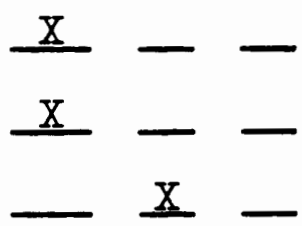

VI. Objects and Environment

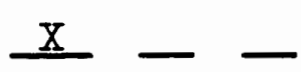

A. Definition of objects and environment $\mathbb{X}-$

B. Communicative effects of objects (artifacts) 


\section{YES NO NA}

C. Communicative effects of environmental

features

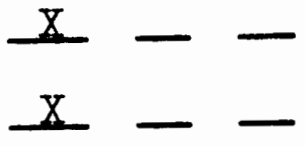

1. Size or volume of artifacts

2. Arrangement of artifacts within an environment

3. Types of materials in use

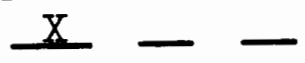

4. Lighting and shading

$\mathrm{X}-\mathrm{C}$

5. Color

6. Temperature

$\mathrm{x}-$

7. Noise

D. Cultural differences

E. Gender differences

VII. OIfactory

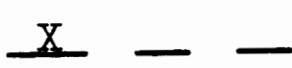

$\mathrm{X}-$

$\mathrm{X}-$

$+\mathrm{X}-$

I

- $\mathrm{X}-$

A. Definition of olfactory communication

$-x$

B. Communicative function of odor

$-\underline{x}$

C. Types of smells and messages communicated

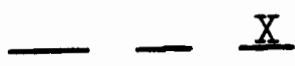

D. Cultural differences

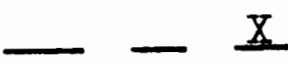

E. Gender differences

VIII. Paralanguage

A. Definition of paralanguage

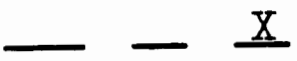

B. Communicative function of paralanguage

C. Sound attributes which give vocal cues their unique characteristics

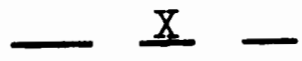

D. Vocal cues in relation to:

1. Speaker recognition

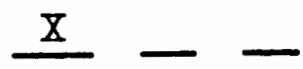

2. Personality judgments 
YES NO NA

3. Personal characteristics

4. Judgments of emotion

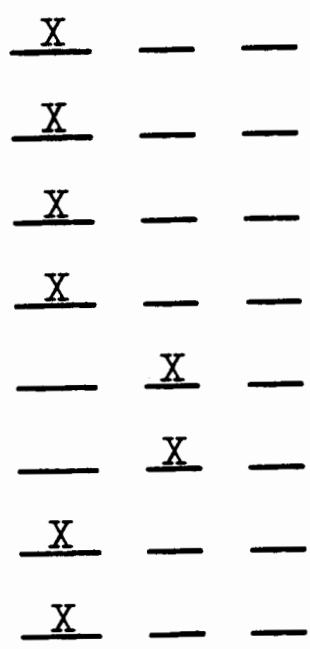

A. Definition of physical appearance

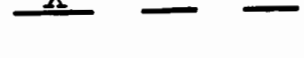

B. Communicative potential of physical appearance

$\mathrm{X}-$

C. Body types

1. Endomorph

2. Mesomorph

3. Ectomorph

D. Traits associated with body types

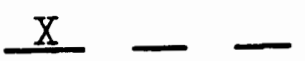

E. Indicators of attractiveness

1. General attractiveness

X

2. Body shape

3. Body color

4. Smell

5. Hair (cranial, facial, body)

6. Clothes and artifacts

F. Cultural differences

X

X - -

X - -

$\underline{X}-$

$\mathrm{X}-$

X - -

$\underline{X}-$

X - -

$\underline{X}-$

$\mathrm{X}-$

G. Gender differences

X -

$x-$

X. Proxemics

$\underline{\mathrm{X}}-$

A. Definition of proxemics 
B. Communicative function of proxemics

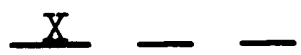

C. Factors relating to individual space preference

1. Age

2. Sex

3. Ethnic and cultural background

4. Topic or subject matter

5. Setting of the interaction

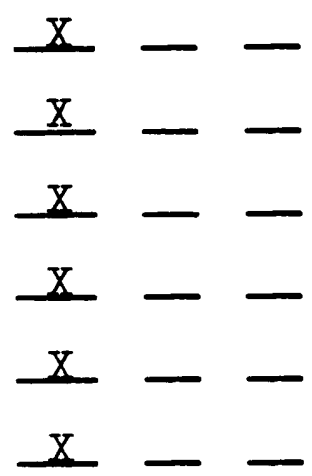

6. Physical characteristics of the interactants

7. Attitudinal orientation

8. Emotional orientation

9. Characteristics of the interpersonal relationship

10. Personality characteristics
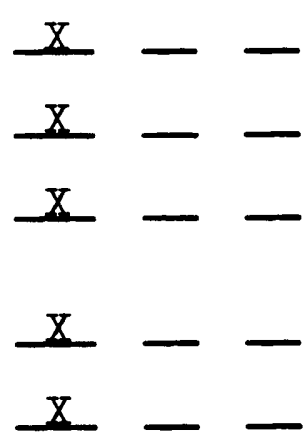

D. Territoriality

1. Intimate-Personal space

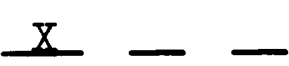

2. Private space

3. Public space

XI. General Summary Material

A. Brief review of the material in the chapters in terms of the usage and importance of nonverbal communication
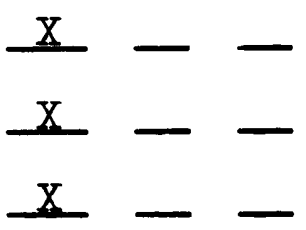

x -

Characteristics of a skilled nonverbal receiver/decoder

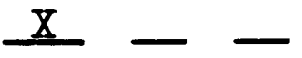

C. Characteristics of a skilled nonverbal sender/encoder

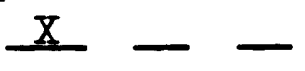

D. Relationship between nonverbal sending and receiving skills

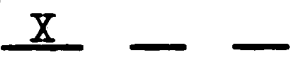


' Jerry Frye, Frye's Index to Nonverbal Data (Minneapolis: University of Minnesota Press, 1978), p. 2, 3, 4, 5, 6, 7, et seq.

${ }^{2}$ Interview with Robert McLaughlin, Sales Representative, William C. Brown Co. Publishers, Tacoma, Washington, May 6, 1982.

${ }^{3}$ Haig Bosmajian, The Rhetoric of Nonverbal Communication: Readings (Glenview, IL: Scott, Foresman and Co. 1971), p. vii.

${ }^{4}$ Mark I. Knapp, Nonverbal Communication in Human Interaction (New York: Holt, Rinehart and Winston Inc., 1972), pp. vii-viii.

${ }^{5}$ Randall P. Harrison, Beyond Words: An Introduction to Nonverbal Communication (Englewood Cliffs, N.J.: Prentice-Hall Inc., 1974), pp. v-vii.

${ }^{6}$ Shirley Weitz, Nonverbal Communication: Readings with Commentary (New York: Oxford University Press, 1974), pp. ix-x.

7 Lawrence Rosenfeld and Jean Civikly, With Words Unspoken (New York: Holt, Rinehart and Winston Inc., 1976), p. ix.

${ }^{8}$ Dale G. Leathers, Nonverbal Communication Systems (Allyn and Bacon, 1976), pp. vi-ix.

9 Judee Burgoon and Thomas Saine, The Unspoken Dialogue: An Introduction to Nonverbal Communication

(Boston: Houghton Mifflin, 1976), pp. vii-ix.

10 Marianne LaFrance and Clara Mayo, Moving Bodies: Nonverbal Communication in Social Relationships (Monterey, CA: West Publishing Co., 1978), pp. ix-xi.

$1 l_{\text {Mark I. Knapp, Essentials of Nonverbal Communication }}$ (New York: Holt, Rinehart and Winston Inc., 1980), pp. vivii. 


\section{CHAPTER VII}

\section{SUMIMARIES AND TABLES FOR THE NINE NONVERBAL COMMUN ICATION TEXTBOOKS}

This chapter will consist of nine tables which represent each of the nonverbal communication texts being studied. The tables will show the percentages of the essential nonverbal material present in each of the texts. This is based on the components which have been deemed as being necessary for inclusion in all comprehensive, introductory nonverbal communication textbooks (see pages 2935). Additionally, preceding each table there will be a summary of the text under scrutiny.

The final section of the chapter will consist of a table which lists the overall percentages of the essential material contained in all the texts being studied. Included in this section, along with the table, is a statement of implications for further study. 
The Rhetoric of Nonverbal Communication: Readings. 1971. Haig A. Bosmajian.

The text is an anthology which brings together some of the best thinking (of the time) from a large number of prominent scholars and scientists. The anthological format is used because the text draws upon the nonverbal concepts and principles that are operative in the many disciplines represented by the published works of the authors.

The purpose of the text is to introduce students to some of the facets, implications, principles, and effects of nonverbal communication. The text is intended for classes which deal with the practical and theoretical aspects of persuasion, rhetoric, discussion, and interpersonal relations in their curriculum. Students in courses dealing with theoretical bases of rhetoric and communication will find selections that are useful for portraying the breadth and scope of those subject areas and for definitions and analyses of the various forms of nonverbal communication. 1

The text would be a good supplementary reader for clarifying concepts presented in an advanced course in nonverbal communication. 


\section{TABLE I}

PERCENTAGES OF ESSENTIAIS IN RHETORIC OF NONVERBAI COMMUNICATION: READINGS NECESSARY FOR COMPREHENS IVE, INTRODUCTORY

NONVERBAL COMMUN ICATION TEXTS

Components

Introductory Material

Adornment

Chronemics

Haptics

Kinesics

Objects and Environment .......

Olfactory . . . . . . . . .

Paralanguage

Physical Appearance

Proxemics . . . . . . . . . .

General Summary Material . . . .
Percentage

37

0

0

100

0

25

0

0

0

0

0 
Nonverbal Communication in Human Interaction. 1972. Mark I. Knapp

The text was originally written to restore balance in the study of human communication by including the area of nonverbal communication because no other substantive text on this topic had been published at the time. The author's purpose was to survey the literature on nonverbal communication and to summarize the behavioral research in each of the stated areas of the field. In this capacity, the main orientation of the work focuses on behavioral research. A descriptive approach is used because the available knowledge of nonverbal communication was limited in 1972 .

The text is divided into six major sections, representing six nonverbal variables which impinge on, and influence, the process of human communication. The areas were selected on the basis of how likely they are to occur in almost any human interaction. Knapp begins by presenting several basic perspectives including the problems of defining nonverbal communication, the place of nonverbal communication in the total communication process, its prevalence and importance as well as a treatment of the origins and universality of nonverbal communication. The central areas of nonverbal behavior which comprise the remainder of the text include: the influence of environmental factors on human communication, the effects of 
physical appearance and dress on human communication, the effects of the vocal cues that accompany spoken words and the various methods of observing and recording nonverbal communication. 2

The text is short and easily read so that it could also be used as a supplement to other lower or upper division courses in verbal communication in addition to being an excellent choice for the main text in a beginning nonverbal course. An extensive list of references follows each chapter, thereby making the book useful to advanced as well as beginning students. Although the publication date was in 1972, the book is well written, and contains such pertinent, applicable information about nonverbal communication that it is still an excellent tool for use in a beginning nonverbal communication class. 
TABLE II

PERCENTAGES OF ESSENT IALS IN NONVERBAL COMMUN ICATION IN HUMAN INTERACTION NECESSARY FOR COMPREHENSSIVE, INTRODUCTORY NONVERBAL COMIUNICATION TEXTS

Components

Introductory Material . . . . . .

Adornment . . . . . . . . . .

Chronemics ............

Haptics . . . . . . . . . . 47

Kinesics ........... 66

Objects and Environment . . . . . 75

Olfactory . . . . . . . . . . . . 0

Paralanguage ........... 100

Physical Appearance . . . . . . 87

Proxemics . . . . . . . . 82

General Summary Material . . . . . . 0 
Beyond Words: An Introduction to Nonverbal Communication. 1974.

Randall P. Harrison.

This book was designed as an introductory text for a beginning class in nonverbal communication but would be much more effective as a supplementary reader to a more comprehensive text. It is stated in the introduction that the book will cover all areas of nonverbal communication but, to this end, it falls very short. Of the nine major components of nonverbal communication under study, the text focuses on: (1) Paralanguage, (2) Kinesics, (3) Artifacts, and (4) Chronemics. There are also sections on the media, various nonverbal systems and the implications, applications, and complications of nonverbal communication in human interaction. 3

What is done, is done very well. The content is written in a manner that is easy to read and comprehend. Many visual aids are used with most of these being in the form of cartoons. Each chapter contains a list of "learning tips" (words to know/concepts to learn, etc.) and thought starters, thereby indicating to the student what to expect from the reading. Discussion exercises are also contained in each chapter and most of the chapters are summarized prior to the end of the material. 


\section{TABLE III}

PERCENTAGES OF ESSENTIAIS IN BEYOND WORDS NECESSARY FOR COMPREHENS IVE, INTRODUCTORY NONVERBAI COMMUNICATION TEXTS

Components

Introductory Material

Adornment

Chronemics

Haptics

Kinesics

Objects and Environment

Olfactory .............

Paralanguage ... . . . . . .

Physical Appearance.

Proxemics

General Summary Material
Percentage

37

33

100

23

75

25

0

27

12

35

100 
Nonverbal Communication: Readings with Commentary. 1974. Shirley Weitz.

The overall emphasis of the text is on the place of nonverbal research in the psychological literature in order to indicate how work relating to the study of emotion, cognition, social interaction, and the ethology of human behavior has been enhanced by attention to nonverbal communication. The focus is on the most recent works which indicate significant new trends in this area of research. The selections represent the contemporary perspectives of many of the major authors in the field (Birdwhistell, Dittman, Ekman, Exline, Hall, Kendon, Mehrabian, Scheflen).

A comprehensive introduction to each section is provided which discusses significant theoretical and empirical directions of nonverbal research as well as the rationale for the choice of articles. Among the topics fully covered are the biological and cultural roots of expressive behavior; the recognition of emotion from the face, body, and voice; physiological and cognitive concomitants of nonverbal communication; the regulation of social interaction through paralinguistic, kinesic, and proxemic cues; the relationship between verbal and nonverbal communication; applications in psychotherapy; and new research techniques in all areas.

Weitz selected each article because she feels it is a classic, or a fine representative of its genre. This serves to make the book readable and authoritative while 
touching on the major theories and methods in the field in 1974. The book's comprehensiveness is insured by Weitz's (ambitious) commentaries in which she describes and integrates a great deal of research, including much that is not covered in the reprinted articles.

The only real weakness in the book is an undimensional organizational scheme whereby the 22 papers are grouped into the five topic areas. To divide the field along the five channel lines, as Weitz has done, is an obvious, but not necessarily the best, way to organize the material. The reader can be led to believe that the five topic areas overlap much less than they actually do and that such distinctions are inherently meaningful. This false impression is further compounded by the fact that, following a short general introduction, the commentary on each of the five sections is printed at the section's beginning. The reader who, therefore, expects to find topical discreteness is surprised to find that, for example, Birdwhistell's paper on body movement and gestures also touches on paralanguage, facial expressions, head movements, and multichannel redundancy. Weitz, herself, subverts the scheme by including in the topical commentaries, observations and facts that are equally relevant to other topics. Based on this, some other organizational scheme might allow for less crossing of topical boundaries and, might too, have more intrinsic interest. 
Weitz says, "The various areas of nonverbal research [that is, her five topic areas] have mainly developed independently of each other." 4 That may be, but probably only in the superficial sense that different researchers tend to concentrate their energies on particular nonverbal channels. However, the same methodological, conceptual distinctions, as well as some of the basic research questions are not channel specific.

The text is not suitable for a contemporary, introductory course but would make an excellent supplement to an advanced or graduate class because it requires a basic understanding of the field of nonverbal communication in order to comprehend the material. 


\section{TABLE IV}

PERCENTAGES OF ESSENTIAIS IN NONVERBAL COMMUNICATION: READ INGS AND COMMENTARY NECESSARY FOR COMPREHENSIVE, INTRODUCTORY NONVERBAL COMMUN ICATION TEXTS

Components Percentage

Introductory Material . . . . . . 22 Adornment . . . . . . . . . . 0

Chronemics ............. . . 0

Haptics . . . . . . . . . . . 0

Kinesics . . . . . . . . . . 91

Objects and Environment......... 0

Olfactory ............ . . . 0

Paralanguage . . . . . . . . . 72

Physical Appearance . . . . . . . . 0

Proxemics . . . . . . . . . 100

General Summary Material . . . . . 25 
With Words Unspoken. 1976.

Lawrence Rosenfeld and Jean Civikly.

The purpose of this text is to help individuals understand the complexities of human relationships. It was designed to make the students experience the different aspects of nonverbal behavior in relation to themselves and the other people with whom they interact. To this end, many experiential exercises and activities are provided to help promote growth and understanding in the realm of nonverbal communication. The authors strive to make the experience of using the text meaningful to the reader and definitely succeed in accomplishing this goal.

The authors deal with nonverbal communication in relation to oneself, others, the environment, and the nonverbal experience itself. The material is presented in an energetic and thoughtful manner that relates directly to the function of nonverbal communication in everyday life. 5

This book would be a good choice for the main text in a beginning, introductory nonverbal course. The material is well organized, well written, substantive, definitive, and fun to read. The main orientation is toward the nonverbal aspects of interpersonal communication.

The major drawback is that many of the sources cited in the text are outdated and were outdated when the text was initially written. The credibility of the text would be enhanced if the results of more recent studies were used. 
TABLE V

PERCENTAGES OF ESSENTIALS TN WITH WORDS UNSPOKEN NECESSARY FOR COMPREHENS IVE, INTRODUCTORY NONVERBAL COMMUN ICATION TEXTS

Components

Introductory Material . . . . .

Adornment . . . . . . . . .

Chronemics .......... 100

Haptics . . . . . . . . 88

Kinesics ........... 83

Objects and Environment . . . . . 83

Olfactory . . . . . . . . 80

Paralanguage ......... . 72

Physical Appearance . . . . . . 93

Proxemics .......... . 100

General Summary Material . . . . 25 
Nonverbal Communication Systems. 1976.

Dale G. Leathers.

Leathers states the text was written to satisfy the

following criteria: (1) a course in nonverbal communication could be designed to parallel the treatment of the subject matter in the text; (2) the text will be designed to promote students' active involvement in testing and developing their own capacity to communicate nonverbally; (3) the text will clearly delineate and analyze the functional capacity of the different systems comprising nonverbal communication; (4) the text will provide an integrated treatment of the functional relationships between, and among, the nonverbal communication systems and the interaction of these systems with verbal communication; (5) the text will be extensively and creatively illustrated to facilitate extensive examination of nonverbal communication behaviors. To this end, the author has succeeded in accomplishing his original goal.

The students are provided with practical and accurate tests to determine their encoding and decoding capacity in relation to facial communication, vocalic communication, and tactile communication. An answer is provided to the often asked question, "Which communication system has the greatest potential to exchange specific types of meanings accurately and efficiently?" The chapters on the invisible communication systems (tactile, olfactory, telepathic) delineate a set of important communicative functions which 
have probably never been treated in the same depth, or in the same way, in a single volume. The potential to achieve specific communicative objectives is rated for the first time in this text (one of the unique aspects of the text). The content covers the areas of: kinesics, proxemics, physical appearance, paralanguage, haptics, olfactory, and telepathic communication. It could be used to satisfy a considerable range of needs. In addition to being an excellent choice for the main text in a beginning or advanced course in nonverbal communication, it would also prove useful in interpersonal communication, public speaking (with justifiable emphasis on kinesic, spatial, vocal, and other dimensions of the nonverbal process), small group, and communication theory. 
PERCENTAGES OF ESSENTIAIS IN NONVERBAL COMMUNICATION SYSTEMS NECESSARY FOR COMPREHENSIVE, INTRODUCTORY NONVERBAL COMMUNICATION TEXTS

\section{Components}

Introductory Material . . . . . .

Adornment . . . . . . . . .

Chronemics ............

Haptics . . . . . . . . . .

Kinesics ..............

Objects and Environment . . . . . . Olfactory . . . . . . . . . .

Paralanguage

Physical Appearance . . . . . . .

Proxemics ............ 100

General Summary Material ...... 100
67

67

0

94

83

83

80

100

93 
The Unspoken Dialogue: An Introduction to Nonverbal Communication. 1978.

Judee Burgoon and Thomas Saine.

The authors feel that by studying the different areas of nonverbal communication independently, they would be taking a fragmented approach to the subject. It is felt that this would be a misrepresentation of the subject and would cause the reader to miss much of the actual meaning of nonverbal communication. The book is directed toward focusing on ways in which such behaviors combine to fulfill certain communicative functions. Thus, the text takes a functional as well as a definitive approach to the study of nonverbal communication and investigates information transfer, persuasion, decision making, cohesion, social solidarity, and impression formation.

The focus is not on dissecting each nonverbal component separately, but on revealing how the codes interact to satisfy important communicative functions. Burgoon and Saine are convinced this is the most coherent way of viewing nonverbal communication while providing an approach that most closely parallels the perspective of many other communication courses. Additionally, they feel that one of the difficulties in studying and teaching nonverbal communication is that concepts and research findings range from the very simple to highly sophisticated and complex variable relationships, thereby making it difficult to keep a text on one level. To counter this problem, they have let the 
nonverbal literature dictate the level of the book because they do not want to force simplicity on relatively sophisticated concepts. Some chapters are, therefore, more demanding than others, owing to the necessity of developing an appreciation for the complexity of the ideas presented. The authors have cited what they feel are relevant and seminal works in each area of investigation. For the more advanced students, the book attempts to raise important issues regarding the testability of ideas. It acquaints both beginning and advanced students with basic theories that provide insight into the research methodologies used to study nonverbal communication. The text would be an excellent tool for use in both beginning and advanced courses, in fact, of all the texts analyzed, this has been chosen as the best, most comprehensive text currently being used. It presents the essential information about the nonverbal components in section 1 and then illustrates the function of the components in section 2 . The text is exceptionally well written, well organized, substantive, definitive, well illustrated, and factual.? 
TABLE VII

PERCENTAGES OF ESSENTIALS IN THE UNSPOKEN DIALOGUE NECESSARY FOR COMPREHENS IVE, INTRODUCTORY NONVERBAL COMMUN ICATION TEXTS

Components

Percentage

Introductory Material . . . . . 88

Adornment . . . . . . . . . 100

Chronemics ............ 100

Haptics . . . . . . . . . 64

Kinesics ............ . 100

Objects and Environment . . . . . 100

Olfactory ............ . . . 0

Paralanguage ......... . . 81

Physical Appearance .. . . . . . 100

Proxemics . . . . . . . . . 100

General Summary Material . . . . 100 
Moving Bodies: Nonverbal Communication in Social Relationships. 1978.

Marianne LaFrance and Clara Mayo.

This text differs markedly from most other books on the topic. Instead of being primarily descriptive, the text develops a conceptual framework that allows for explanation and interpretation of the material. Rather than taking the nonverbal components one at a time and treating each of them in separate chapters, the book brings the various channels together and integrates them to provide a more realistic assessment of the ways in which communication processes naturally operate. The authors have presented a thorough accounting of the relevant work of many disciplines. The text is organized into three major sections. The first deals with what nonverbal clues tell about the psychology of the individual and includes chapters on emotional expression, personality, and psychotherapy. The second section addresses the question of what information nonverbal behavior provides about the relationship between, and among, people. This contains chapters on attraction, aggression, status, and influence. The last section looks at the role nonverbal processes play in larger systems of communication. These chapters deal with the integration of verbal and nonverbal modes and with the ways in which nonverbal behavior cues social memberships, i.e., age, sex, and culture.

The text could serve as a supplementary reader for courses in interpersonal communication, group communication, 
social psychology, and linguistics, as well as the main text in a beginning or advanced course in nonverbal communication. $^{8}$ 


\section{TABIE VIII}

PERCENTAGES OF ESSENTIAIS IN MOVING BODIES: NONVERBAI COMMUN ICATION IN SOCIAL REIATIONSHIPS NECESSARY FOR COMPREHENS IVE, INTRODUCTORY NONVERBAL

COMMUNICATION TEXTS

Components

Introductory Material

Adornment

Chronemics

Haptics . . . . . . . . . . .

Kinesics

Objects and Environment Olfactory

Paralanguage

Physical Appearance

Proxemics

General Summary Material . . . . .
Percentage

48

0

0

58

83

25

0

81

18

94

0 
Essentials of Nonverbal Communication. 1980. Mark I. Knapp.

The text presents the reader with information the author feels is essential for developing a basic understanding of nonverbal behavior. It was designed to serve as an update on the latest findings of the research conducted since publication of Knapp's last book, Nonverbal Communication in Human Interaction, published in 1972. Knapp contends the material presented will serve to dispel the myths commonly associated with nonverbal communication, i.e., (1) Isolation Myth, (2) Key to Success Myth, and (3) Single Meaning Myth.

The Isolation Myth is where the nonverbal system is viewed as an entity distinct and isolated from the total system of human communication. Although the book focuses almost exclusively on the separate nonverbal processes, the reader is reminded they are inextricably bound up with verbal and contextual aspects of communication. The Key to Success Myth argues that an understanding of nonverbal communication is somehow a magic elixir for success in all interpersonal relations. Knapp states that understanding nonverbal communication is only a part of understanding the communication process and only a part of the skills needed to become an effective communicator. The Single Meaning Myth is based on the assumption that when a particular nonverbal signal is observed, it can be confidently 
associated with a particular behavior or emotion. Knapp contends that nonverbal behavior, like verbal, may have many meanings depending on the social context of the communication and the current feelings of the communicator. In addition to being an excellent text for use as the main text in a nonverbal communication course, Knapp declares the book was written so that it could also be used as a supplementary reader to enhance the material in many other courses. 9 
TABLE IX

PERCENTAGES OF ESSENTIAIS IN ESSENT IAIS OF NONVERBAL COMMUN ICATION NECESSARY FOR COMPREHENSIVE, INTRODUCTORY NONVERBAL COMIUNNICATION TEXTS

Components

Percentage

Introductory Material . . . . . . 92

Adornment . . . . . . . . . 83

Chronemics . . . . . . . . . . . 0

Haptics . . . . . . . . . 70

Kinesics . . . . . . . . . 83

Objects and Environment . . . . . . 83

Olfactory ............ . . . 0

Paralanguage . . . . . . . . 27

Physical Appearance . . . . . . 100

Proxemics . . . . . . . . . . . 0

General Summary Material . . . . . 100 


\section{IMPIICATIONS FOR FURTHER STUDY}

As can be seen in Table $\mathbf{X}$, olfactory (smell) and chronemics (time) are the two nonverbal components which are contained in the fewest number of texts. For some reason, most authors do not include these two essential components in their work when they set out to write a comprehensive, introductory nonverbal communication textbook. This is a major oversight.

\section{TABLE X}

PERCENTAGES OF THE ESSENTIAL COMPONENTS CONTAINED IN ALL THE NONVERBAL COMMUNICATION TEXTS

Components

Introductory Material

Adornment

Chronemics

Haptics

Kinesics

Objects and Environment Olfactory

Paralanguage

Physical Appearance

Proxemics . . . . . . . . 67

General Summary Material . . . . 50
Percentage

58

44.33

33.33

60

73

64

17.77

62

55 
Olfactory communication, along with the visual stimulus, has an enormous amount of impact on first impressions as well as subsequent encounters. Madison Avenue, the seat of advertising in the United States, has inculcated American society with the notion that all natural body odors are offensive, therefore they should be eliminated or covered up via the various products designed for this purpose. People have been socialized into believing that the only inoffensive odors are those that have been artificially manufactured to emulate various facets of the natural environment, i.e., flowers, fruits, trees, fresh air etc. Each product that an individual purchases for use on their body (shaving cream, deodorant, oil, aftershave/cologne/ perfume, mouthwash, powder) contains an aroma which is designed to satisfy a need and to convey a message. Advertisers assert that by using their product, a person will be perceived as more attractive and more appealing, thereby increasing the individual's likelihood for obtaining sexual gratification.

The implications of this form of nonverbal communication are far reaching and are very pervasive in American society as well as in many other cultures. To neglect or ignore this form of communication when studying nonverbal communication is a serious omission that should be rectified.

Chronemics is another form of nonverbal communication that should not be overlooked. Time, it is safe to say, 
controls or affects the life of almost every individual in the United States. It's impact cannot, and should not, be ignored. There is not one facet of American society that is not directly affected by the passage, or use, of time. It can be a major problem in a relationship if both people have different perceptions of how time should be used or structured. In the work place, a person lives by the clock. Most companies have rigid rules governing individuals with regard to time. Learning, and abiding by, these rules is an important responsibility of all employees. Time determines when people arise and when they go to bed. People learn at an early age what is expected of them in terms of time. A life is divided into one year increments that are celebrated as they pass. Additionally, the passage of time determines, to a large extent, what responsibilities society places on the shoulders of its members. The perception and use of time is, therefore, one of the major threads that binds American society and its people together. 
Chapter 7--Notes

$I_{\text {Haig Bosmajian, The Rhetoric of Nonverbal Communica- }}$ tion: Readings (Glenview, IL: Scott, Foresman and Co., 1971), pp. iv-vi, viii-xii.

${ }^{2}$ Mark I. Knapp, Nonverbal Communication in Human Interaction (New York: Holt, Rinehart and Winston, 1972), pp. v-vi.

${ }^{3}$ Randall P. Harrison, Beyond Words: An Introduction to Nonverbal Communication (Englewood Cliffs, N.J.: Prentice-Hall Inc., 1974), p. ix.

${ }^{4}$ Shirley Weitz, Nonverbal Communication: Readings with Commentary (New York: Oxford University Press, 1974), pp. 3-7.

${ }^{5}$ Lawrence Rosenfeld and Jean Civikly, With Words Unspoken (New York: Holt, Rinehart and Winston, 1976), p. vii.

$6_{\text {Dale G. Leathers, Nonverbal Communication Systems }}$ (Boston: Allyn and Bacon Inc., 1976), pp. ix-xii.

7 Judee Burgoon and Thomas Saine, The Unspoken Dialogue: An Introduction to Nonverbal Communication (Boston: Houghton Mifflin, 1976), pp. xi-xii.

8 Marianne LaFrance and Clara Mayo, Moving Bodies: Nonverbal Communication in Social Relationships (Monterey, CA: West Publishing Co., 1978), pp. vi-vii.

$9_{\text {Knapp, Essentials of Nonverbal Communication }}$ (New York: Holt, Rinehart and Winston, 1980), pp. iii-v. 


\section{CHAPTER VIII}

\section{SUMMARY OF THE TEXT SELECTED AS THE MOST COMPREHENSIVE, THOROUGH ONE EVALUATED}

In reading, reviewing, and evaluating the nine texts on nonverbal communication which comprise the basis of this study, one has emerged as the overall leader. The Unspoken Dialogue: An Introduction to Nonverbal Communication by Judee Burgoon and Thomas Saine is a unique text in that it focuses on the communicative effects of nonverbal behavior rather than on the separate components of this form of communication. Burgoon and Saine both feel that studying the various components of this form of communication independently is a piecemeal approach because the human body is not an amalgamation of unrelated parts. When viewed as such, a great deal of the meaning related to nonverbal communication is, consequently, missing. The text takes a descriptive and then a functional approach to the study of nonverbal communication and concentrates on the ways in which behaviors combine to fulfill various communicative functions.

Rather than having each nonverbal code studied or reviewed independently, the text suggests how the codes intertwine and interact to satisfy important nonverbal 
functions. The authors feel that this is the most coherent way of viewing these areas of nonverbal communication.

Concepts and research findings range from the simple to highly complex, thus the authors have let the literature dictate the level of the book rather than trying to simplify sophisticated, intricate concepts. Some chapters are, therefore, more demanding than others, making the text useful to both beginning and advanced courses alike.

The following list is a summary of the reasons why this text was deemed the best, most comprehensive, and useful one evaluated:

1. The material is from a functional-behavioral viewpoint that examines the impact of nonverbal behavior on the total communication process.

2. The material is comprehensive, factually accurate, objective, and up to date.

3. All the information sources are well documented, both in the chapters and in the bibliographies.

4. The material in the text is appropriate for both beginning and advanced nonverbal communication classes.

5. The vocabulary can be easily understood by both beginning and advanced students.

6. The material is both stimulating and pertinent and will have wide appeal among many disciplines. It is presented as clearly and simply as possible with many examples .to aid students in the conceptualization of the subject matter. 
7. The content of each chapter is clearly outlined with major titles and subtitles.

8. The transitions from chapter to chapter and point to point are excellent. The same format is used in each chapter.

9. A sensitivity quiz which tests a student's awareness of specific components of nonverbal communication is located at the beginning of each chapter.

10. A list of new, esoteric terms and phrases that the material will cover is located at the beginning of each chapter.

11. Mini-exercises are contained in each chapter.

12. Each chapter contains a brief summary of the material covered.

13. Iists of additional readings relating to the different components of nonverbal communication covered in the material are provided at the end of each chapter.

14. Visual aids are used extensively throughout the entire text. These are in the form of pictures, drawings, charts, graphs, and tables. They supplement the text very well.

15. Last, and equally important, the text is enjoyable reading that will not intimidate or discourage students and should prove to be a useful, welcome addition to any library. 


\section{BIBLIOGRAPHY}

Birdwhistell, Ray I. Kinesics and Context: Essays on Body Motion. Philadelphia, PA: University of Pennsylvania Press, 1970.

Bosmajian, Haig A. The Rhetoric of Nonverbal Communication. Glenview, IL: Scott, Foresman and Co., 1971.

Broudy, Eric. "The Trouble with Textbooks," Teachers College Record, 7 (September, 1975), 13-34.

Burgoon, Judee and Saine, Thomas. The Unspoken Dialogue: An Introduction to Nonverbal Communication. Boston: Houghton Mifflin Co., 1978.

Burgoon, Michael. Approaching Speech Communication. New York: Holt, Rinehart and Winston, 1974.

Campbell, Ellen K. Content Analysis: A Tool for Choosing Texts. Toronto, Canada: Ontario Institute for Studies in Education, Department of Measurement and Evaluation, 1973.

Castan, Frances. "The Great Instructional Materials Game," Scholastic Teacher (February, 1973), 10-16.

Fast, Julius. Body Language. Philadelphia: M. Evans and Co., 1970 .

Fontana, John M. Mankinds Greatest Invention. New York: Stratford Press, 1964.

Frye, Jerry. Frye's Index to Nonverbal Data. Duluth, MN: University of Minnesota Computer Center, 1980.

Fuller, Ralph N. "Textbook Selection: Burning Issue?" Compact, 9 (June, 1975), 6-8.

Hall, Edward T. The Silent Language. Greenwich, CT: Fawcett Publications Inc., 1959.

Handley, Theresa B. Models for the Evaluation of Bias Content in Instructional Materials. Olympia, WA: Equal Educational Opportunities Section, 1975. 
Harrison, Randall P. Beyond Words: An Introduction to Nonverbal Communication. Englewood Cliffs, N.J.: Prentice-Hall Inc., 1974.

Hartley, James. Designing the Instructional Text. Iondon: Nichols Publishing Co., 1978.

- Improving Materials Selection Procedures: A Basic How To Handbook. New York: EPIE Educational Products, 1973.

Jackson, Philip W. "Technology and the Teacher," in Communication for Economic Development. the School and the Challenge of Innovation. New York: Hill Book Co., 1969.

Knapp, Mark I. Essentials of Nonverbal Communication. San Francisco: Holt, Rinehart and Winston, 1980.

Nonverbal Communication in Human Interaction. New York: Holt, Rinehart and Winston, 1972.

Kunder, Iinda. Procedures for Textbook and Instructional Materials Selection. Arlington, VA: Educational Research Service, Inc., 1976.

LaFrance, Marianne and Mayo, Clara. Moving Bodies: Nonverbal Communication in Social Relationships. Monterey, CA: West Publishing Co., 1978.

Leathers, Dale G. Nonverbal Communication Systems. Boston: Aliyn and Bacon, 1976.

Lester, Richard I. "Try Out this Checklist for Evaluating New Textbooks," Nation's Schools, 85 (January, 1970), 97,122 .

Mason, Stephen F. A History of the Sciences. New York: Collier Books, 1966.

McAuley, Jack G. People to People: Essentials of Personal and Public Communication. Belmont, CA: Wadsworth Publishing Co., 1979.

McCloud, Paul I. "A Survey of State Textbook Practices," Educational Leadership, 31 (February, 1974), 438-441.

McLoughlin, John A. and Trlica, Jack S. "Teacher Evaluation of Instructional Materials, "Educational Technology,

16 (March, 1976), 51-54. 
Malloy, John T. Dress for Success. New York: Warner Books, 1978.

Mehrabian, Albert. Silent Messages. Belmont, CA: Wadsworth Publishing Co., 1972.

Montagu, Ashley. Touching: The Human Significance of Skin. New York: University Press, 1971.

Padrow, Ben. Oral Communication: Preparation and Presentation. Portland, OR: Portland State University Copy Center, n.d.

Pei, Mario. The Story of Language. Philadelphia: J. B. Lippincott, 1949.

Penta, Frank B., Fleming, G. A., and Penta, M. Q. "A Guide to the Appraisal of Instructional Materials," Educational Technology, 14 (December, 1974), 31-32.

Rosenfeld, Lawrence and Civikly, Jean. With Words Unspoken: The Nonverbal Experience. New York: Holt, Rinehart and Winston, 1976.

Ruesch, Jurgen and Kees, Weldon. Nonverbal Communication: Notes on the Visual Perception of Human Relations. Berkeley, CA: University of California Press, 1956.

Scheflen, Albert and Scheflen, Alice. Body Language and Social Order: Communication as Behavioral Control. Englewood Cliffs, N.J.: Prentice-Hall Inc., 1972.

"Science and Technology--Communications," place and date of publication unknown, $5 \mathrm{pp}$.

"Textbook Adoption: Has Anything Changed?" Education Daily, 18 (November, 1975), 55.

"Textbook Selection and Adoption," (February, 1976), 14 pp. "Textbook Selection and Adoption," The School Administrator's Policy Portfolio, 7 (May, 1976), $5 \mathrm{pp}$.

Weitz, Shirley. Nonverbal Communication: Readings with Commentary. New York: Oxford University Press, 1974.

Wilson, Adrian. The Design of Books. Salt Lake City: Peregrine Smith Inc., 1974. 
APPENDIX

GENERAL EVALUATION SCALE FOR NONVERBAL TEXTS 
GENERAL EVALUATION SCALE FOR NONVERBAL TEXTS

Text :

Author:

YES NO NA

I. Purpose

A. Does the author accomplish the overall purpose of the text?

B. Is the purpose accomplished in good literary style?

II. Author

A. Is there pertinent, factual information about the educational background, profession, and qualifications of the author?

III. Authenticity

A. Is the material factually accurate and objective in its presentation?

B. Is the material up-to-date?

C. Are the information sources well documented?

IV. Appropriateness

A. Does the material promote the educational goals and objectives of the curriculum?

B. Is the material appropriate to the level of instruction intended?

C. Is the interest level appropriate to the user?

1. Will the material stimulate the curiosity of the user?

2. Will the material appeal to many students? 
YES NO NA

V. Content

A. Is the content of the material well presented by providing adequate scope, range, depth, and continuity?

B. Is the material well organized and well balanced?

C. Is the material presented as clearly and simply as possible for the level intended?

D. Does the material aid conceptualization of the subject matter?

E. Does the material achieve its stated purpose?

F. Are the transitions from one point to another, or one section to another, smooth and clear?

G. Does the text present information not otherwise available?

H. Does the material give a new dimension to the subject?

I. Are the sources, purposes, and points of view readily identifiable?

VI. Technical Quality

A. Is the text hardcover?

B. Is the text softcover?

C. Is the typography clear and easy to read?

D. Are the page layouts well designed?

E. Is the pagination definite and clear?

1. Is there a table of contents?

2. Is there an outline listing the contents of each chapter? 
a. Is this at the beginning of each chapter?

b. Is this in the table of contents?

3. Are the major titles and subtitles of each section delineated in each chapter?

4. Is there a list of priorities at the beginning of each chapter?

5. Are internal summaries and reviews provided where appropriate?

6. Is there a list of related exercises or activities contained in each chapter?

7. Is there a list of additional readings in each chapter?

8. Does the text contain an appendix?

a. Is the appended material useful?

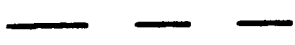


13. Are the chapters footnoted or endnoted?

G. Are visual aids used?

1. Do they contribute to the development of the text?

2. Is the art of photographic quality of the visual aid acceptable (sharpness, composi-

3. Is there a good balance between artistic technique and educational need?

4. Are the captions readable?

5. Are the captions a good interpretation of the material, yet not distracting?

6. Are the illustrations and captions suitable for teaching and learning purposes?

7. Are the visual aids located properly for greatest usefulness?

8. Are the visual aids adequate in number?

9. Is the content of the visual aid well organized and well balanced?

10. Is explanatory material provided?

\section{SPEC IFIC EVALUATION FORM FOR NONVERBAL TEXTS}

I. Introductory Material

A. Definition of nonverbal communication

B. Issues involved in defining and classifying nonverbal communication

1. Environmental 
YES NO NA

2. Cultural

3. Contextual

C. Relationship between sending and receiving skills

D. Developing sending and receiving skills

E. Components of nonverbal communication mentioned in the text

1. Adornment

2. Chronemics

3. Haptics

4. Kinesics

5. Objects and Environment

6. Olfactory

7. Paralanguage

8. Physical Appearance

9. Proxemics

F. Definition of the functions of nonverbal communication

1. Accentuation

2. Complementation

3. Contradiction

4. Redundancy

5. Regulation

6. Substitution

G. Relationship between verbal and nonverbal communication 


\section{YES NO NA}

H. Brief history of the study of nonverbal communication (optional)

II. Adornment

A. Definition of adornment

B. Communicative effects of clothes

C. Communicative effects of accessories

D. Communicative effects of cosmetics

E. Cultural differences

F. Gender differences

III. Chronemics

A. Definition of chronemics

B. Communicative function of chronemics

C. American concept of time

D. Effects of time orientations

1. Psychological

2. Biological

3. Cultural

IV. Haptics

A. Definition of haptics

B. Communicative function of haptics

C. Tactile communication and human development

D. Different types of touching behavior

1. Functional-professional

2. Social-polite

3. Friendship-warmth

4. Love-intimacy 
201

YES NO NA

5. Sexual arousal ${ }^{*}$

E. Needs for human touch

1. Biological

2. Psychological

3. Sociological

F. The skin as a communication system

G. Touch norms and the reason for norms

H. Gender differences

I. Cultural differences

V. Kinesics

A. Definition of kinesics

B. Communicative function of kinesics

C. Kinesic channels

1. Whole head

2. Whole body

3. Face only

4. Eyes and eyebrows only

5. Hands and arms

6. Legs and feet

7. Dyad (whole body with another person)

D. Gender differences

E. Cultural differences

* Mark L. Knapp, Essentials of Nonverbal Communication (New York: Holt, Rinehart and Winston, 1980), pp. 153-155. 
YES NO NA

VI. Objects and Environment

A. Definition of objects and environment

B. Communicative effects of objects (artifacts)

C. Communicative effects of environmental features

1. Size or volume of artifacts

2. Arrangement of artifacts within an environment

3. Types of materials in use

4. Lighting and shading

5. Color

6. Temperature

7. Noise

D. Cultural differences

E. Gender differences

VIX. Olfactory

A. Definition of olfactory communication

B. Communicative function of odor

C. Types of smells and messages communicated

D. Cultural differences

E. Gender differences

VIIX. Paralanguage

A. Definition of paralanguage

B. Communicative function of paralanguage

C. Sound attributes which give vocal cues their unique characteristics 
YES NO NA

D. Vocal cues in relation to:

1. Speaker recognition

2. Personality judgments

3. Personal characteristics

4. Judgments of emotion

5. Comprehension and persuasion

6. Hesitations and pauses*

E. Gender differences

F. Cultural differences

ix. Physical Appearance

Vil A. Definition of physical appearance

B. Communicative potential of physical appearance

C. Body types

1. Endomorph

2. Mesomorph

3. Ectomorph

D. Traits associated with body types

E. Indicators of attractiveness

1. General attractiveness

2. Body shape

3. Body color

4. Smell

5. Hair (cranial, facial, body)

6. Clothes and artifacts

*Ibid., pp. 204-224. 
F. Cultural differences

G. Gender differences

IX. Proxemics

A. Definition of proxemics

B. Communicative function of proxemics

C. Factors relating to individual space preference

1. Age

2. Sex

3. Ethnic and cultural background

4. Topic or subject matter

5. Setting of the interaction

6. Physical characteristics of the interactants

7. Attitudinal orientation

8. Emotional orientation

9. Characteristics of the interpersonal relationship

10. Personality characteristics*

D. Territoriality

1. Intimate-Personal space

2. Private space

3. Public space

$X \notin$ General Summary Material

A. Brief review of the material in the chapters in terms of the usage and importance of nonverbal communication

*Tbid., pp. 82-86 
B. Characteristics of a skilled nonverbal receiver/decoder

C. Characteristics of a skilled nonverbal sender/encoder

D. Relationship between nonverbal sending and receiving skills 